\title{
Análise longitudinal de coinfecções por HPV em pacientes HIV-positivas
}

\author{
Marcel de Souza Borges Quintana \\ DisSERTAÇÃO APRESENTADA \\ $\mathrm{AO}$ \\ Instituto de Matemática e Estatística \\ DA \\ Universidade DE SÃo PAUlo \\ PARA \\ OBTENÇÃO DO TÍTULO \\ DE \\ Mestre em EstatísticA \\ Programa: Mestrado em Estatística \\ Orientador: Prof. Dr. Julio da Motta Singer
}

Durante o desenvolvimento deste trabalho o autor recebeu auxílio financeiro da CAPES

São Paulo, Janeiro de 2013 


\title{
Análise longitudinal de coinfecções por HPV em pacientes HIV-positivas
}

\author{
Esta dissertação contém as correções e alterações \\ sugeridas pela Comissão Julgadora durante a defesa \\ realizada por Marcel de Souza Borges Quintana em 01/02/2013. \\ O original encontra-se disponível no Instituto de \\ Matemática e Estatística da Universidade de São Paulo.
}

Comissão Julgadora:

- Prof. Dr. Julio da Motta Singer (orientador) - IME-USP

- Profa. Dra. Luciane de Souza Velasque - CCET-UNIRIO

- Prof. Dr. Enrico Antônio Colosimo - ICEx-UFMG 


\section{Agradecimentos}

Primeiramente gostaria de agradecer a Deus por ter me dado condições de realizar este trabalho. Em segundo lugar gostaria de agradecer aos meus familiares, principalmente ao meu pai Ronaldo Quintana e minha mãe Shirley Quintana porque sempre investiram na minha educação e muitas vezes se sacrificaram por mim, a minha noiva Juliana Montovani e ao amigo Fábio Lessa Messa que me deram apoio, foram compreensivos e sempre me incentivaram a persistir. Quero agradecer ao meu orientador Julio da Motta Singer que teve paciência para me corrigir, e por ter me ajudado a direcionar este trabalho tão sabiamente, me ensinando não somente a ser um bom aluno, mas também a ter iniciativa e caminhar com minhas próprias pernas. Agradeço também a Luciane Velasque, Paula Mendes e Beatriz Grinjstein pelo apoio e direcionamentos que foram imprescindíveis para o desenvolvimento deste trabalho. Agradeço a Marilia Sá Carvalho e Dayse Campos pelo curso de análise de sobrevivência e pelas opiniões que realmente fizeram a diferença. Agradeço aos meus amigos e em especial aos do IME: Alfredo Salgado, Anibal Emiliano, Rodrigo Bulhões e Bruno Santos entre outros pelos momentos alegres e por terem deixado ainda mais agradável o convívio no IME, e também a Elizabeth González e ao Prof. Antonio Carlos Pedroso pela prestatividade em ajudar indicando boas referências que foram muito úteis neste trabalho. Muito obrigado a todos! 


\section{Resumo}

\section{Análise longitudinal de coinfecções por HPV em pacientes HIV-positivas}

Avaliamos a incidência e o clareamento para o vírus do papiloma humano (HPV) dos tipos oncogênicos e não-oncogênicos em uma coorte aberta com 202 mulheres portadoras do vírus da imunodeficiência humana (HIV), e identificamos alguns fatores de risco e proteção associados a cada desfecho utilizando modelos de fragilidade Gama. No modelo de incidência, foram estudados os tempos até incidência de HPV oncogênicos e não-oncogênicos para cada mulher; no modelo de clareamento, foram estudados os correspondentes tempos até clareamento. Comparamos os errospadrões estimados pela matriz de informação observada com os erros-padrões bootstrap para ambos os modelos e verificamos que a proposta de Verweij \& Houwelingen (1994) para a matriz de variâncias e covariâncias dos parâmetros é a mais apropriada. Para a incidência de HPV oncogênicos, identificamos como fator de risco o uso de drogas em que a taxa de incidência para as pacientes que usam drogas é 1.88 (IC 90\%, 1.01; 3.5) vezes aquela correspondente a mulheres que não usam e como fator de proteção a renda em que a taxa de incidência de pacientes com renda igual ou superior a 3 salários mínimos é 0.62 (IC 90\%, 0.38; 1.00) vezes a taxa referente àquelas com renda menor que 3 salários mínimos. Para a incidência de HPV não-oncogênicos identificamos como fatores de risco a escolaridade e o total de gestações, em que, para a última, a taxa de incidência para as mulheres que tiveram mais do que uma gestação é 1.76 (IC 90\%, 1.09; 2.86) vezes aquela correspondente a mulheres que as que tiveram uma ou nenhuma. Para o clareamento de HPV oncogênicos identificamos como fatores que indicam um clareamento mais rápido a renda, a idade e o tratamento antirretroviral (ARV), em que, para a última, supondo mulheres com fragilidades iguais, a taxa de clareamento para as pacientes que eram tratadas com o esquema inibidor de protease (IP) é 1.79 (IC $90 \%, 1.1 ; 2.9)$ vezes aquela correspondente a mulheres que não foram tratadas com nenhum tratamento ARV e como fator que indicam um clareamento mais lento o número de parceiros sexuais no último ano, em que, as pacientes com mais de um parceiro tiveram taxa de clareamento 0.39 (IC $90 \%, 0.16 ; 0.98)$ vezes a taxa de clareamento referente à uma mulher que teve um parceiro ou menos. Para o clareamento de HPV não-oncogênicos tivemos como fator que indica um clareamento mais lento o hábito tabagista em que, supondo fragilidades iguais, pacientes fumantes tem a taxa de clareamento 0.53 (IC 90\%, 0.32; 0.87) vezes a taxa referente à uma mulher que não fuma.

Palavras-chave: Modelos de Fragilidade, Incidência e Clareamento de HPV, bootstrap. 


\section{Abstract}

\section{Longitudinal analysis of HPV coinfection in HIV-positive patients}

We evaluated the incidence and clearance for oncogenic and non-oncogenic human papilloma virus (HPV) in an open cohort of 202 women infected with human immunodeficiency virus (HIV), and we identified some risk factors and protective factors for each outcome using Gamma frailty models. In the incidence model, we studied the incidence of stroke by oncogenic and non-oncogenic HPV for each woman; in the clearance model, the corresponding times to clearance were studied. We compared the standard errors estimated by the observed information matrix with bootstrap standard errors for both models and found that the variance and covariance matrix of the parameters proposed by Verweij \& Houwelingen (1994) is more appropriate. For the incidence of oncogenic HPV, identified as a risk factor drug use and the incidence rate for patients who use drugs is 1.88 ( $90 \% \mathrm{CI}, 1.01 ; 3.5)$ times the rate for those who do not use and as a protective factor income where the incidence rate is $0.62(90 \%$ CI, 0.38; 1.00) times the rate for those earning less than 3 minimum wages. For the incidence of non-oncogenic HPV identified as risk factors schooling and total pregnancies, in which, for the latter, the incidence rate for women who had more than one pregnancy is 1.76 (90\% CI, 1.09; 2.86) times the rate referring to those which have one or none. For clearance of oncogenic HPV identified as factors that indicate a faster clearance income, age and antiretroviral therapy (ART), in which, to the last, with women assuming equal frailties, the rate of clearance for patients who were treated with the protease inhibitor (IP) regimen is 1.79 (90\% CI, $1.1 ; 2.9)$ times the rate for those who were not treated with any antiretroviral regimen and as a factor that indicates slower clearance the number of sexual partners in the last year, and for patients with more than one partner the clearance rate 0.39 (IC 90\%, 0.16; 0.98) times the clearance rate referring to a woman who had up to a partner. For the clearance of non-oncogenic HPV had a factor which indicates a slower clearance smoking habit, assuming equal frailties, smokers have the clearance rate $0.53(90 \% \mathrm{CI}, 0.32 ; 0.87)$ times the rate referring to a woman who does not smoke.

Keywords: Frailty Models, Incidence and Clearance of HPV, bootstrap. 


\section{Sumário}

$\begin{array}{ll}\text { Lista de Figuras } & \text { ix }\end{array}$

Lista de Tabelas $\quad$ xi

1 Introdução $\quad 1$

2 Análise descritiva $\quad 9$

$\begin{array}{lll}3 & \text { Metodologia } & 17\end{array}$

4 Ajuste dos Modelos $\quad 23$

4.1 Análise da Incidência . . . . . . . . . . . . . . . . . . . . . . . . 24

4.2 Análise do Clareamento . . . . . . . . . . . . . . . . . . 28

4.3 Comparação com erro padrão bootstrap . . . . . . . . . . . . . 35

5 Conclusões e Considerações Finais $\quad 41$

5.1 Comentários finais . . . . . . . . . . . . . . . . . . . . . 42

5.2 Trabalhos futuros . . . . . . . . . . . . . . . . 43

A Tabelas e Gráficos $\quad 45$

$\begin{array}{ll}\text { Referências Bibliográficas } & 51\end{array}$ 
viii SUMÁRIO 


\section{Lista de Figuras}

1.1 Histograma e boxplot para o tempo entre as visitas (meses) . . . . . . . . . . . 2

2.1 Histogramas para tempo até incidência de (a) HPV oncogênicos e (b) HPV nãooncogênicos. . . . . . . . . . . . . . . . . . . . . . . 10

2.2 Curvas de sobrevivência (Kaplan-Meier) para a incidência de HPV oncogênicos e

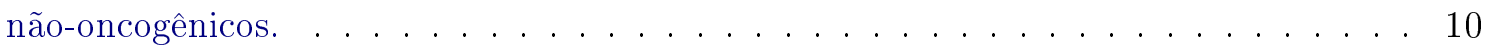

2.3 Curvas de sobrevivência (Kaplan-Meier) para a incidência de HPV oncogênicos por variáveis demográficas e comportamentais associadas às maiores diferenças. . . . . . 11

2.4 Curvas de sobrevivência (Kaplan-Meier) para a incidência de HPV não-oncogênicos por variáveis demográficas, comportamentais e clínico-laboratoriais associadas às maiores diferenças. . . . . . . . . . . . . . . . . . . . . . 12

2.5 Histograma para tempo até clarear (a) HPV oncogênicos e (b) HPV não-oncogênicos. 13

2.6 Curvas de sobrevivência (Kaplan-Meier) para o clareamento de HPV oncogênicos e não-oncogênicos. . . . . . . . . . . . . . . . . . . . . . . 13

2.7 Curvas de sobrevivência (Kaplan-Meier) para o clareamento de HPV oncogênicos por variáveis demográficas, comportamentais e clínico-laboratoriais associadas às maiores diferenças. . . . . . . . . . . . . . . . . . . . . . . 14

2.8 Curvas de sobrevivência (Kaplan-Meier) para clareamento de HPV não-oncogênicos por variáveis demográficas, comportamentais e clínico-laboratoriais associadas às maiores diferenças. . . . . . . . . . . . . . . . . . . . . 16

4.1 Resíduos de Cox-Snell para o modelo de incidência. . . . . . . . . . . . . . . . . 25

4.2 Resíduos de Schoenfeld para o modelo de incidência. . . . . . . . . . . . . . . . 26

4.3 Resíduos de (a) Martingal e (b) Deviance para o modelo de incidência. . . . . . . . . 27

4.4 Resíduos de escore para o modelo de incidência. . . . . . . . . . . . . . . . . . . 29

4.5 Estimativa pontual da fragilidade e seu intervalo de confiança de $90 \%$ para as 10 mulheres com menores fragilidades e as $10 \mathrm{com}$ maiores fragilidades utilizando os modelos: (a)Gama-EM (b)Normal-REML (c)Gama-AIC (d)Normal-AIC. . . . . . . . 34 


\section{Lista de Tabelas}

1.1 Coorte ilustrativa de pacientes e taxa de incidência para cada tempo de observação . 4

2.1 Dados demográficos, comportamentais e clínico-laboratoriais para a coorte de 202 mulheres HIV-positivas. . . . . . . . . . . . . . . . . . . . . . . . . 15

2.2 Total observado de visitas/pacientes. . . . . . . . . . . . . . . . . . . . 15

4.1 Coeficientes estimados exponencializados/Razões de taxas de incidência, erros padrões, limites inferiores (LI) e superiores (LS) para intervalos de confiança com coeficiente de confiança $90 \%$ e valores-P para as variáveis explicativas relacionadas com o tempo até incidência de HPV oncogênicos e não-oncogênicos. . . . . . . . . . . . . 25

4.2 Teste de Therneau e Grambsch para proporcionalidade dos riscos. . . . . . . . . . . . 27

4.3 Variáveis demográficas e comportamentais, tipo do HPV, tempo até incidência e status do evento, em que 0 indica censura e 1 indica falha, para as pacientes referentes aos pontos aberrantes observados na Figura 4.3. . . . . . . . . . . . . . . . . . . 28

4.4 Razão entre taxas de incidência para pacientes com determinadas características demográficas e comportamentais e razão entre taxas de incidência de HPV oncogênicos e HPV não-oncogênicos (e intervalos de confiança de 90\%) . . . . . . . . . . . . . . 30

4.5 Coeficientes estimados exponencializados/Razões de taxas de clareamento, erros padrões, limites inferiores (LI) e superiores (LS) para intervalos de confiança com coeficiente de confiança $90 \%$ e valores-P para as variáveis explicativas relacionadas com o tempo até clareamento de HPV oncogênicos e não-oncogênicos. . . . . . . . . . . . 30

4.6 Coeficientes estimados exponencializados/Razões de taxas de clareamento, limites inferiores (LI) e superiores (LS) para intervalos de confiança com coeficiente de confiança 90\% e valores-P para as variáveis explicativas do modelo final para o clareamento de HPV oncogênicos e não-oncogênicos com e sem o termo de fragilidade. . . 31

4.7 Comparação dos efeitos fixos dos modelos de fragilidade para o clareamento de HPV oncogênicos e não-oncogênicos (coeficientes estimados exponencializados/Razões de taxas de clareamento, limites inferiores (LI) e superiores (LS) dos intervalos de confiança com coeficiente de confiança $90 \%$ e valores-P). . . . . . . . . . . . . . . 33

4.8 Comparações das taxas de clareamento para pacientes com determinadas características demográficas, comportamentais e clínico-laboratoriais (razões de taxas e intervalos de confiança de 90\%). . . . . . . . . . . . . . . . . . . . . . . . . . . 37

4.9 Totais por desfecho e por filtro de dados. . . . . . . . . . . . . . . . . . . . . 38 
4.10 Comparação dos erros padrões estimados pela matriz $\widehat{\mathbf{V}}=\widehat{\mathbf{F}}^{-1}$ e por bootstrap e os respectivos intervalos de confiança de $90 \%$ para os coeficientes exponencializados do modelo de incidência de HPV oncogênicos e não-oncogênicos. . . . . . . . . . . . . 38

4.11 Comparação dos erros padrões estimados pela matriz $\widehat{\mathbf{V}}=\widehat{\mathbf{H}}^{-1}$, pela matriz $\widehat{\mathbf{V}}=\widehat{\mathbf{H}}^{-1} \widehat{\mathbf{F}} \widehat{\mathbf{H}}^{-1}$ e por bootstrap para $\theta$ fixado e os respectivos intervalos de confiança de $90 \%$ para os coeficientes exponencializados do modelo de clareamento de HPV oncogênicos e

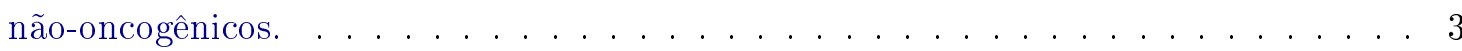

4.12 Porcentagem de amostras bootstrap em que não houve convergência do modelo final de clareamento de HPV oncogênicos e não-oncogênicos para determinadas covariáveis no modelo.

A.1 Coeficientes estimados exponencializados/Razões de taxas de incidência, erros padrões, limites inferiores (LI) e superiores (LS) para intervalos de confiança com coeficiente de confiança $90 \%$ e valores-P para o modelo de incidência de HPV oncogênicos e não-oncogênicos obtido por meio do método forward stepwise com todas as variáveis

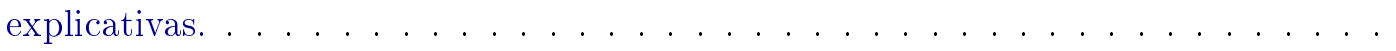

A.2 Coeficientes estimados exponencializados/Razões de taxas de incidência, erros padrões, limites inferiores (LI) e superiores (LS) para intervalos de confiança com coeficiente de confiança $90 \%$ e valores-P para o modelo de incidência de HPV oncogênicos e não-oncogênicos obtido por meio do método forward stepwise apenas com as variáveis explicativas dos artigos relacionados. . . . . . . . . . . . . .

A.3 Coeficientes estimados exponencializados/Razões de taxas de incidência, erros padrões, limites inferiores (LI) e superiores (LS) para intervalos de confiança com coeficiente de confiança $90 \%$ e valores-P para o modelo de incidência de HPV oncogênicos e não-oncogênicos selecionando cada variável uma a uma, dentre todas as variáveis explicativas, comparando-as com o modelo nulo e colocando-as em um único modelo. 46

A.4 Coeficientes estimados exponencializados/Razões de taxas de incidência, erros padrões, limites inferiores (LI) e superiores (LS) para intervalos de confiança com coeficiente de confiança $90 \%$ e valores-P para o modelo de incidência de HPV oncogênicos e não-oncogênicos selecionando cada variável uma a uma, dentre todas as variáveis dos artigos relacionados, comparando-as com o modelo nulo e colocando-as em um único modelo. . . . . . . . . . . . . . . . . . . . . . . . 4

A.5 Coeficientes estimados exponencializados/Razões de taxas de clareamento, erros padrões, limites inferiores (LI) e superiores (LS) para intervalos de confiança com coeficiente de confiança $90 \%$ e valores-P para o modelo de clareamento de HPV oncogênicos e não-oncogênicos obtido por meio do método forward stepwise com todas as variáveis explicativas. . . . . . . . . . . . . . .

A.6 Coeficientes estimados exponencializados/Razões de taxas de clareamento, erros padrões, limites inferiores (LI) e superiores (LS) para intervalos de confiança com coeficiente de confiança $90 \%$ e valores-P para o modelo de clareamento de HPV oncogênicos e não-oncogênicos selecionando cada variável uma a uma, dentre todas as variáveis explicativas, comparando-as com o modelo nulo e colocando-as em um único modelo. 
A.7 Coeficientes estimados exponencializados/Razões de taxas de incidência, limites inferiores (LI) e superiores (LS) para intervalos de confiança com coeficiente de confiança 90\% e valores-P para as variáveis explicativas do modelo final para a incidência de HPV oncogênicos e não-oncogênicos com e sem o termo de fragilidade. . . . . . . . . 48

A.8 Comparação dos efeitos fixos do modelo final para a incidência de HPV oncogênicos e não-oncogênicos com e sem pontos aberrantes. (coeficientes estimados e valores-P). 49

A.9 Coeficientes estimados exponencializados/Razões de taxas de incidência, erros padrões, limites inferiores (LI) e superiores (LS) para intervalos de confiança com coeficiente de confiança $90 \%$ e valores-P para as variáveis explicativas relacionadas com o tempo até incidência de HPV oncogênicos e não-oncogênicos apenas para as pacientes que iniciaram sem HPV oncogênicos ou HPV não-oncogênicos. . . . . . . . . . . . . . 49

A.10 Coeficientes estimados exponencializados/Razões de taxas de clareamento, erros padrões, limites inferiores (LI) e superiores (LS) para intervalos de confiança com coeficiente de confiança $90 \%$ e valores-P para as variáveis explicativas relacionadas com o tempo até clareamento de HPV oncogênicos e não-oncogênicos apenas para as pacientes que iniciaram com HPV oncogênicos ou HPV não-oncogênicos. . . . . . . . 50 


\section{Capítulo 1}

\section{Introdução}

As infecções provocadas pelo vírus do papiloma humano (HPV) têm sido consistentemente identificadas como o mais importante fator de risco para lesões intraepiteliais escamosas de colo do útero e câncer invasivo de colo do útero [Walboomers et al. (1999)]. Em muitos países subdesenvolvidos, o câncer do colo do útero é a forma mais comum de câncer em mulheres [Orem et al. (2004)], e particularmente no Brasil é a segunda forma de câncer mais comum e a quarta maior causa de morte por câncer [INCA (2012)]. Vários estudos [Massad et al. (1999), Palefsky (2003)] indicam que o HPV é um vírus com maior prevalência em indivíduos HIV-positivos ${ }^{1}$ por conta da imunossupressão (baixa imunidade) a que estão sujeitos.

Os HPV podem ser classificados como oncogênicos de alto risco (HR-HPV), aqui denominados oncogênicos, e oncogênicos de baixo risco (LR-HPV), aqui denominados não-oncogênicos. Segundo Trottier \& Franco (2006), Clifford et al. (2011), Sahasrabuddhe et al. (2007), de Sanjose et al. (2010), etc., os tipos 16, 18, 31, 33, 35, 39, 45, 51, 52, 56, 58, 59 e 68 são oncogênicos de alto risco, e dentre estes os mais comuns são aqueles rotulados 16 e 18, responsáveis por $70 \%$ dos casos de câncer do colo do útero [McKenzie et al. (2010)]. Hoje em dia, acredita-se que infecções por HR-HPV são necessárias mas não suficientes para causar câncer do colo do útero, neoplasias anogenitais e carcinomas de células escamosas bucais [Trottier \& Franco (2006)]. Indivíduos infectados com LR-HPV identificados pelos rótulos $6,11,40,42,43,44,54,55,61,62,71,81$, e CP6108 podem sofrer lesões benignas conhecidas como condilomas (verrugas genitais), bem como lesões intraepiteliais de baixo grau do colo do útero. Estudos realizados por Levi et al. (2002) e Levi et al. (2004) indicam que os 7 tipos de HPV mais frequentes no Brasil entre as mulheres HIV-positivas com lesões no colo do útero são aqueles identificados pelos rótulos 16, 18, 51, 52, 58, 59 e 68 .

A coinfecção por múltiplos tipos de HPV é comum em muitos casos. Na coorte brasileira de LudwigMcGill [Franco et al. (1999)] foram detectados múltiplos tipos de HPV na mesma visita em $20 \%$ das mulheres infectadas por HPV em algum momento durante o acompanhamento [Rousseau et al. (2001)].

Pouco se sabe sobre a relação entre o tempo de persistência ${ }^{2}$ de HPV e a coinfecção de multiplos tipos do HPV. Ho et al. (1998) e Perrons et al. (2005) encontraram associação entre coinfecção por multiplos tipos de HPV e o tempo de persistência; no entanto, Rousseau et al. (2000) não

\footnotetext{
${ }^{1} \mathrm{O}$ vírus da imunodeficiência humana (HIV) é o organismo patogênico responsável pela sindrome da imunodeficiência adquirida (AIDS). A AIDS é diagnósticada quando ocorrem determinadas doenças oportunistas causadas pelo comprometimento das respostas de imunidade do organismo [Last (2001)].

${ }^{2} \mathrm{O}$ clareamento do HPV é definido como o primeiro resultado negativo subsequente a resultados positivos. A persistência de um HPV é o tempo até o clareamento do HPV após este ter sido detectado [Xue et al. (2010)].
} 
encontraram evidências dessa relação.

Um estudo realizado no Instituto de Pesquisa Evandro Chagas (IPEC) da Fundação Oswaldo Cruz (FIOCRUZ) tem como objetivo avaliar a incidência e o clareamento/persistência do HPV em mulheres portadoras do HIV. Os dados de uma coorte aberta ${ }^{3}$ de mulheres HIV-positivas avaliadas são oriundos do Hospital de Pesquisas Clínicas do IPEC e foram colhidos entre setembro de 2005 e dezembro de 2009. Eles correspondem a 1217 visitas de acompanhamento de 378 pacientes. Em cada visita verificou-se se a paciente estava infectada por algum tipo de HPV ${ }^{4}$, que em caso positivo, foi identificado. Além disso, obtiveram-se informações demográficas, como idade, raça, estado civil, informações comportamentais, como hábito tabagista, uso de drogas, número de parceiros sexuais no ultimo ano e informações clínico-laboratoriais, como nível de CD $4^{5}$, tratamento antirretroviral $(\mathrm{ARV})^{6}$ etc. O objetivo é estudar tanto o tempo até a primeira incidência ${ }^{7}$ quanto o tempo até o primeiro clareamento de HPV oncogênicos e não-oncogênicos ${ }^{8}$. As pacientes que não tinham resultados de exames de HPV e as pacientes que tinham apenas uma consulta foram retiradas do estudo, reduzindo a amostra para 831 visitas referentes a 202 pacientes.

Como existe um intervalo entre as consultas, não se sabe o instante exato em que ocorre a infecção pelo HPV (caracterizando censura intervalar). Para efeito de análise, consideramos que a infecção ocorre no ponto médio do intervalo entre as visitas. A distribuição do tempo entre visitas é mostrada na Figura 1.1.
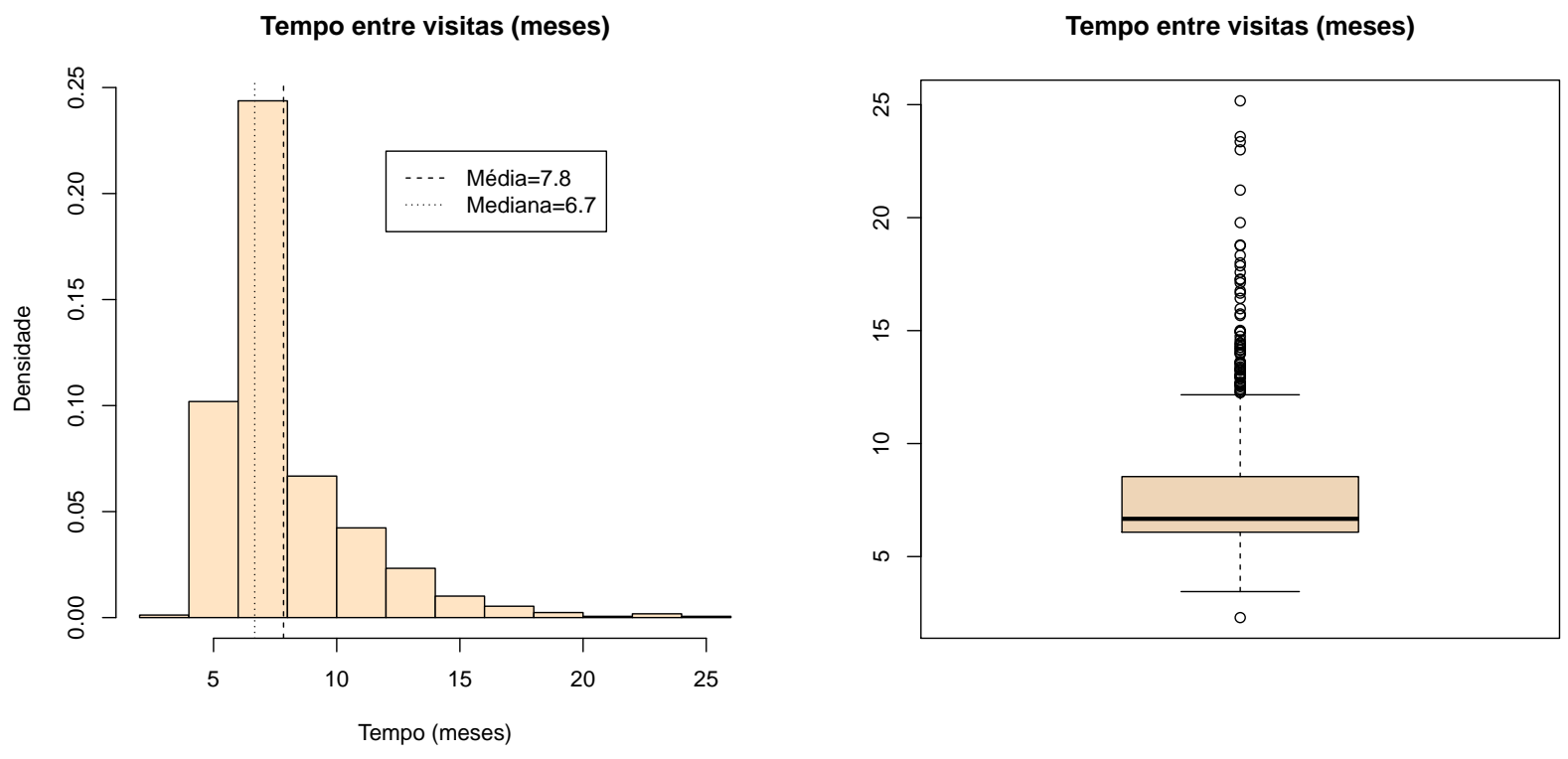

Figura 1.1: Histograma e boxplot para o tempo entre as visitas (meses).

Por definição, o tempo até a primeira incidência (ou o tempo até o primeiro clareamento) de

\footnotetext{
${ }^{3}$ Em que os participantes podem entrar e sair do estudo em qualquer instante.

${ }^{4}$ Existem cerca de 120 tipos de HPV [McKenzie et al. (2010)], porém apenas 35 são avaliados nesse estudo.

${ }^{5}$ Células de imunidade do organismo; quanto maior for o nível de CD4 mais protegido o organismo está contra doenças oportunistas, assim como do HPV.

${ }^{6}$ Medicamentos para tratar a infecção por algum retrovirus, principalmente HIV. Neste estudo avaliamos os esquemas baseados em medicamentos inibidores de protease (IP) ou inibidores da transcriptase reversa não análogos de nucleosídeos (ITRNN)

${ }^{7}$ Incidência é o número de novos casos de uma determinada doença, durante um determinado período para uma população específica [Last (2001)].

${ }^{8}$ Os 35 tipos de HPV avaliados neste estudo foram agrupados como oncogênicos e não-oncogênicos.
} 
HPV exige que a paciente não esteja (ou esteja) infectada na primeira visita. No entanto, incluimos as pacientes admitidas com HPV mas que clarearam em alguma visita posterior e contamos o tempo até a primeira incidência de HPV desde essa visita. De forma análoga, para avaliar o clareamento, incluimos as pacientes admitidas sem HPV mas que em algum momento contraíram algum desses vírus e contamos o tempo até o primeiro clareamento do HPV. Comparamos as análises com e sem a inclusão destas pacientes.

Existem algumas medidas para quantificar associações entre a ocorrência de um evento de interesse e subgrupos da população em um estudo de coorte. Uma delas é o risco relativo (ver Ahrens \& Pigeot (2004), por exemplo), em que se assume que o tempo de acompanhamento de todas as pacientes da coorte é o mesmo [Athanasiou \& Darzi (2010)]. Outra medida de associação é a razão de taxas (de incidência) definida abaixo; neste caso os indivíduos não precisam ter o mesmo tempo de acompanhamento pois o tempo até a ocorrência do evento é levado em conta em sua definição.

Consideremos primeiramente a variável

$$
Y_{i}(t)=\left\{\begin{array}{cc}
1 & \text { se a paciente } i \text { foi infectada por HPV entre os instantes } t \text { e } t+\Delta t \\
0 & \text { em caso contrário }
\end{array}\right.
$$

em que $\Delta t$ é uma unidade de tempo pré-estabelecida. Denotando por $n(t)$ o total de pacientes sob risco no inicio do intervalo e por $\bar{n}(t)$ o número médio de pacientes sob risco no intervalo, a taxa (média) de incidência de HPV é definida [Ahrens \& Pigeot (2004)] como

$$
\lambda(t)=\sum_{i=1}^{n(t)} Y_{i}(t) /[\bar{n}(t) \Delta t]
$$

Usualmente utiliza-se o número médio de pacientes sob risco no ponto médio do intervalo $(t, t+$ $\Delta t$ ) como uma aproximação para o número médio de pacientes sob risco no intervalo [Elandt-Johnson (1975) / Ahrens \& Pigeot (2004)], definindo a taxa (média) aproximada de incidência como

$$
\lambda_{a}(t)=\frac{\sum_{i=1}^{n(t)} Y_{i}(t)}{\left[n(t)-1 / 2 \sum_{i=1}^{n(t)} Y_{i}(t)\right] \Delta t}
$$

A Tabela 1.1 apresenta uma coorte hipotética de 40 pacientes sob risco de infecção por HPV no instante 0 e acompanhados por 50 meses. Para cada intervalo $\Delta t=5$ meses, a taxa média aproximada de incidência de HPV é obtida por intermédio de (1.2).

Quando se tem informação sobre o tempo até a incidência da doença para cada indivíduo, uma outra aproximação de (1.1) é a taxa (média) de incidência pessoa-tempo (ver Ahrens \& Pigeot 


\begin{tabular}{cccc}
\hline $\begin{array}{c}\text { Tempo em } \\
\text { meses }(\mathrm{t})\end{array}$ & $\begin{array}{c}\text { Pacientes } \\
\text { sob risco }\end{array}$ & $\begin{array}{c}\text { Contrairam } \\
\operatorname{HPV}\left(Y_{. t}\right)\end{array}$ & $\lambda_{a}(t)$ \\
\hline $0 \vdash 5$ & 40 & 5 & 0,027 \\
$5 \vdash 10$ & 35 & 7 & 0,044 \\
$10 \vdash 15$ & 28 & 6 & 0,048 \\
$15 \vdash 20$ & 22 & 4 & 0,040 \\
$20 \vdash 25$ & 18 & 5 & 0,065 \\
$25 \vdash 30$ & 13 & 4 & 0,073 \\
$30 \vdash 35$ & 9 & 4 & 0,114 \\
$35 \vdash 40$ & 5 & 0 & 0,000 \\
$40 \vdash 45$ & 5 & 2 & 0,100 \\
$45 \vdash 50$ & 3 & 1 & 0,080 \\
$\geq 50$ & 2 & 2 & - \\
\hline
\end{tabular}

Tabela 1.1: Coorte ilustrativa de pacientes e taxa de incidência para cada tempo de observação

(2004), por exemplo), dada por

$$
\lambda_{p t}(t)=\frac{\sum_{i=1}^{n(t)} Y_{i}(t)}{\sum_{i=1}^{n(t)} T_{i}(t)}
$$

em que $T_{i}(t)$ corresponde ao tempo até a paciente $i$ ser infectada, se isto ocorreu no intervalo ( $t$, $t+\Delta t)$ ou ao tempo de acompanhamento da paciente se ela não foi infectada. Em geral esta taxa é apresentada como uma média para todo o período de acompanhamento, e não fracionada em subintervalos $(t, t+\Delta t)$ como em (1.3).

Para avaliar a relação entre taxas de incidência para dois subgrupos da população, casadas ou solteiras por exemplo, pode-se utilizar a razão de taxas de incidência dada por

$$
\operatorname{RTI}(t)=\lambda_{s}(t) / \lambda_{c}(t)
$$

em que $\lambda_{s}(t)$ é a taxa de incidência para as mulheres solteiras e $\lambda_{c}(t)$ a taxa de incidência para as mulheres casadas. Analogamente, avaliamos a razão das taxas de clareamento substituindo o desfecho "tempo até a incidência de HPV" por "tempo até o clareamento do HPV" na razão das taxas de incidência.

Com o intuito de relacionar variáveis demográficas, comportamentais e clinico-laboratoriais com a prevalência ${ }^{9}$ de HPV oncogênicos e não-oncogênicos, Giuliano et al. (2003), Kjaer et al. (1997), Rousseau et al. (2000) e Sahasrabuddhe et al. (2007), utilizaram o modelo logístico [McCullagh \& Nelder (1989)] e obtiveram associações significativas entre a prevalência de HPV oncogênicos principalmente com a idade (fator de proteção para mulheres mais velhas), total de parceiros na vida (fator de risco para mulheres com mais parceiros), nível de CD4 (fator de proteção para níveis mais altos) entre outras menos frequentes, como o uso de drogas (fator de risco) e número de gestações (fator de proteção no caso de mais de uma gestação). Os mesmos autores avaliaram a associação entre HPV não-oncogênicos e fatores de risco como o total de parceiros na vida, o hábito tabagista ,

\footnotetext{
${ }^{9}$ Proporção da população que tem uma doença em um momento específico [Ahrens \& Pigeot (2004)].
} 
escolaridade, etc. e com fatores de proteção como a idade entre outros.

Embora o uso de modelos estatísticos (e.g., modelos lineares generalizados) para se obter a informação da prevalência do HPV em planejamentos transversais (em que apenas uma visita em um instante pré-fixado é avaliada) seja comum, há poucos trabalhos com o enfoque longitudinal ou de sobrevivência sobre o tema [Xue et al. (2010)].

Com o intuito de estimar a razão de taxas de incidência ${ }^{10}$ de HPV entre subgrupos da população na primeira ocorrência de um determinado tipo de HPV, poderíamos usar o modelo de Cox [ver Colosimo \& Giolo (2006), por exemplo]

$$
\lambda_{i}(t)=\lambda_{0}(t) \exp \left(\mathbf{x}_{i}^{T} \boldsymbol{\beta}\right)
$$

$i=1, \ldots, n$, em que $\lambda_{0}(t)$ é a função de incidência basal, $\boldsymbol{\beta}^{T}=\left(\beta_{1}, \ldots, \beta_{p}\right)$ é o vetor que contém os coeficientes de regressão a serem estimados e $\mathbf{x}_{i}^{T}=\left(x_{i 1}, \ldots, x_{i p}\right)$ é o vetor com os valores de $p$ covariáveis referentes ao $i$-ésimo indivíduo. Esta formulação assume que as covariáveis têm um efeito multiplicativo na taxa de incidência, $\lambda_{i}(t)$, e que a razão das taxas (ou razão de riscos) é constante ao longo do tempo. Este modelo é semiparamétrico pois não assumimos nenhuma distribuição para a taxa de falha basal $\lambda_{0}(t)$, que é estimada de forma não-paramétrica.

Woodman et al. (2001) utilizaram esse modelo para avaliar a associação entre variáveis demográficas e comportamentais e o tempo até a incidência de HPV em uma coorte de pacientes que tinham recém-iniciado atividades sexuais. Esses autores também utilizaram o modelo de Cox para avaliar a função de taxa de falha acumulada [ver Colosimo \& Giolo (2006), por exemplo] e o tempo de persistência do HPV. Como a infecção por mais de um tipo de HPV simultanemente é um fenômeno comum, o modelo de Cox usual não é adequado, pois considera que as observações dos tempos até a ocorrência do evento de interesse (no caso, a incidência de HPV) são independentes. Para contornar esta limitação, Brown et al. (2005) utilizaram um modelo de fragilidade compartilhada, com o intuito de avaliar o efeito de cada tipo de HPV no tempo até o seu clareamento. O modelo de fragilidade insere um efeito aleatório $u_{i}$ com densidade $f_{u_{i}}$ para cada paciente no modelo de Cox usual, com o intuito de incorporar a possível correlação intraindivíduo, e é dado por

$$
\lambda_{i k}(t)=\lambda_{0}(t) u_{i} \exp \left(\mathbf{x}_{i k}^{T} \boldsymbol{\beta}\right)
$$

para $k=1, \ldots, m_{i}$ e $i=1, \ldots, n$, em que $\boldsymbol{\beta}=\left(\beta_{1}, \ldots, \beta_{p}\right)^{T}$ denota o vetor que contém os coeficientes de regressão, $\mathbf{x}_{i k}=\left(x_{i k 1}, \ldots, x_{i k p}\right)^{T}$ é um vetor de dimensão $p$ com o valor das covariáveis relativas ao $k$-ésimo tipo de HPV para a paciente $i, m_{i}$ é o total de tipos de HPV associados à $i$-ésima paciente e $n$ é o total de pacientes na coorte. Neste caso, o efeito aleatório $u_{i}$ representa a suscetibilidade individual (não-observável) de a $i$-ésima paciente clarear o HPV.

No caso particular discutido em Brown et al. (2005) temos que

$$
x_{i k}=\left\{\begin{array}{cc}
1 & \text { se a paciente } i \text { está infectada por HPV do tipo } k \\
0 & \text { em caso contrário }
\end{array}\right.
$$

e $t$ é o tempo até o clareamento do virus.

O termo fragilidade foi introduzido por Vaupel et al. (1979) para indicar indivíduos que estão sob riscos diferentes mesmo que pareçam semelhantes no que diz respeito a características mensuráveis

\footnotetext{
${ }^{10}$ Também conhecida como razão de riscos ou razão de taxas de falha.
} 
como sexo, idade, peso, etc. Como exemplos, temos indivíduos da mesma família, em que podem contar fatores genéticos, pessoas do mesmo bairro, que podem compartilhar os mesmos fatores comportamentais ou condições de risco para uma determinada doença, indivíduos com eventos recorrentes, em que uma mesma pessoa pode contrair a mesma doença mais de uma vez, etc.

Uma alternativa proposta por Wei et al. (1989) para o modelo de fragilidade (1.6) é outra extensão do modelo de Cox que também leva em consideração possíveis correlações intraindivíduo. Enquanto no modelo de fragilidade (1.6) os parâmetros são estimados de forma condicional (para cada indivíduo), neste, eles são estimados de forma marginal. A expressão do modelo de Wei, Lin e Weissfeld (WLW) [Wei et al. (1989)] é

$$
\lambda_{i k}(t)=\lambda_{0 k}(t) \exp \left(\mathbf{x}_{i k}^{T}(t) \boldsymbol{\beta}\right)
$$

em que $\lambda_{0 k}(t)$ é a função de risco basal para o $k$-ésimo tipo de HPV, e $\exp \left(\beta_{j}\right), j=1, \ldots, p$ é a razão de riscos correspondente à $j$-ésima covariável, e os vetores $\mathbf{x}_{i k}(t)=\left(x_{i k 1}(t), \ldots, x_{i k p}(t)\right)^{T}$ podem ser tempo-dependentes (i.e. podem mudar durante o acompanhamento). Xue et al. (2010) encontraram associações significativas entre o nível de CD4 e a CV e a incidência de 5 tipos de HPV oncogênicos, comparando mulheres com e sem HIV. As mulheres com maior carga viral e menor CD4 apresentaram maior incidência de HPV oncogênicos. Xue et al. (2010) também compararam as taxas de incidência obtidas sob o modelo de fragilidade com aquelas obtidas sob o modelo WLW e verificaram que as estimativas correspondentes apresentaram valores maiores que as últimas.

A interpretação das estimativas da razão de taxas de falha nos modelos de fragilidade tem uma sutileza em relação ao modelo de Cox clássico (1.5) e ao modelo de Cox marginal (1.7) pois para estes interpretamos o coeficiente de cada variável como um efeito médio populacional enquanto para os modelos de fragilidade, o coeficiente de cada variável é interpretado como um efeito para uma unidade típica [Carvalho et al. (2011)]. Em nosso trabalho as unidades são mulheres e a unidade típica seria uma mulher com fragilidade $u_{i}=1$; também podemos comparar o efeito de cada covariável em cada tipo de HPV para uma mesma mulher, quando isto fizer sentido, ou ainda assumir que cada efeito é comparável para mulheres com fragilidades iguais. Segundo Klein (1992), podemos comparar, o efeito de pacientes diferentes com covariáveis diferentes, e neste caso a razão de taxas de falha dependerá de $t$; no entanto vamos nos deter em comparar efeitos fixando cada paciente.

Como os modelos de Cox são expressos em termos de razões de taxas de falha (que em nosso estudo podem ser vistas como razões de taxas de incidência/clareamento instantânea), e em especial os modelos de fragilidade apresentam uma interpretação desejada em ensaios clínicos [Lindsey \& Lambert (1998)], estes são os modelos adotados neste estudo.

Grinsztejn et al. (2009) analisaram o mesmo conjunto de dados sob investigação neste trabalho, avaliando a prevalência apenas de HPV oncogênicos em um determinado período. Nosso objetivo é avaliar esta coorte com enfoque longitudinal, investigando o efeito de: idade, raça, situação conjugal, escolaridade, renda mensal, status de emprego, hábito tabagista, uso de drogas, idade da primeira relação sexual, total de parceiros, total de gestações, histórico de HPV autoinformado, uso de preservativos e CD4 nadir ${ }^{11}$, além de: uso de anticoncepcional hormonal, contagem de CD4, tratamento ARV e total de HPV no momento da visita na incidência e clareamento de HPV, diferenciando-os

\footnotetext{
${ }^{11}$ Nível de CD4 mais baixo antes de iniciar qualquer tratamento ARV
} 
por tipo (oncogênico e não-oncogênico). Além disso, neste trabalho pretendemos:

- diferenciar os fatores de risco associados à incidência ou clareamento de HPV oncogênicos e não-oncogênicos;

- verificar se existe dependência entre os tempos até incidência (clareamento) de HPV oncogênicos e não-oncogênicos, ou seja, se existem mulheres com diferentes fragilidades para incidência (clareamento) de HPV;

- avaliar a adequabilidade do modelo semiparamétrico de fragilidade para estimar eventos múltiplos (tempo até incidência (clareamento) de HPV oncogênicos e não-oncogênicos) e apontar suas limitações.

No Capítulo 2, apresentamos análises descritivas do conjunto de dados. No Capítulo 3, apresentamos detalhes dos modelos propostos neste trabalho. Os ajustes dos modelos serão apresentados no Capítulo 4. Por fim, uma discussão dos resultados será apresentada no Capítulo 5. 


\section{Capítulo 2}

\section{Análise descritiva}

A coorte em estudo tem dados de 831 visitas de 202 mulheres HIV-positivas ${ }^{1}$. O total pessoasmês ${ }^{2}$ é 4999 meses. A frequência de HPV oncogênicos é de 465 e a dos não-oncogogênicos é de 419 ao longo de todas as visitas e a prevalência de HPV oncogênicos na primeira visita é 0.65 e de HPV não-oncogênicos é 0.52. As mulheres que iniciaram o estudo com (sem) algum tipo de HPV e saíram do estudo sem clarear (incidir) não poderão ser avaliadas para a incidência (clareamento) desta classe específica de vírus. Levando em conta este detalhe e retirando as pacientes que tiveram mais de 12 meses entre uma visita e outra, obtivemos um total de 134 mulheres para o estudo de incidência de HPV oncogênicos e não-oncogênicos, 153 para o clareamento de HPV oncogênicos e 141 para o clareamento de HPV não-oncogênicos.

Histogramas e curvas de sobrevivência estimadas pelo método de Kaplan-Meier [Kaplan \& Meier (1958)] para incidência de HPV oncogêncios e HPV não-oncogênicos são apresentados nas Figuras 2.1 e 2.2 respectivamente. Com base na Figura 2.1 verificamos que as distribuições dos tempos até incidência de HPV oncogênicos e HPV não-oncogênicos são assimétricas à direita, com moda no intervalo de 5-10 meses. Para a comparação das curvas de sobrevivência deste capítulo utilizamos testes Log-Rank (ver Colosimo \& Giolo (2006), por exemplo) e de Peto \& Peto (ver Kleinbaum (2005), por exemplo). Este último é mais indicado quando os riscos não são proporcionais, hipótese que não podemos descartar a princípio. As curvas de sobrevivência apresentadas na Figura 2.2 sugerem que as distribuições do tempo até incidência de HPV oncogênicos e não-oncogênicos são similares $(\mathrm{P}=0.705$ para o teste Log-Rank e $\mathrm{P}=0.854$ para o teste de Peto \& Peto).

A taxa de incidência média pessoa-mês em todo o período de acompanhamento é de 0.047 para os HPV oncogênicos e de 0.043 para os HPV não-oncogênicos.

Na Tabela 2.1 apresentamos a distribuição das variáveis demográficas e comportamentais além do nível de CD4 nadir. Observa-se uma quantidade pequena de dados omissos para cada covariável (em média 9.8\%).

Temos também informações de variáveis clínico-laboratoriais como o nível de CD4 e tratamento antirretroviral (ARV) que podem variar ao longo do tempo (variáveis tempo-dependentes). Como as informações do nível de CD4 e do tratamento ARV não são obtidas na mesma consulta em que a paciente realiza o exame de diagnóstico de HPV, existem visitas para as quais não se tem estas informações. A Tabela 2.2 mostra o total de visitas e pacientes na amostra, além dos totais para os seguintes filtros de dados:

\footnotetext{
${ }^{1}$ Após terem sido retiradas as mulheres com apenas uma visita ou sem a informação da infecção por algum HPV

${ }^{2}$ Pessoa-mês é a soma dos tempos de acompanhamento (em meses) de cada mulher.
} 

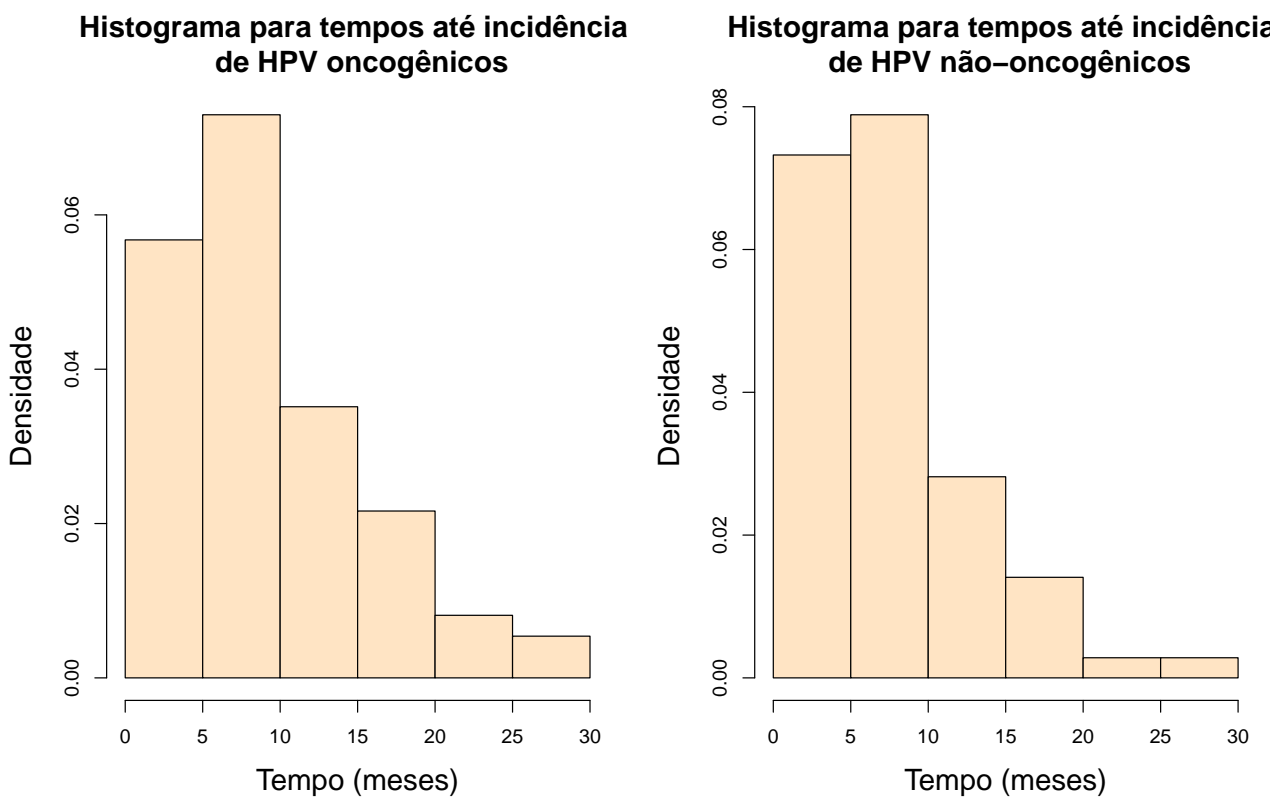

Figura 2.1: Histogramas para tempo até incidência de (a) HPV oncogênicos e (b) HPV não-oncogênicos.

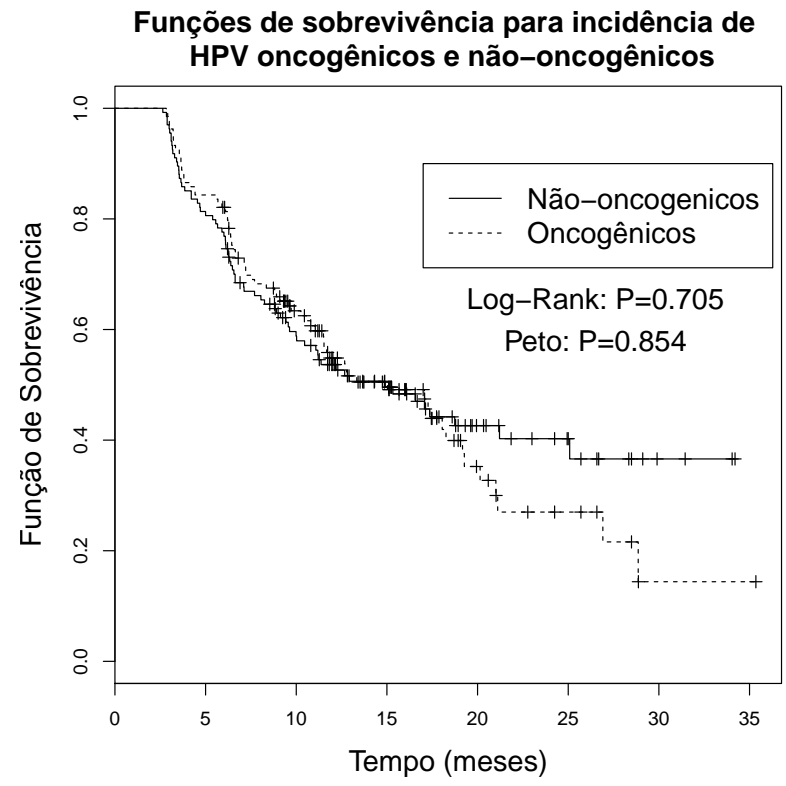

Figura 2.2: Curvas de sobrevivência (Kaplan-Meier) para a incidência de HPV oncogênicos e nãooncogênicos.

- pacientes com diagnóstico de HPV e mais de uma visita;

- pacientes com exame de CD4;

- pacientes sob tratamento com algum medicamento ARV.

A Figura 2.3 apresenta algumas curvas de sobrevivência, o valor-P do teste Log-Rank e o valor-P do teste de Peto \& Peto para comparação dos tempos até incidência de HPV oncogênicos segundo as características demográficas e comportamentais (Tabela 2.1) que geraram as maiores diferenças, a saber: usuária de drogas, total de parceiros no ano anterior, renda e total de gestações. As curvas de sobrevivência correspondenter às demais variáveis da Tabela 2.1 e também às clínico-laboratoriais 
(CD4 e ARV), para cada desfecho (incidência de HPV oncogênicos e não-oncogênicos e clareamento de HPV oncogênicos e não-oncogênicos) podem ser obtidas em

https://www.dropbox.com/sh/4a9k1ryvcx6jsvr/QQe6PxeWEz
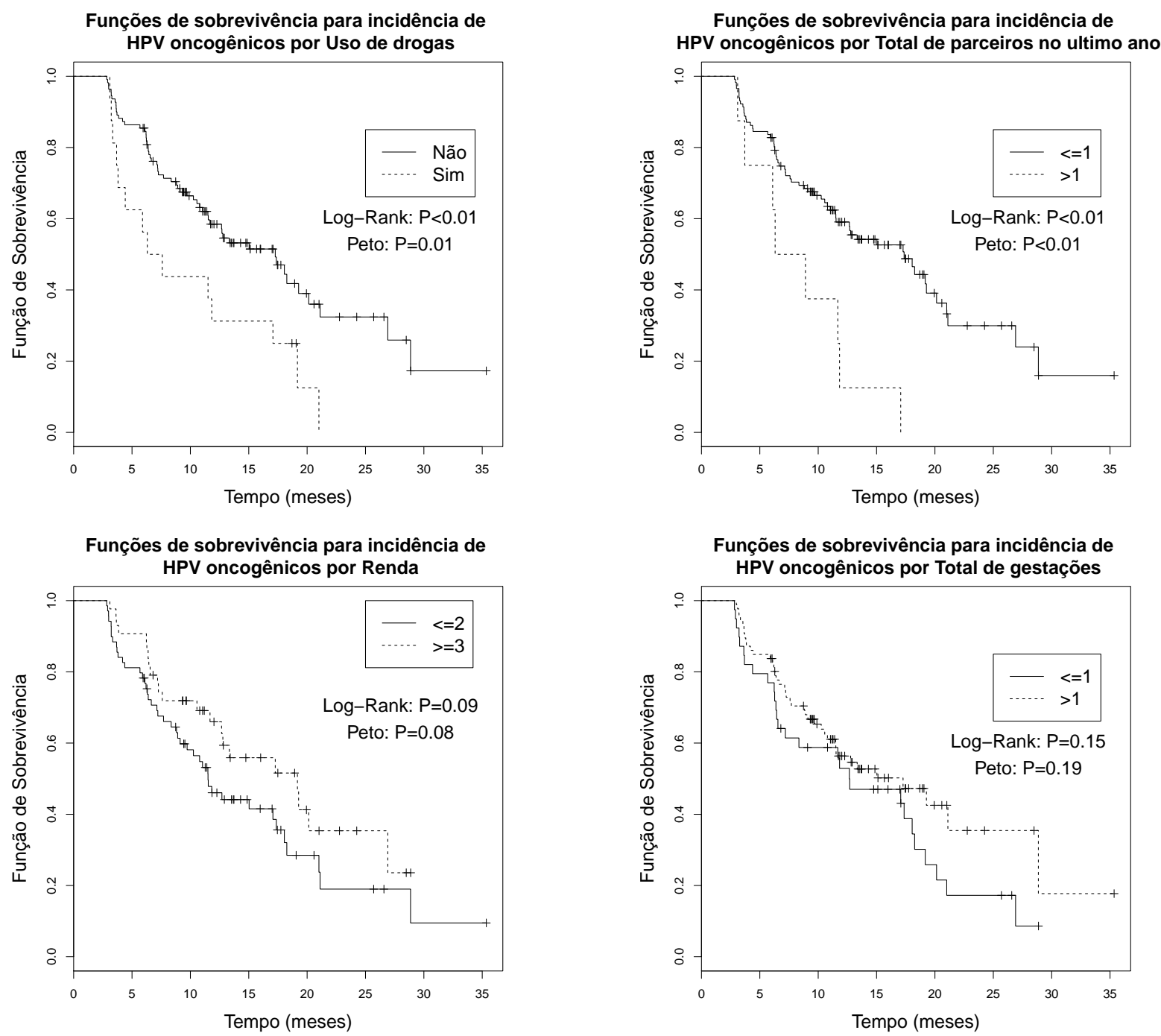

Figura 2.3: Curvas de sobrevivência (Kaplan-Meier) para a incidência de HPV oncogênicos por variáveis demográficas e comportamentais associadas às maiores diferenças.

A Figura 2.4 apresenta as curvas de sobrevivência para a incidência de HPV não-oncogênicos correspondentes às variáveis demográficas, comportamentais e clínico-laboratoriais associadas às maiores diferenças, nomeadamente: escolaridade, total de gestações e nível de CD4.

Da mesma forma que apresentamos os dados para o tempo até a incidência de HPV oncogênicos e não-oncogênicos analisamos seu clareamento. Os histogramas e as curvas de sobrevivência para o clareamento de HPV oncogêncios e HPV não-oncogênicos são apresentados nas Figuras 2.5 e 2.6 respectivamente. Com base na Figura 2.5 verificamos que as distribuições dos tempos até incidência de HPV oncogênicos e HPV não-oncogênicos são assimétricas à direita, com moda no intervalo de 5-10 meses. As curvas de sobrevivência apresentadas na Figura 2.6 sugerem que a distribuição do tempo até clareamento de HPV oncogênicos e não-oncogênicos são similares ( $\mathrm{P}=0.258$ para o teste de Log-Rank e o $\mathrm{P}=0.854$ para o teste de Peto \& Peto). A taxa de clareamento média pessoa-mês em todo o período de acompanhamento é de 0.051 para os HPV oncogênicos e de 0.042 para os HPV 

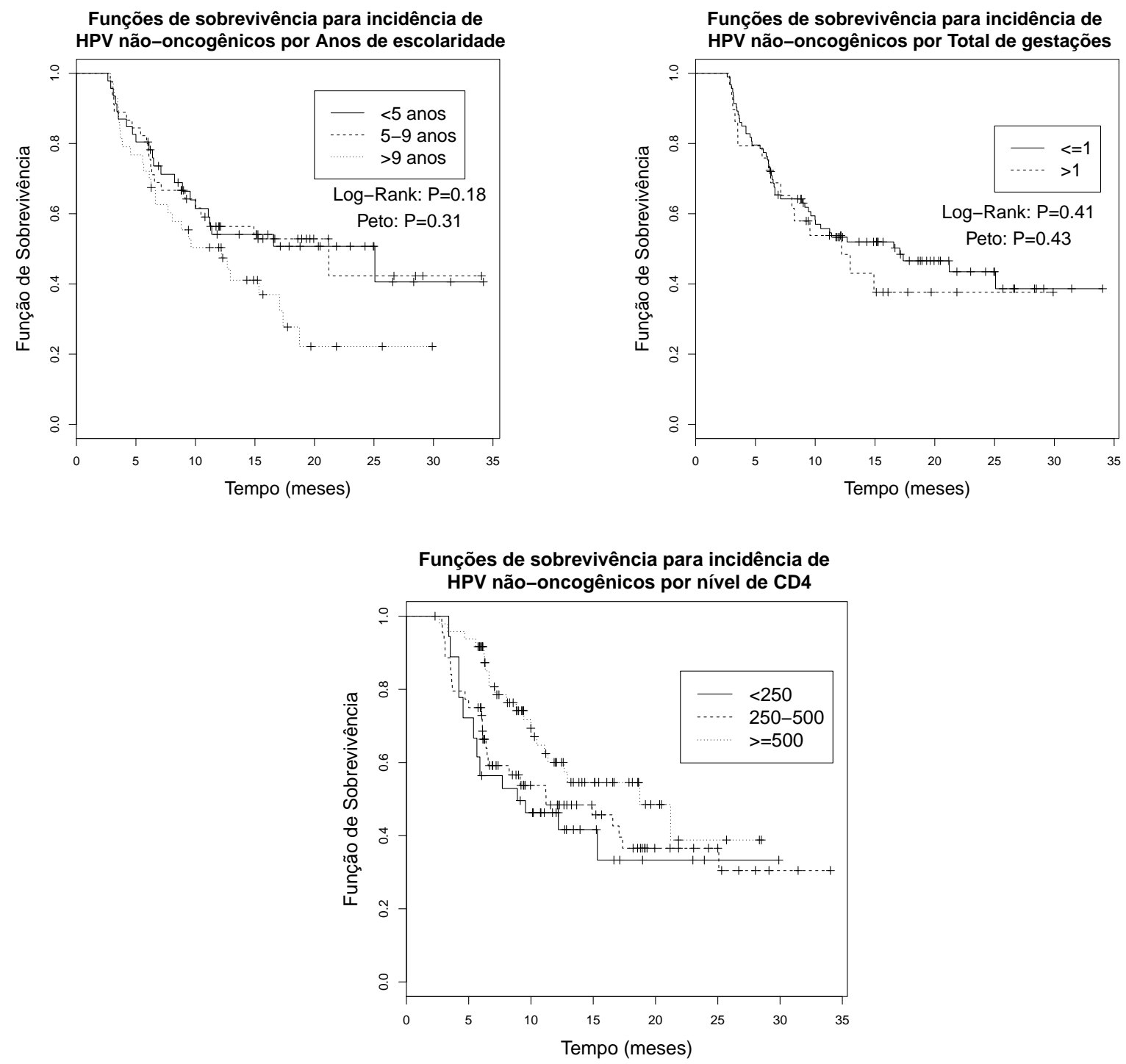

Figura 2.4: Curvas de sobrevivência (Kaplan-Meier) para a incidência de HPV não-oncogênicos por variáveis demográficas, comportamentais e clínico-laboratoriais associadas às maiores diferenças.

não-oncogênicos. A Figura 2.7 apresenta curvas de sobrevivência e o valor-P do teste Log-Rank para comparação dos tempos até clareamento de HPV oncogênicos segundo as características demográficas, comportamentais e clínico-laboratoriais associadas às maiores diferenças, a saber: renda, total de parceiros no último ano, uso de tratamento ARV, e idade. A Figura 2.8 apresenta as curvas de sobrevivência para o clareamento de HPV não-oncogênicos correspondentes às variáveis demográficas, comportamentais e clínico-laboratoriais associadas às maiores diferenças, nomeadamente: renda, hábito tabagista e nível de CD4.

Com base nas diferenças entre os níveis de cada variável, apresentadas nas Figuras 2.3, 2.4, 2.7 e 2.8 temos indícios de algumas variáveis relacionadas a cada desfecho. No Capítulo 4 avaliaremos o efeito de cada uma destas, e também das demais, utilizando o modelo de fragilidade (1.6). Alguns trabalhos ([Rezza et al. (1998)], [Palefsky (2003)], [Rousseau et al. (2000)], [Kjver et al. (1997)] entre outros) apresentaram algumas das variáveis das Figuras 2.3, 2.4, 2.7 e 2.8 como sendo fatores de risco (uso de drogas, total de parceiros, total de gestações etc) ou proteção (renda, nível de CD4 etc) para a incidência de HPV oncogênicos e não-oncogênicos, e pouco se sabe sobre os fatores 


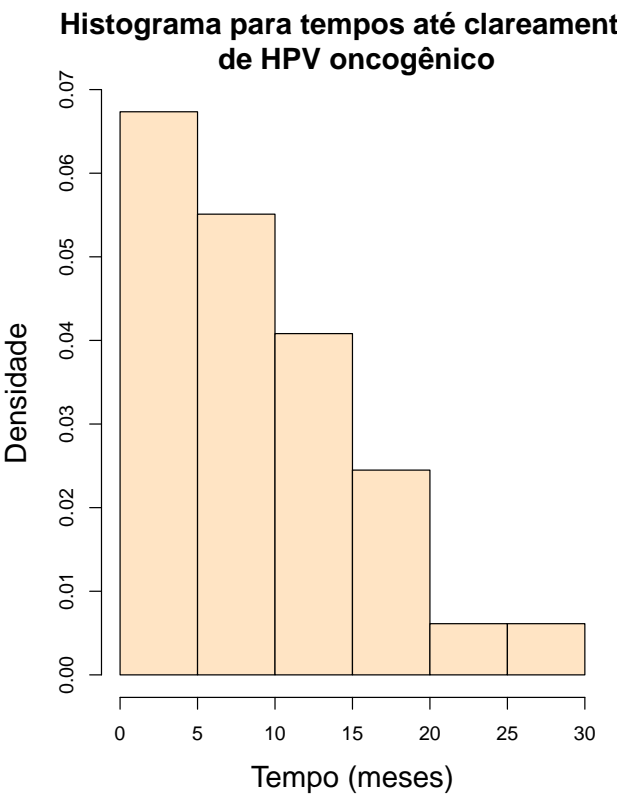

Histograma dos tempos até clareamento de HPV não-oncogênico

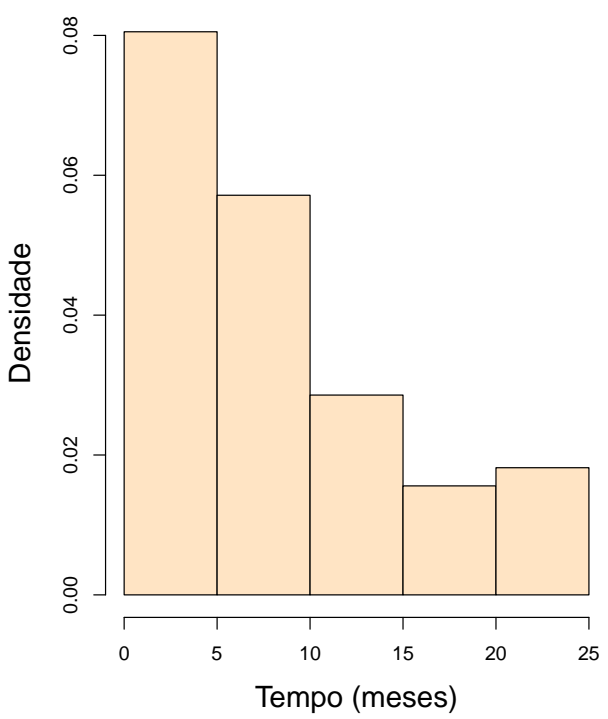

Figura 2.5: Histograma para tempo até clarear (a) HPV oncogênicos e (b) HPV não-oncogênicos.

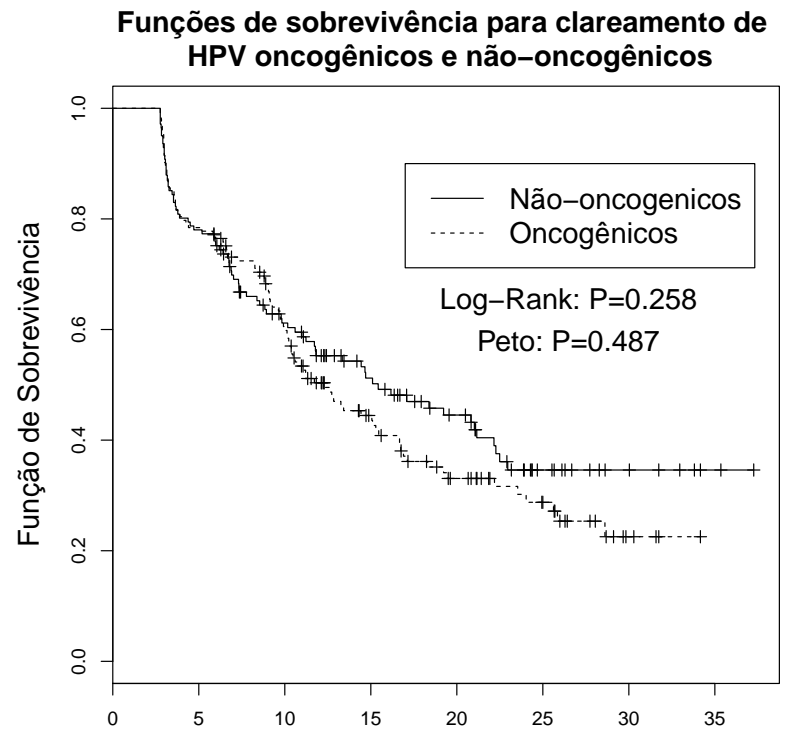

(b) Tempo (meses)

Figura 2.6: Curvas de sobrevivência (Kaplan-Meier) para o clareamento de HPV oncogênicos e nãooncogênicos.

associados ao clareamento de HPV oncogênicos e não-oncogênicos. 
Funções de sobrevivência para clareamento de HPV oncogênicos por Renda

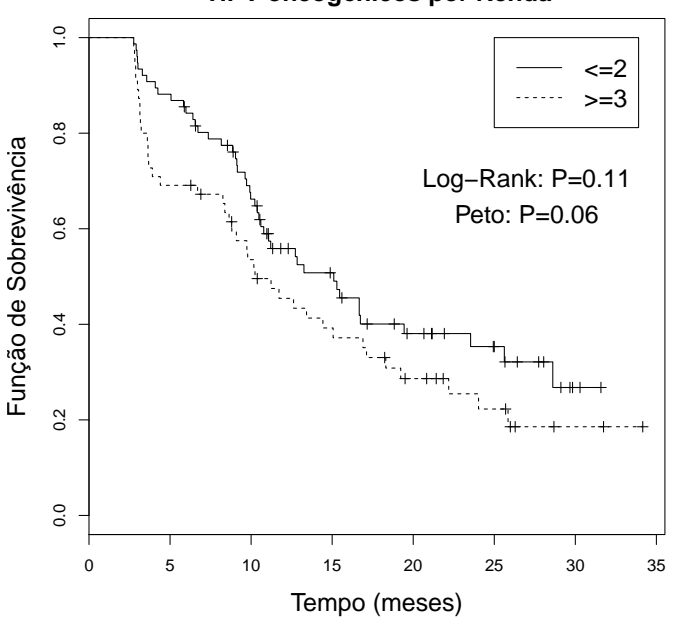

Funções de sobrevivência para clareamento de HPV oncogênicos por Tratamento ARV

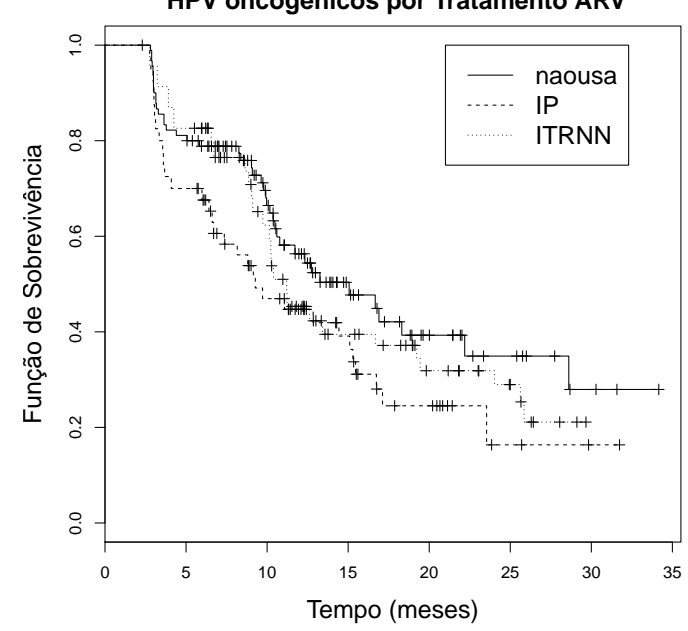

Funções de sobrevivência para clareamento de HPV oncogênicos por Total de parceiros no ultimo ano

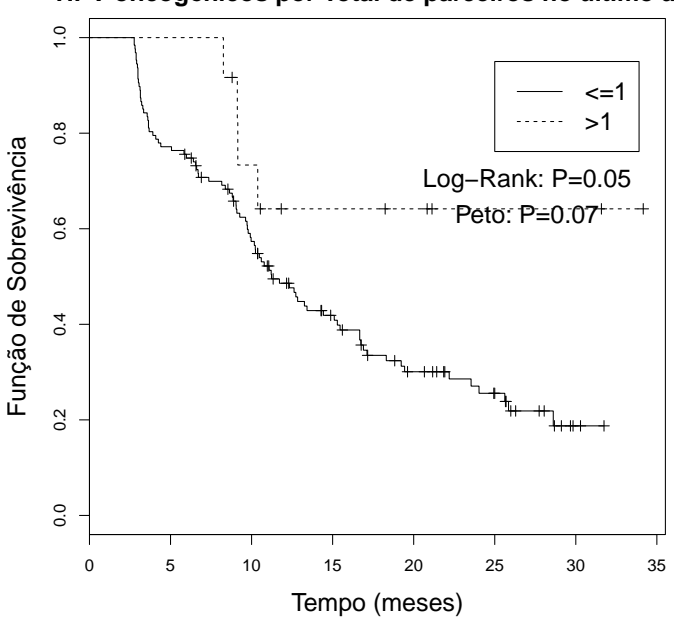

Funções de sobrevivência para clareamento de HPV oncogênicos por Idade

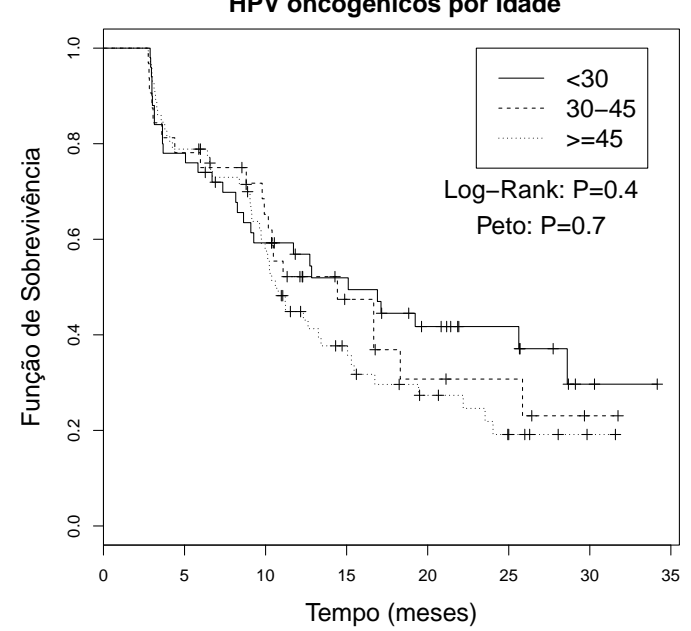

Figura 2.7: Curvas de sobrevivência (Kaplan-Meier) para o clareamento de HPV oncogênicos por variáveis demográficas, comportamentais e clínico-laboratoriais associadas às maiores diferenças. 


\begin{tabular}{|c|c|c|c|}
\hline Características (1) & $\mathrm{n}(\%)$ & Características (2) & $\mathrm{n}(\%)$ \\
\hline Idade (anos) & & Idade primeira relação sexual (anos) & \\
\hline$<30$ & $65(32,2)$ & $\leq 15$ & $69(34,2)$ \\
\hline $30-45$ & $38(18,8)$ & $15-20$ & $97(48,0)$ \\
\hline$>45$ & $99(49,0)$ & $\geq 20$ & $21(10,4)$ \\
\hline Raça & & NA & $15 \quad(7,4)$ \\
\hline Branco & $91(45,0)$ & Número de parceiros no ano anterior & \\
\hline Não-Branco & $111(55,0)$ & $\leq 1$ & $171(84,7)$ \\
\hline Casada/vivendo com parceiro & & $\geq 2$ & $14 \quad(6,9)$ \\
\hline Sim & $135(66,8)$ & NA & $17 \quad(8,4)$ \\
\hline Não & $46(22,8)$ & Número de parceiros em toda a vida & \\
\hline NA & $21(10,4)$ & $\leq 10$ & $142(70,3)$ \\
\hline Escolaridade (anos de educação) & & $10-20$ & $29(14,4)$ \\
\hline$<5$ & $68(33,7)$ & $\geq 20$ & $13(6,4)$ \\
\hline $5-8$ & $69(34,2)$ & NA & $18 \quad(8,9)$ \\
\hline$>9$ & $65(32,2)$ & Número de gestações & \\
\hline Renda mensal (salários mínimos) & & $\leq 1$ & $60(29,7)$ \\
\hline $0-2$ & $100(49,5)$ & $>1$ & $127(62,9)$ \\
\hline $2-9$ & $60(31,2)$ & NA & $15 \quad(7,4)$ \\
\hline$>9$ & $9 \quad(3,0)$ & Histórico de HPV informado & \\
\hline NA & $33(16,3)$ & Não & $159(78,7)$ \\
\hline Status de emprego & & Sim & $26(12,9)$ \\
\hline Empregada (com ou sem vínculo) & $77(38,1)$ & NA & $17(8,4)$ \\
\hline Desempregada & $111(55,0)$ & Usou camisinha na ultima relação sexual & \\
\hline NA & $14 \quad(6,9)$ & Não & $60(29,7)$ \\
\hline Fumou alguma vez & & Sim & $120(59,4)$ \\
\hline Não & $120(59,4)$ & NA & $22(10,9)$ \\
\hline Sim & $68(33,7)$ & Já usou anticoncepcional hormonal & \\
\hline NA & $14 \quad(6,9)$ & Sim & $23(11,4)$ \\
\hline Fuma atualmente & & Não & $164(81,2)$ \\
\hline Não & $154(76,2)$ & NA & $15 \quad(7,4)$ \\
\hline Sim & $34(16,8)$ & CD4 nadir & \\
\hline NA & $14 \quad(6,9)$ & $<100$ & $27(13,4)$ \\
\hline Usou drogas alguma vez & & $100-400$ & $88(43,6)$ \\
\hline Não & $165(81,7)$ & $\geq 400$ & $38(18,8)$ \\
\hline Sim & $23(11,4)$ & NA & $49(24,3)$ \\
\hline NA & $14(6,9)$ & & \\
\hline
\end{tabular}

Tabela 2.1: Dados demográficos, comportamentais e clínico-laboratoriais para a coorte de 202 mulheres HIV-positivas.

\begin{tabular}{lrr}
\hline Filtros & Visitas & Pacientes \\
\hline HPV \& visitas $>1$ & 831 & 202 \\
HPV \& visitas $>1$ \& CD4 & 703 & 199 \\
HPV \& visitas $>1$ \& ARV & 461 & 140 \\
HPV \& visitas $>1$ \& CD4 \& ARV & 394 & 138 \\
\hline
\end{tabular}

Tabela 2.2: Total observado de visitas/pacientes. 
Funções de sobrevivência para clareamento de HPV não-oncogênicos por Renda

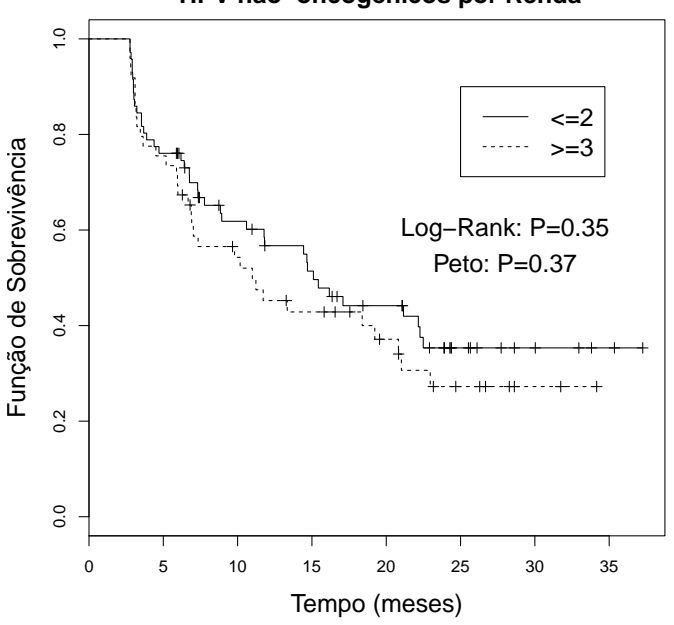

Funções de sobrevivência para clareamento de HPV não-oncogênicos por Hábito tabagista

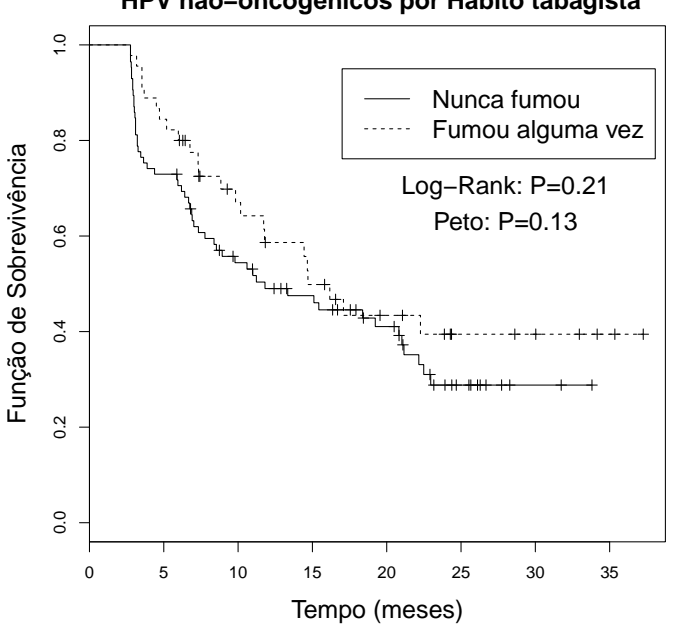

Funções de sobrevivência para clareamento de HPV não-oncogênicos por nível de CD4

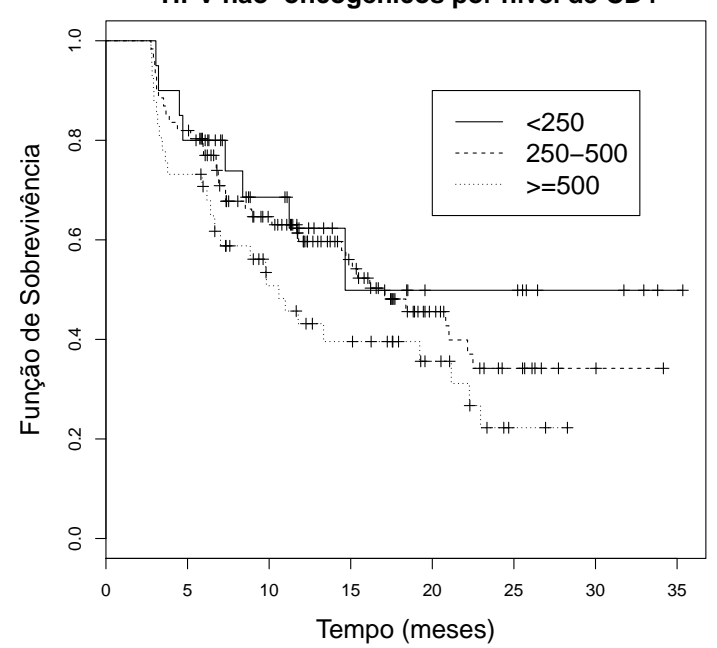

Figura 2.8: Curvas de sobrevivência (Kaplan-Meier) para clareamento de HPV não-oncogênicos por variáveis demográficas, comportamentais e clínico-laboratoriais associadas às maiores diferenças. 


\section{Capítulo 3}

\section{Metodologia}

Para incluir características individuais não-mensuráveis e modelar estruturas de covariância intraunidades amostrais no contexto de análise de sobrevivência, alguns autores propuseram diferentes distribuições para o termo de fragilidade do modelo (1.6). A distribuição Gama foi proposta por Clayton (1978) e Hougaard (1996a,b) propôs as distribuições Positiva Estável (PSD) e Gaussiana Inversa. Outras alternativas de distribuições consideradas na literatura estatística são: Log-normal [McGilchrist \& Aisbett (1991)], Poder de Variância (PVF) [Aalen (1988)] e Uniforme [Lee \& Klein (1998)]. O modelo Gama é muito utilizado devido à facilidade de obteção de determinados resultados por meio de transformadas de Laplace (ver Duchateau \& Janssen (2008), por exemplo) além de ter sido implementado na maioria dos pacotes computacionais [R Development Core Team (2009), Base SAS® 9.3 Procedures Guide (2011), Stata 11 Base Reference Manual (2011)]. Por estas razões, neste trabalho assumiremos distribuições Gama para o termo de fragilidade.

Consideramos o modelo (1.6) com $u_{i}$ representando a fragilidade da paciente $i$ com relação aos HPV oncogênicos e não-oncogênicos conjuntamente. A variabilidade de $u_{i}$ determina a heterogeneidade da resposta não explicada por outros fatores. Em nosso estudo, a fragilidade $u_{i}$ pode ser interpretada, por exemplo, como o efeito de características genéticas ou da imunidade de cada mulher. Assumimos que $u_{i}$ obedece a uma distribuição Gama, cuja função densidade é

$$
f_{u_{i}}(u)=\frac{1}{\theta^{1 / \theta}} u^{1 / \theta-1} e^{-u / \theta} / \Gamma(1 / \theta), \quad u>0, \theta>0 .
$$

e para a qual, $E\left(u_{i}\right)=1$ e $\operatorname{Var}\left(u_{i}\right)=\theta$.

$\mathrm{Na}$ prática, os dados são utilizados tanto para estimar o parâmetro $\theta$ quanto para predizer fragilidades individuais, que podem ser vistas como medidas de risco para cada paciente, pois quanto maior é sua fragilidade, mais suscetível ela está a apresentar os eventos de interesse (infecção por HPV, por exemplo).

Uma medida descritiva para avaliar a associação entre os tempos até incidência (ou clareamento) de HPV oncogênicos e não-oncogênicos na mesma mulher é o coeficiente de Kendall (ver Kendall (1938)). Consideremos duas pacientes $j$ e $l$ escolhidas aleatoriamente, com tempos até incidência (ou clareamento) de HPV oncogênicos e não-oncogênicos dados por $\left(T_{j 1}, T_{j 2}\right)$ e $\left(T_{l 1}, T_{l 2}\right)$ respectivamente. O coeficiente $\tau$ de Kendall é definido como

$$
\tau=E\left[\operatorname{sinal}\left(\left(T_{j 1}-T_{l 1}\right)\left(T_{j 2}-T_{l 2}\right)\right)\right]
$$


em que $\operatorname{sinal}(x)=-1,0,1$ para $x<0, x=0$ e $x>0$, respectivamente. Uma fórmula alternativa para distribuições contínuas [Genest \& MacKay (1986)] é

$$
\begin{aligned}
\tau & =P\left(\left(T_{j 1}-T_{l 1}\right)\left(T_{j 2}-T_{l 2}\right)>0\right)-P\left(\left(T_{j 1}-T_{l 1}\right)\left(T_{j 2}-T_{l 2}\right)<0\right) \\
& =2 p-1
\end{aligned}
$$

em que $p=P\left(\left(T_{j 1}-T_{l 1}\right)\left(T_{j 2}-T_{l 2}\right)>0\right)$. No contexto dos modelos de fragilidade, utilizando a notação de transformada de Laplace teremos, segundo Duchateau \& Janssen (2008),

$$
\tau=4 \int_{0}^{\infty} \int_{0}^{\infty} L(x+y) L^{(2)}(x+y) d x d y-1
$$

em que $x=\Lambda_{1}\left(t_{1}\right)$ e $y=\Lambda_{2}\left(t_{2}\right)$, com $\Lambda_{k}(t)=\int_{0}^{t} \lambda_{k}(u) d u$ representando a função de taxa de falha acumulada até o instante $t$ para o $k$-ésimo tipo de HPV ( $k=1$ ou 2 para HPV oncogênicos e não-oncogênicos, respectivamente), e $\lambda_{k}(u)$ é a função de taxa de falha correspondente no instante $u$ (ver Colosimo \& Giolo (2006), por exemplo). Aqui, $L^{(2)}(x+y)$ denota a segunda derivada da transformada de Laplace, $L(x+y)$. Fazendo a substituição $s=x+y$ e $v=y$ teremos

$$
\tau=4 \int_{0}^{\infty} \int_{0}^{s} L(s) L^{(2)}(s) d v d s-1=4 \int_{0}^{\infty} s L(s) L^{(2)}(s) d s-1
$$

Como para a distribuição Gama,

$$
\begin{gathered}
L(s)=(1+\theta s)^{-1 / \theta} \\
L^{(1)}(s)=-(1+\theta s)^{-1 / \theta-1} \\
L^{(2)}(s)=(1+\theta)(1+\theta s)^{-1 / \theta-2}
\end{gathered}
$$

obtemos

$$
\begin{aligned}
\int_{0}^{\infty} s L(s) L^{(2)}(s) d s & =\int_{0}^{\infty} \frac{1}{\theta}((1+\theta s)-1)(1+\theta s)^{(-1 / \theta)}(1+\theta)(1+\theta s)^{(-1 / \theta-2)} d s \\
& =\frac{\theta+1}{\theta}\left(\frac{1}{2}-\frac{1}{\theta+2}\right)
\end{aligned}
$$

e portanto, de (3.2) segue

$$
\tau=4\left[\frac{\theta+1}{\theta}\left(\frac{1}{2}-\frac{1}{\theta+2}\right)\right]-1=\frac{1}{1+2 / \theta}
$$

Como $0<\tau<1$, para valores maiores de $\theta$ (que indicam maior dependência entre $T_{i 1}$ e $T_{i 2}$ para $i=1, \ldots, n$ ), teremos $\tau$ mais próximo de 1 , e para valores menores de $\theta$ (que indicam menor dependência entre $T_{i 1}$ e $T_{i 2}$ ) teremos o coeficiente $\tau$ mais próximo de 0 .

Para a estimação dos parâmetros do modelo (1.6) com fragilidade Gama, a log-verossimilhança 
marginal (ou observada) (ver Klein (1992), por exemplo) é

$$
\begin{gathered}
l_{\text {marg }}(\theta, \beta)=\sum_{i=1}^{n}\left[d_{i} \log \theta-\log \Gamma(1 / \theta)+\log \Gamma\left(1 / \theta+d_{i}\right)\right. \\
\left.-\left(1 / \theta+d_{i}\right) \log \left(1+\theta \sum_{k=1}^{m_{i}} \Lambda_{0}\left(t_{i k}\right) \exp \left(\mathbf{x}_{i k}^{T} \boldsymbol{\beta}\right)\right)+\sum_{k=1}^{m_{i}} \delta_{i k}\left(\mathbf{x}_{i k}^{T}+\log \lambda_{0}\left(t_{i k}\right)\right)\right]
\end{gathered}
$$

em que $t_{i k}$ é o tempo até a incidência (ou clareamento), no caso de esta ter ocorrido ou ter sido censurada para o HPV do tipo $k$ na $i$-ésima paciente, $\Lambda_{0}\left(t_{i k}\right)=\int_{0}^{t_{i k}} \lambda_{0}(s) d s$ é a função de taxa de falha basal acumulada, $\delta_{i k}=1$ quando ocorre a falha e $\delta_{i k}=0$ quando ocorre censura e $d_{i}=\sum_{k=0}^{m_{i}} \delta_{i k}$. Caso assumíssemos uma forma paramétrica para $\lambda_{0}$, (3.4) poderia ser estimada por máxima verossimilhança utilizando o algoritmo de Newton-Raphson (ver Macleod (1984), por exemplo). Como este não é o caso, uma alternativa seria utilizar o algoritmo EM proposto por Klein \& Moeschberger (2003) maximizando a função de log-verossimilhança completa (ver Klein \& Moeschberger (2003), por exemplo)

$$
\begin{aligned}
& l_{\text {comp }}(\theta, \beta)=-n[(1 / \theta) \log \theta+\log \Gamma(1 / \theta)]+\sum_{i=1}^{n}\left[1 / \theta+d_{i}-1\right] \log u_{i}-u_{i} / \theta \\
&+\sum_{i=1}^{n} \sum_{k=1}^{m_{i}} \delta_{i k}\left[\mathbf{x}_{i k}^{T} \boldsymbol{\beta}+\log \lambda_{0}\left(t_{i k}\right)\right]-u_{i} \Lambda_{0}\left(t_{i k}\right) \exp \left(\mathbf{x}_{i k}^{T} \boldsymbol{\beta}\right) .
\end{aligned}
$$

Outra alternativa é baseada na maximização da função de verossimilhança parcial penalizada (PPL).

A formulação de regressão penalizada para os modelos de fragilidade é mais facilmente desenvolvida para uma versão alternativa de (1.6), em que primeiramente ordenamos os tempos $T_{i k}$, fazendo $T_{11}=T_{1}, T_{12}=T_{2}, \ldots$ de forma que o vetor $\left(T_{11}, \ldots, T_{1 m_{1}}, T_{21}, \ldots, T_{2 m_{2}}, \ldots, T_{n 1}, \ldots, T_{n m_{n}}\right)$ é substituído por $\left(T_{1}, \ldots, T_{m_{1}}, T_{m_{1}+1}, \ldots, T_{m_{1}+m_{2}}, \ldots, T_{\tilde{n}-m_{n}}, \ldots, T_{\tilde{n}}\right) \operatorname{com} \tilde{n}=\sum_{i=1}^{n} m_{i}$. Definindo $\mathbf{x}_{i k}^{T}=\mathbf{x}_{j}^{T}$, $\mathbf{z}_{j}^{T}=\left(z_{j 1}, \ldots, z_{j n}\right)$, em que $z_{j i}=1$ quando o $j$-ésimo tempo avaliado é referente a $i$-ésima paciente e $z_{j i}=0$ em caso contrário e $\boldsymbol{\omega}^{T}=\left(\omega_{1}, \ldots, \omega_{n}\right)$ cujos elementos são as fragilidades das $n$ pacientes o modelo (1.6) pode ser escrito como

$$
\lambda_{j}(t)=\lambda_{0}(t) \exp \left(\mathbf{x}_{j}^{T} \boldsymbol{\beta}+\mathbf{z}_{j}^{T} \boldsymbol{\omega}\right)
$$

A função de verossimilhança parcial penalizada é descrita como um produto em que o primeiro termo é a função de verossimilhança parcial do modelo de Cox tradicional, incluindo as fragilidades como parâmetros e o segundo termo é uma penalidade introduzida com a finalidade de fazer com que os valores de $\boldsymbol{\omega}$ fiquem próximos de zero. Desta forma, a log-verossimilhança parcial penalizada é

$$
P P L=P L(\boldsymbol{\beta}, \boldsymbol{\omega} ; d a d o s)-g(\boldsymbol{\omega} ; \theta)
$$

em que $P L$ é a log-verossimilhança parcial (ver Therneau \& Grambsch (2000), por exemplo),

$$
P L(\boldsymbol{\beta}, \boldsymbol{\omega})=\sum_{j=1}^{\tilde{n}} \int_{0}^{\infty}\left[Y_{j}(t)\left(\mathbf{x}_{j}^{T} \boldsymbol{\beta}+\mathbf{z}_{j}^{T} \boldsymbol{\omega}\right)-\log \sum_{k=1}^{\tilde{n}} Y_{k}(t) \exp \left(\mathbf{x}_{k}^{T} \boldsymbol{\beta}\right)+\mathbf{z}_{k}^{T} \boldsymbol{\omega}\right] d N_{j}(t),
$$

$g$ é a função de penalização e $\theta$ é um valor fixado usado para controlar a penalização. 
Para a equivalência entre os resultados obtidos pela maximização da log-verossimilhança parcial penalizada (3.7), utilizando o algoritmo Newton-Raphson, e pela maximização da verossimilhança completa (3.5), utilizando algoritmo EM, sob modelos de fragilidade Gama, Therneau \& Grambsch (2000) demostram que, para um valor fixo de $\theta$, a função de penalização escolhida deve ser tal que $\exp \left(\omega_{i}\right)$ tenha função densidade Gama. Isto implica que (3.7) seja expressa como

$$
P P L=P L(\boldsymbol{\beta}, \boldsymbol{\omega} ; \text { dados })-(1 / \theta) \sum_{i=1}^{n}\left(\omega_{i}-\exp \left(\omega_{i}\right)\right) \text {. }
$$

O algoritmo de maximização da log-verossimilhança (3.9) é composto por um ciclo interno e um ciclo externo. O ciclo interno é dividido nas três seguintes etapas:

\section{Obtenção da função escore para $\beta$}

Como a função de penalização em (3.9) não depende de $\boldsymbol{\beta}$, temos $\partial P P L / \partial \boldsymbol{\beta}=\partial P L / \partial \boldsymbol{\beta}$, que corresponde à função escore do modelo de Cox padrão tratando $\mathbf{z}_{j}^{T} \boldsymbol{\omega}$ como um termo offset (ver Colosimo \& Giolo (2006), por exemplo).

\section{Obtenção da função escore para $\omega$}

A função escore para $\omega_{i}$ é

$$
\frac{\partial P P L}{\partial \omega_{i}}=\left[d_{i}-\widehat{A}_{i} e^{\omega_{i}}\right]-(1 / \theta)\left(1-\exp \left(\omega_{i}\right)\right)
$$

$\operatorname{com} \widehat{A}_{i}=\sum_{l=1}^{m_{i}} \int_{0}^{\infty} Y_{l}(s) \exp \left(\mathbf{x}_{l}^{T} \boldsymbol{\beta}\right) d \widehat{\Lambda}_{0}(s)$, em que $l$ representa o $l$-ésimo tempo associado a $i$-ésima paciente e

$$
d \widehat{\Lambda}_{0}(s)=\frac{\sum_{j=1}^{\tilde{n}} d N_{j}(t)}{\sum_{j=1}^{\tilde{n}} Y_{j}(t) \exp \left(\mathbf{x}_{j}^{T} \boldsymbol{\beta}+\mathbf{z}_{j}^{T} \boldsymbol{\omega}\right)}
$$

é o estimador de Breslow (1972) para a função de taxa de falha acumulada.

\section{Obtenção da matriz de informação observada}

A matriz de informação observada obtida da log-verossimilhança penalizada é dada por

$$
\mathbf{H}=\mathbf{H}(\boldsymbol{\beta}, \boldsymbol{\omega})=\mathbf{F}+\left(\begin{array}{cc}
0 & 0 \\
0 & g^{\prime \prime}
\end{array}\right)
$$

em que $\mathbf{F}=\mathbf{F}(\boldsymbol{\beta}, \boldsymbol{\omega})$ é a matriz de informação observada obtida sob o modelo de Cox, ou seja, a matriz de segundas derivadas de (3.8) em relação a $\boldsymbol{\beta}$ e $\boldsymbol{\omega}$ com sinal negativo, e $g^{\prime \prime}$ é a matriz de segundas derivadas da função $g$ em relação a $\boldsymbol{\omega}$.

Obtidas as estimativas de $\boldsymbol{\beta}, \boldsymbol{\omega}$ e $\mathbf{H}$, utiliza-se o método de Newton-Raphson, com $\theta$ fixado, para a maximização da log-verossimilhança (3.9); o algoritmo é finalizado na $k$-ésima iteração quando $\left|P P L^{(k)}-P P L^{(k-1)}\right|<\epsilon_{i n}$, em que $\epsilon_{i n}$ é uma constante pré-especificada.

O ciclo externo corresponde à maximização do parâmetro $\theta$, fixados os parâmetros $\boldsymbol{\beta}$ e $\boldsymbol{\omega}$. Therneau et al. (2003) mostraram que (3.4) pode ser escrita como

$$
l_{\text {marg }}(\theta)=P P L(\theta)+\sum_{i=1}^{n} 1 / \theta-\left(1 / \theta+d_{i}\right) \log \left(1 / \theta+d_{i}\right)-(1 / \theta) \log (\theta)+\log \left(\frac{\Gamma\left(1 / \theta+d_{i}\right)}{\Gamma(1 / \theta)}\right)
$$


que é uma função unimodal, com apenas um parâmetro, a ser maximizada.

Portanto, o processo de ajuste do modelo de fragilidade é feito primeiramente fixando um valor para $\theta$ com a finalidade de se obter as estimativas para $\boldsymbol{\beta}$ e $\boldsymbol{\omega}$ por meio da maximização de (3.9) (ciclo interno), e posteriormente fixando $\widehat{\boldsymbol{\beta}}$ e $\widehat{\boldsymbol{\omega}}$ em (3.12) para que esta seja maximizada em função de $\theta$ (ciclo externo); nesse caso o processo iterativo é finalizado quando para a $j$-ésima iteração do ciclo externo $\left|\theta^{(j)}-\theta^{(j-1)}\right|<\epsilon_{e x}$, em que $\epsilon_{e x}$ é uma constante pré-especificada.

Para testar a hipótese $H_{0}: \theta=0$, de independência entre os tempos até incidência (ou clareamento) dos dois tipos de HPV, podemos usar o teste de razão de verossimilhanças, cuja estatística de teste é

$$
\chi_{L R_{\theta}}^{2}=2\left[\log L\left(\widehat{\boldsymbol{\beta}}, \widehat{\lambda}_{0}, \widehat{\theta}\right)-\log L\left(\widehat{\boldsymbol{\beta}}^{*}, \widehat{\lambda}_{0}^{*}\right)\right]
$$

em que $L\left(\boldsymbol{\beta}, \lambda_{0}, \theta\right)=\exp \left(l_{\text {marg }}\left(\lambda_{0}, \beta, \theta\right)\right)$ com $l_{\text {marg }}$ dado por (3.4), $\widehat{\boldsymbol{\beta}}, \widehat{\lambda}_{0}$ e $\widehat{\theta}$ são as estimativas obtidas sob o modelo (1.6) assumindo $u_{i}$ com distribuição Gama (3.1) e $\widehat{\boldsymbol{\beta}}^{*}, \widehat{\lambda}_{0}^{*}$, as estimativas obtidas sob o mesmo modelo assumindo $u_{i}=1$ para $i=1,2, \ldots, n$. Sob a hipótese nula, (3.13) segue uma distribuição Qui-quadrado com 1 grau de liberdade. Quando a hipótese nula é verdadeira o parâmetro se encontra na borda do espaço paramétrico, o que é uma limitação do teste [Wienke (2012)], à vista disso, outra alternativa para testar a significância dos termos de fragilidade é baseada nos valores estimados para $\omega_{i}$. Um teste proposto por Therneau et al. (2003) para testar hipóteses da forma

$$
H_{0}: \mathbf{z}=\mathbf{C}\left(\boldsymbol{\beta}^{T}, \boldsymbol{\omega}^{T}\right)^{T}=\mathbf{0}
$$

em que $\mathbf{C}$ é uma matriz de constantes com $k$ linhas $(k \leq p+n)$, é o teste de Wald baseado na estatística

$$
W=\mathbf{z}^{T}\left(\mathbf{C} \widehat{\mathbf{H}}^{-1} \mathbf{C}^{T}\right)^{-1} \mathbf{z}
$$

com $\widehat{\mathbf{H}}^{-1}$ representando a inversa da matriz de informação observada da $P P L$ e os graus de liberdade são dados por

$$
d f=\operatorname{traço}\left[\left(\mathbf{C} \widehat{\mathbf{H}}^{-1} \mathbf{C}^{T}\right)^{-1}\left(\mathbf{C} \widehat{\mathbf{V}} \mathbf{C}^{T}\right)\right]
$$

em que

$$
\widehat{\mathbf{V}}=\widehat{\mathbf{H}}^{-1} \widehat{\mathbf{F}} \widehat{\mathbf{H}}^{-1}
$$

conforme sugerido por Gray (1992). Para testar se todos os valores de $\boldsymbol{\omega}$ são iguais a zero, basta tomar $\mathbf{C}=\mathbf{C}_{\mathbf{1}}=\left[\begin{array}{ll}\mathbf{0}_{n p} & \mathbf{I}_{n}\end{array}\right]$ em (3.14) em que $\mathbf{0}_{n p}$ é uma matriz com todos os elementos iguais a zero com $n$ linhas e $p$ colunas e $\mathbf{I}_{n}$ uma matriz identidade com dimensão $n$. Desta forma (3.15) pode ser escrita como

$$
W_{\boldsymbol{\omega}}=\boldsymbol{\omega}^{T}\left(\left(\widehat{\mathbf{H}}^{-1}\right)_{22}\right)^{-1} \boldsymbol{\omega}
$$

em que $\left(\widehat{\mathbf{H}}^{-1}\right)_{22}$ é a submatriz de $\widehat{\mathbf{H}}^{-1}$ referente as $n$ últimas linhas e $n$ últimas colunas. Quando $H_{0}$ é verdadeira, a distribuição assintótica de (3.18) é $\sum e_{j} x_{j}^{2}$ em que $e_{j}$ são os autovalores da matriz $\left(\mathbf{C}_{\mathbf{1}} \widehat{\mathbf{H}}^{-1} \mathbf{C}_{\mathbf{1}}^{T}\right)^{-1}\left(\mathbf{C}_{\mathbf{1}} \widehat{\mathbf{V}} \mathbf{C}_{\mathbf{1}}{ }^{T}\right)$ e $x_{j}$ uma sequência de variáveis aleatórias independentes e identicamente distribuidas com distribuição normal padrão. Desta forma a estatística de teste (3.18) tem média $\sum e_{j}$ e variância $2 \sum e_{j}^{2}$ e segue uma distribuição Qui-quadrado com $\sum e_{j}$ graus de liberdade.

Para testar a significância de $q \leq p$ parâmetros de $\boldsymbol{\beta}$, basta tomar $\mathbf{C}=\mathbf{C}_{\mathbf{2}}=\left[\begin{array}{ll}\mathbf{C}_{q p}^{*} & \mathbf{0}_{q n}\end{array}\right]$ em (3.14) em que $\mathbf{C}_{q p}^{*}$ é uma matriz de constantes com $q$ linhas e $p$ colunas. Desta forma, (3.15) pode 
ser escrita como

$$
W_{\boldsymbol{\beta}^{*}}=\boldsymbol{\beta}^{* T}\left(\left(\widehat{\mathbf{H}}^{-1}\right)_{* *}\right)^{-1} \boldsymbol{\beta}^{*}
$$

em que $\left(\widehat{\mathbf{H}}^{-1}\right)_{* *}$ é a submatriz apropriada de $\widehat{\mathbf{H}}^{-1}$. A estatística (3.19) tem distribuição assintótica $\sum e_{j} x_{j}^{2}$ em que $e_{j}$ são os autovalores da matriz $\left(\mathbf{C}_{\mathbf{2}} \widehat{\mathbf{H}}^{-1} \mathbf{C}_{\mathbf{2}}{ }^{T}\right)^{-1}\left(\mathbf{C}_{\mathbf{2}} \widehat{\mathbf{V}} \mathbf{C}_{\mathbf{2}}{ }^{T}\right)$ e $x_{j}$ uma sequência de variáveis aleatórias independentes e identicamente distribuidas com distribuição normal.

Além da proposta de Gray (1992) para a matriz de covariâncias $\widehat{\mathbf{V}}$ em (3.16), Verweij \& Houwelingen (1994) sugerem

$$
\widehat{\mathbf{V}}=\widehat{\mathbf{H}}^{-1}
$$

como alternativa e desta forma o teste (3.19) corresponde ao teste de Wald com distribuição assintótica Qui-quadrado com $q$ graus de liberdade sob a hipótese nula. Por ser uma escolha mais conservadora [Therneau et al. (2003)], assumimos (3.20) para os testes de hipóteses sobre os efeitos fixos $\boldsymbol{\beta}$ e no Capítulo 4 avaliamos a adequabilidade de ambas as propostas para $\widehat{\mathbf{V}}$ comparando-as com a matriz de covariâncias obtida pelo método bootstrap [Efron (1979)].

Outra alternativa para testar hipóteses sobre os elementos de $\boldsymbol{\beta}$ é baseada no teste de razão de verossimilhanças dado por

$$
\chi_{L R_{\boldsymbol{\beta}^{*}}}^{2}=2\left[\log L\left(\widehat{\boldsymbol{\beta}}^{*}, \widehat{\lambda}_{0}, \widehat{\theta}\right)-\log L\left(\boldsymbol{\beta}^{*}=0, \widehat{\lambda}_{0}, \widehat{\theta}\right)\right]
$$

em que $\boldsymbol{\beta}^{*}$ é um subvetor de $\boldsymbol{\beta}$ com dimensão $q$ e $L\left(\boldsymbol{\beta}^{*}, \lambda_{0}, \theta\right)$ é a função de verossimilhança marginal (3.4) correspondente. Esta estatística de teste também tem distribuição assintótica Qui-quadrado com $q$ graus de liberdade sob a hipótese nula (ver Colosimo \& Giolo (2006), por exemplo). 


\section{Capítulo 4}

\section{Ajuste dos Modelos}

Neste capítulo investigaremos associações entre as variáveis da Tabela 2.1, além do nível de CD4 e tratamento ARV e a incidência e o clareamento de HPV oncogênicos e não-oncogênicos com base nos modelos descritos no Capítulo 3.

Para a incidência, o preditor linear do modelo (1.6) pode ser expresso como

$$
\mathbf{q}_{i k}^{T}(t) \boldsymbol{\delta}_{\boldsymbol{k}}=\left[\begin{array}{ccc}
y_{i k} & \mathbf{z}_{i k}^{T} & \mathbf{v}_{i k}(t)^{T}
\end{array}\right]\left[\begin{array}{c}
\phi \\
\boldsymbol{\delta}_{\mathbf{1 k}} \\
\boldsymbol{\delta}_{\mathbf{2 k}}
\end{array}\right]=y_{i k} \phi+\mathbf{z}_{i k}^{T} \boldsymbol{\delta}_{\mathbf{1 k}}+\mathbf{v}_{i k}^{T}(t) \boldsymbol{\delta}_{\mathbf{2 k}}
$$

com

- $\mathbf{q}_{i k}(t)$ representando o vetor com o valor das covariáveis associadas ao $k$-ésimo tipo de HPV ( $k=1$ para HPV oncogênico e $k=2$ para HPV não-oncogênico) para a paciente $i$ no tempo $t$;

- $y_{i 1}=1$ e $y_{i 2}=0$;

- $\mathbf{z}_{i k}^{T}=\left(z_{i k 1}, z_{i k 2}, \ldots, z_{i k 17}\right)$ denotando o vetor com as informações demográficas e comportamentais (Tabela 2.1) para o $k$-ésimo tipo de HPV e $i$-ésima paciente;

- $\mathbf{v}_{i k}^{T}(t)=\left(v_{i k 1}(t), v_{i k 2}(t)\right)$ indicando o vetor referente aos valores das variáveis tempo-dependentes, nomeadamente, nível de CD4 e tratamento $\mathrm{ARV}^{1}$ para o $k$-ésimo tipo de HPV e $i$-ésima paciente;

- $\boldsymbol{\delta}_{1 k}$ e $\boldsymbol{\delta}_{2 k}$ representando os vetores com os coeficientes a serem estimados para o tipo $k$ de $\mathrm{HPV}$;

- $\phi$ representando um possível efeito do tipo de HPV oncogênico em relação ao não-oncogênico; com isto, em (1.6), assumimos que a razão de taxas (de incidência ou clareamento) entre os tipos de HPV oncogênicos e não-oncogênicos é constante.

Utilizamos 4 estratégias para seleção de covariáveis, a saber:

1. O método forward stepwise [adaptado para modelos de sobrevivência por Colosimo \& Giolo (2006)] em que a cada etapa avalia-se a significância da estatística de razão de verossimilhanças (3.21) para todas as covariáveis (Tabela 2.1), para o nível de CD4 e para o tratamento ARV (para o clareamento, incluimos também o total de tipos de HPV);

\footnotetext{
${ }^{1}$ Para o clareamento, $\mathbf{v}_{i k}(t)$ incluirá o total de tipos de HPV infectados no instante $t$ (apenas para esta covariável, o total de tipos foi baseado nos 35 possíveis tipos de HPV comentados no Capítulo 1.)
} 
2. O método forward stepwise apenas para as variáveis que apresentam relevância na literatura [Giuliano et al. (2002), Grinsztejn et al. (2009), Kjver et al. (1997), Rousseau et al. (2000), Sahasrabuddhe et al. (2007), Trottier \& Franco (2006), Ho et al. (1998)];

3. Avaliação do ajuste do modelo com cada uma das covariáveis relativamente ao ajuste do modelo nulo e utilização apenas daquelas que apresentaram efeitos significativos;

4. Avaliação do ajuste do modelo com cada uma das covariáveis relativamente ao ajuste do modelo nulo e utilização apenas daquelas que apresentaram efeitos significativos.

Para as estratégias 1 e 2 utilizamos um nível de significância de $\alpha_{i n}=0.10$ na etapa de inserção e $\alpha_{\text {out }}=0.15$ na etapa de retirada das variáveis, reduzindo-os para $\alpha_{i n}=0.05$ e $\alpha_{\text {out }}=0.10$ nos casos em que a convergência exigiu mais de 50 iterações. A função em $\mathrm{R}$ criada para implementação do método forward stepwise pode ser obtida em

https://www.dropbox.com/sh/4a9k1ryvcx6jsvr/QQe6PxeWEz .

Para todos os modelos, mantivemos as variáveis Idade e "Fumou alguma vez", mesmo quando não foram significativas, dadas as evidências de seus efeitos obtidas da literatura estatística. Os modelos finais para incidência utilizando as quatro estratégias explicadas acima são mostrados nas Tabelas A.1 à A.4 do Apêndice A. Como não encontramos trabalhos sobre clareamento na literatura utilizamos apenas as estratégias 1 e 3 nesse caso. Os respectivos modelos finais são mostrados nas Tabelas A.5 e A.6 do Apêndice A.

Para obtenção do modelo final, consideramos todas as variáveis selecionadas por meio das estratégias 1 a 4 e retiramos as variáveis não significativas $(\alpha=0.10)$, com base no teste de Wald (3.19). Para a incidência, mantivemos as variáveis "Número de parceiros no ano anterior" mesmo com valor$\mathrm{P}>0.10$, por ser uma variável que controla principalmente o efeito da variável Renda ${ }^{2}$ e também pelo conhecimento prévio de que ambas afetam o desfecho [Giuliano et al. (2002), Ho et al. (1998), Kjver et al. (1997), Palefsky (2003), Rousseau et al. (2000), Trottier \& Franco (2006), Winer et al. (2003)].

\subsection{Análise da Incidência}

Na Tabela 4.1 apresentamos as estimativas dos parâmetros do modelo final de fragilidade compartilhada (1.6) para o tempo até a incidência de HPV oncogênicos e não-oncogênicos. Dado o valor- $\mathrm{P}=0.26$ correspondente ao teste de Wald (3.18) para a hipótese de independência entre os tempos até incidência de HPV oncogênicos e não-oncogênicos em uma mesma mulher, concluímos que não há necessidade de inclusão de um efeito de fragilidade no modelo. Além disso o termo de fragilidade não altera as estimativas pontuais e intervalares das demais covariáveis como mostra a Tabela A.7 do Apêndice A. As variáveis tempo-dependentes (nível de CD4 e tratamento ARV) também não foram significativas sugerindo que um modelo de Cox pode ser empregado para a análise de incidência de HPV oncogênicos e não-oncogênicos.

Um gráfico com os resíduos de Cox-Snell ${ }^{3}$ (ver Klein \& Moeschberger (2003), por exemplo) está apresentado na Figura 4.1 e sugere uma boa qualidade do ajuste. Para avaliar a suposição

\footnotetext{
${ }^{2}$ Quando retiramos a variável Número de parceiros no último ano, o valor-P da variável Renda mudou de de 0.10 para 0.15 .

${ }^{3}$ Função implementada para o R encontradas em https://www.dropbox.com/sh/4a9k1ryvcx6jsvr/QQe6PxeWEz.
} 


\begin{tabular}{c|c|ccccc}
\hline HPV & Variáveis & Exp(Coef) & Erro padrão & LI & LS & valor-P \\
\hline \multirow{5}{*}{ Oncogênicos } & Usou Drogas & 1.88 & 0.38 & 1.01 & 3.5 & 0.10 \\
& Núm. parceiros $(>1)$ & 1.83 & 0.45 & 0.88 & 3.83 & 0.18 \\
& Renda $(\geq 3)$ & 0.62 & 0.29 & 0.38 & 1 & 0.10 \\
& Idade $(30-45)$ & 1.07 & 0.37 & 0.58 & 1.97 & 0.86 \\
& Idade $(>45)$ & 0.68 & 0.3 & 0.42 & 1.12 & 0.21 \\
& Fumou & 0.76 & 0.29 & 0.47 & 1.21 & 0.33 \\
\hline \multirow{5}{*}{ Não-oncogênicos } & Escolaridade (5-8) & 0.97 & 0.35 & 0.55 & 1.71 & 0.92 \\
& Escolaridade (>9) & 2.08 & 0.33 & 1.21 & 3.6 & 0.03 \\
& Gestações (>1) & 1.76 & 0.29 & 1.09 & 2.86 & 0.05 \\
& Idade $(30-45)$ & 0.9 & 0.36 & 0.5 & 1.64 & 0.78 \\
& Idade $(>45)$ & 0.74 & 0.33 & 0.43 & 1.27 & 0.36 \\
& Fumou & 0.75 & 0.29 & 0.46 & 1.2 & 0.31 \\
\hline & HPV oncogênicos & 2.15 & 0.46 & 1.01 & 4.55 & 0.09 \\
\hline
\end{tabular}

Tabela 4.1: Coeficientes estimados exponencializados/Razões de taxas de incidência, erros padrões, limites inferiores (LI) e superiores (LS) para intervalos de confiança com coeficiente de confiança $90 \%$ e valores-P para as variáveis explicativas relacionadas com o tempo até incidência de HPV oncogênicos e não-oncogênicos.

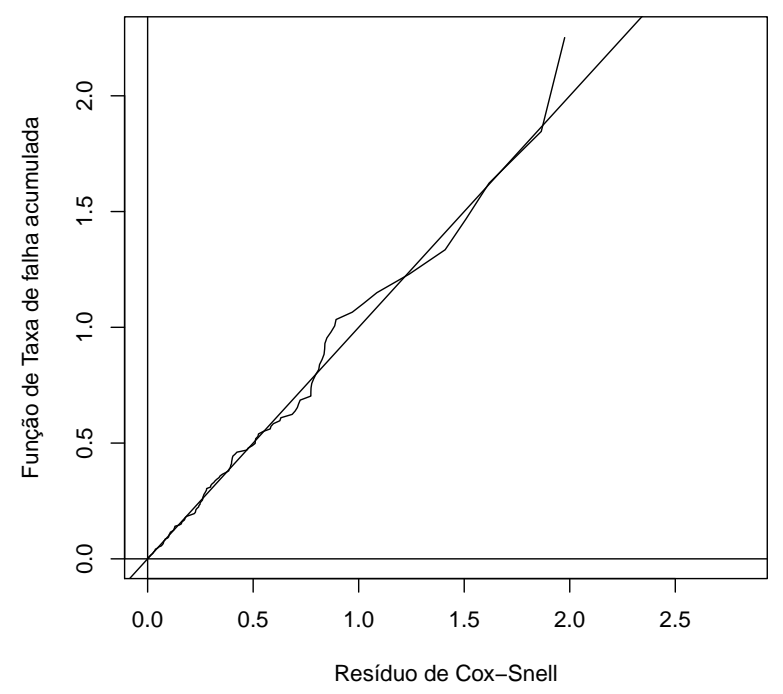

Figura 4.1: Resíduos de Cox-Snell para o modelo de incidência.

de riscos proporcionais calculamos os resíduos de Schoenfeld (1982), dispostos na Figura 4.2; para todas as variáveis, não há evidências que contrariem a hipótese de efeito constante ao longo do tempo e a estimativa do parâmetro associado a cada variável (linha sólida) manteve-se dentro das bandas de confiança estimadas por splines [Hastie \& Tibshirani (1990)]. Valores-P para os testes de proporcionalidade dos riscos propostos por Therneau \& Grambsch (2000), também estão apresentados na Tabela 4.2, sugerindo que o modelo é aceitável.

Com base nos resíduos do tipo martingal (ver Therneau \& Grambsch (2000), por exemplo), dispostos na Figura 4.3(a) não identificamos pontos aberrantes. Entretanto com base nos resíduos do tipo deviance (ver Therneau \& Grambsch (2000), por exemplo), dispostos na Figura 4.3(b) foram identificados alguns pontos aberrantes. Na Tabela 4.3 apresentamos as características demográficas 

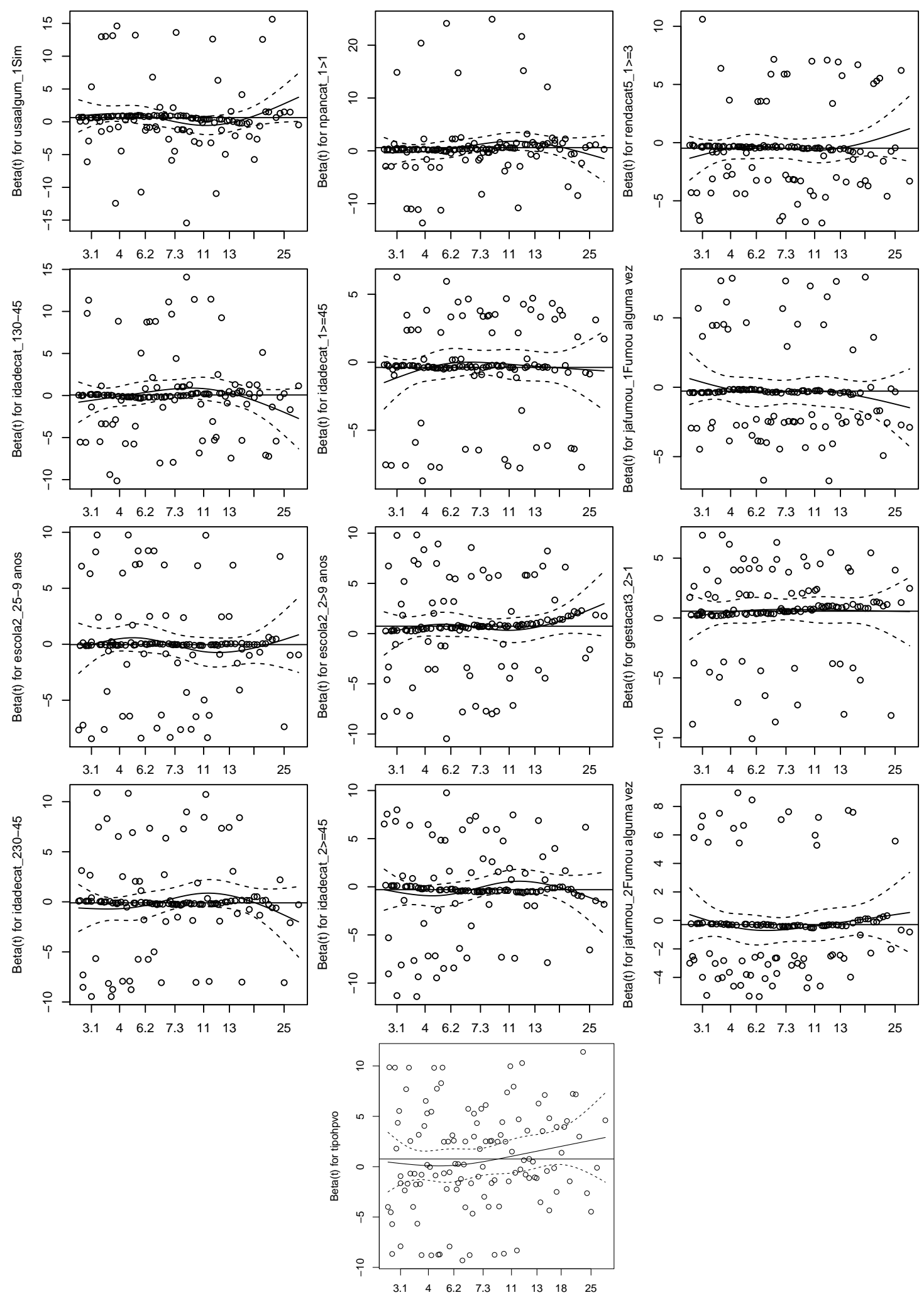

$\begin{array}{lllllll}3.1 & 4 & 6.2 & 7.3 & 11 & 13 & 25\end{array}$

Figura 4.2: Resíduos de Schoenfeld para o modelo de incidência.

e comportamentais relevantes associadas às pacientes referentes a esses pontos para cada tipo de HPV, além do tempo até a incidência de cada tipo de HPV e um indicador de censura (0, caso tenha ocorrido censura e 1, caso tenha ocorrido o evento). Com base na Tabela 4.3 verificamos que, para os tempos até incidência de HPV oncogênicos, a observação 125 refere-se a uma paciente com renda baixa, o que seria um fator de risco; no entanto, para essa paciente o tempo foi maior do que 


\begin{tabular}{c|c|c}
\hline HPV & Variáveis & valor-P \\
\hline \multirow{5}{*}{ Oncogênicos } & Usou Drogas & 0.740 \\
& Núm. parceiros $(>1)$ & 0.361 \\
& Renda $(\geq 3)$ & 0.292 \\
& Idade $(30-45)$ & 0.885 \\
& Idade $(>45)$ & 0.559 \\
& Fumou & 0.255 \\
\hline \multirow{5}{*}{ Não-oncogênicos } & Escolaridade (5-8) & 0.559 \\
& Escolaridade ( $>9)$ & 0.413 \\
& Gestações $(>1)$ & 0.721 \\
& Idade $(30-45)$ & 0.478 \\
& Idade $(>45)$ & 0.446 \\
& Fumou & 0.818 \\
\hline & HPV oncogênicos & 0.142 \\
& GLOBAL & 0.442 \\
\hline
\end{tabular}

Tabela 4.2: Teste de Therneau e Grambsch para proporcionalidade dos riscos.

a média (12 meses, considerando as censuras e as falhas). A observação 135 refere-se a uma paciente que teve poucos parceiros sexuais, o que seria um fator de proteção; no entanto, essa paciente foi infectada por HPV oncogênico com apenas 6 meses de acompanhamento. A observação 12 refere-se a uma paciente com escolaridade baixa, o que seria um fator de proteção para HPV não-oncogênicos; no entanto, essa paciente contraiu HPV não-oncogênico em um tempo inferior ao tempo médio (12 meses, considerando as censuras e as falhas). A observação 107 refere-se a uma paciente que teve um maior número de gestações, o que seria um fator de risco; no entanto, ela demorou mais do que o tempo médio até a incidência por HPV não-oncogênico, considerando apenas os eventos não censurados (8 meses).
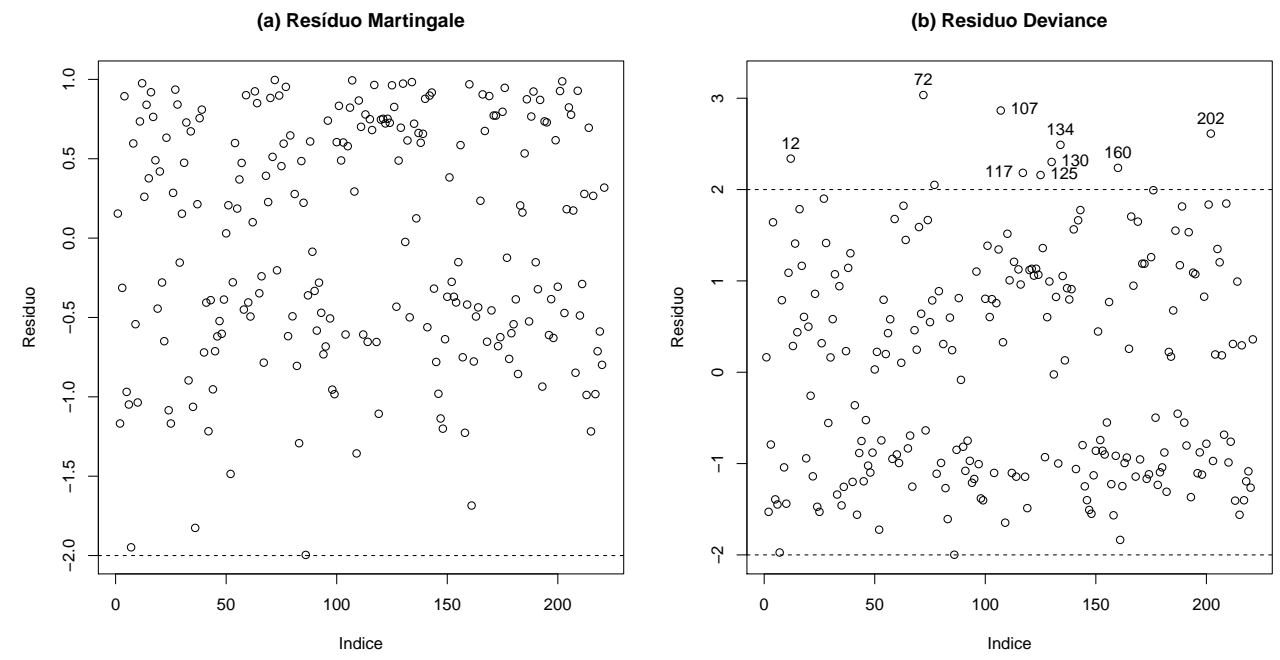

Figura 4.3: Resíduos de (a) Martingal e (b) Deviance para o modelo de incidência.

Ajustamos o mesmo modelo retirando essas observações, e verificamos que não houve grande diferença na significância de cada covariável (ver Tabela A.8 do Apêncide A).

Com o objetivo de encontrar pontos influentes, obtivemos os resíduos do tipo escore (ver Therneau \& Grambsch (2000), por exemplo); boxplots para cada categoria são apresentados na 


\begin{tabular}{c|cccccccc}
\hline $\begin{array}{c}\text { Pontos } \\
\text { observados }\end{array}$ & HPV & Tempo & Status & $\begin{array}{c}\text { Usa } \\
\text { drogas }\end{array}$ & $\begin{array}{c}\text { Número de } \\
\text { parceiros }\end{array}$ & Renda & Escolaridade & $\begin{array}{c}\text { Número de } \\
\text { gestações }\end{array}$ \\
\hline 72 & Oncogênico & 12.67 & 1 & Não & $\leq 1$ & $>2$ & - & - \\
125 & Oncogênico & 15.98 & 0 & Não & $\leq 1$ & $\leq 2$ & - & - \\
130 & Oncogênico & 5.68 & 1 & Não & $\leq 1$ & $\leq 2$ & - & - \\
160 & Oncogênico & 12.02 & 0 & Não & $\leq 1$ & $>2$ & - & - \\
\hline 12 & Não-oncogênico & 3.52 & 1 & - & - & - & $<5$ anos & $>1$ \\
107 & Não-oncogênico & 11.19 & 1 & - & - & - & $5-9$ anos & $>1$ \\
117 & Não-oncogênico & 3.85 & 1 & - & - & - & $>9$ anos & $>1$ \\
134 & Não-oncogênico & 7.70 & 1 & - & - & - & $>9$ anos & $>1$ \\
202 & Não-oncogênico & 3.64 & 1 & - & - & - & $>9$ anos & $>1$ \\
\hline
\end{tabular}

Tabela 4.3: Variáveis demográficas e comportamentais, tipo do HPV, tempo até incidência e status do evento, em que 0 indica censura e 1 indica falha, para as pacientes referentes aos pontos aberrantes observados na Figura 4.3.

Figura 4.4, sugerindo a inexistência de pontos influentes.

Admitindo a validade dos pressupostos do modelo, verificamos por intermédio do resumo apresentado na Tabela 4.1 que para mulheres que usam drogas a taxa de incidência de HPV oncogênicos é 1.88 (IC 90\%, 1.01; 3.50) vezes a taxa correspondente àquelas que não as usam. Verificamos também que para mulheres com renda maior ou igual a 3 salários mínimos, a taxa de incidência de HPV oncogênicos é 0.62 (IC 90\%, 0.38; 1.00) vezes a taxa referente a mulheres que ganham menos do que 3 salários mínimos. Para mulheres com escolaridade de mais de 9 anos a taxa de incidência de HPV não-oncogênicos é 2.08 (IC 90\%, 1.21; 3.6) vezes a taxa correspondente àquelas com escolaridade de 5 anos ou menos. As mulheres com mais de uma gestação apresentaram taxa de incidência é 1.76 (IC 90\%, 1.09; 2.86) vezes a taxa correspondente àquelas com até uma gestação. A taxa de incidência de HPV oncogênicos é 2.15 (IC 90\%, 1.01; 4.55) vezes a taxa de HPV não-oncogênicos, fixadas as demais covariáveis.

Com base no modelo final de incidência cujos resultados são apresentados na Tabela 4.1, calculamos as razões de taxas de incidência e os respectivos intervalos de confiança de $90 \%$ para a comparação de determinadas pacientes segundo suas características demográficas e comportamentais. Os resultados estão apresentados na Tabela 4.4. Para a incidência de HPV oncogênicos, pacientes com as características "não usa drogas" e "renda $\geq 3$ salários" foram tomadas como referêcia e para a incidência de HPV não-oncogênicos, pacientes com as caracaterísticas "escolaridade menor que 5 anos" e "número de gestações $\leq 1$ " foram tomadas como referência por serem as características que indicam a menor taxa de incidência para cada tipo de HPV. A Tabela 4.4 apresenta também a razão de taxas de incidência de HPV oncogênicos em relação aos não-oncogênicos.

\subsection{Análise do Clareamento}

$\mathrm{O}$ valor- $\mathrm{P}=0.03$ associado à estatística (3.15) sugere que o termo de fragilidade deve ser mantido no modelo de fragilidade compartilhada (1.6) para o clareamento de HPV oncogênicos e nãooncogênicos sugerindo que existe uma variabilidade entre as mulheres que não pode ser explicada pelas demais covariáveis e portanto precisa ser levada em conta. Os resultados estão apresentados na Tabela 4.5. Além disso há mudança na significância de algumas covariáveis quando os modelos com e sem o termo de fragilidade são comparados como mostra a Tabela 4.6. Com isto temos indícios 

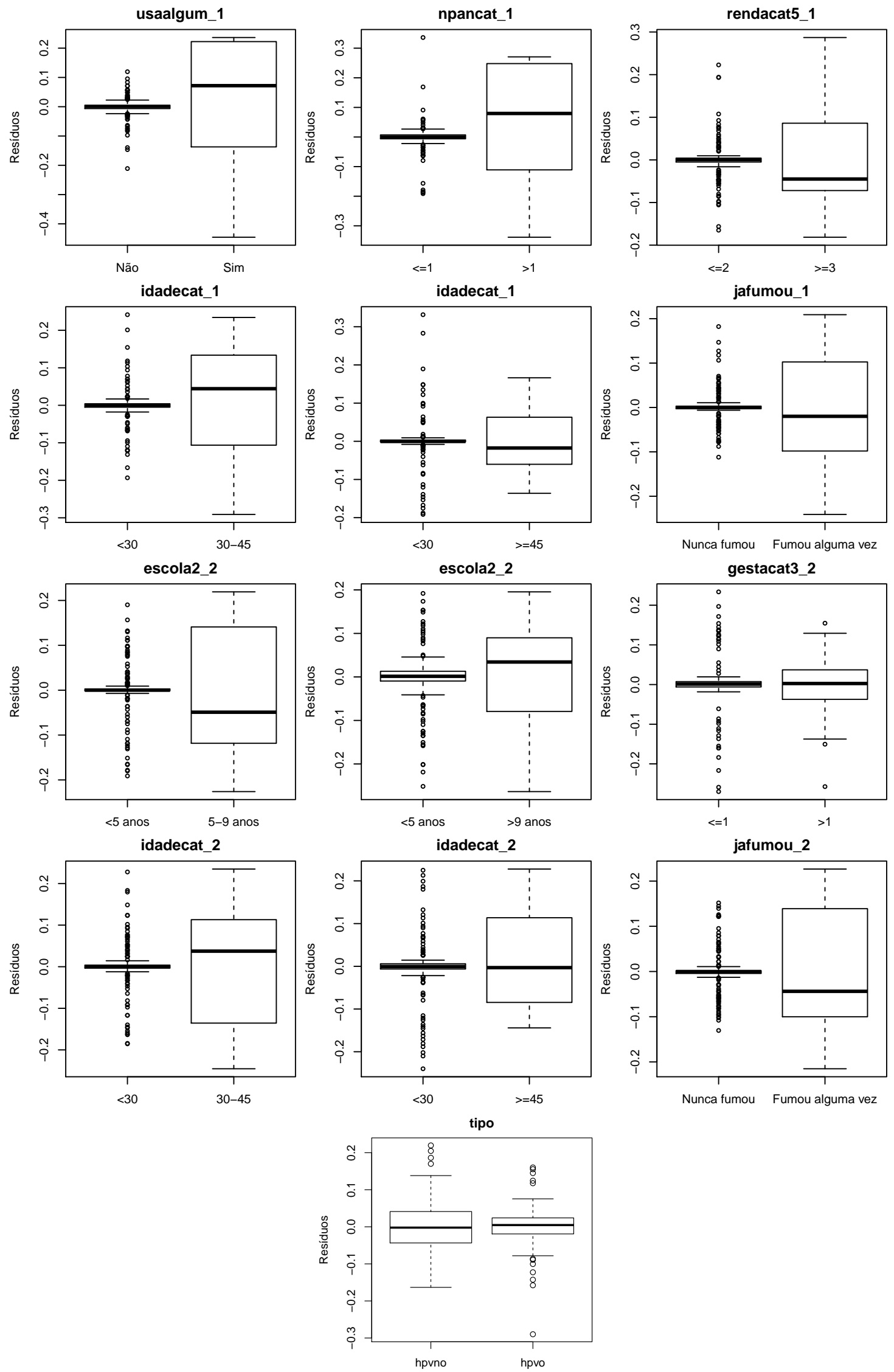

Figura 4.4: Resíduos de escore para o modelo de incidência. 


\begin{tabular}{|c|c|c|c|c|c|c|}
\hline HPV & Usou Drogas & Renda & Escolaridade & Gestações & $\begin{array}{c}\text { Razão de taxas } \\
\text { de incidência }\end{array}$ & $\mathrm{IC}(90 \%)$ \\
\hline Oncogênico & Sim & $<3$ & - & - & 3.0 & $(1.5 ; 6.3)$ \\
\hline Oncogênico & Não & $\geq 3$ & - & - & & \\
\hline Oncogênico & Sim & $\geq 3$ & - & - & 1.9 & $(1.0 ; 3.5)$ \\
\hline Oncogênico & Não & $\geq 3$ & - & - & & \\
\hline Oncogênico & Não & $<3$ & - & - & 1.6 & $(0.4 ; 1.0)$ \\
\hline Oncogênico & Não & $\geq 3$ & - & - & & \\
\hline Não-oncogênico & - & - & $>9$ & $>1$ & 3.7 & $(1.6 ; 8.3)$ \\
\hline Não-oncogênico & - & - & $<5$ & $\leq 1$ & & \\
\hline Não-oncogênico & & & $>9$ & $\leq 1$ & 2.1 & $(1.2 ; 3.6)$ \\
\hline Não-oncogênico & & & $<5$ & $\leq 1$ & & \\
\hline Não-oncogênico & & & $<5$ & $>1$ & 1.8 & $(1.1 ; 2.9)$ \\
\hline Não-oncogênico & & & $<5$ & $\leq 1$ & & \\
\hline Oncogênico & - & - & - & - & 2.1 & $(1.0 ; 4.5)$ \\
\hline Não-oncogênico & - & - & - & - & & \\
\hline
\end{tabular}

Tabela 4.4: Razão entre taxas de incidência para pacientes com determinadas características demográficas e comportamentais e razão entre taxas de incidência de HPV oncogênicos e HPV não-oncogênicos (e intervalos de confiança de 90\%).

\begin{tabular}{c|c|ccccc}
\hline HPV & Variáveis & Exp(Coef) & Erro padrão & LI & LS & valor-P \\
\hline \multirow{5}{*}{ Oncogênicos } & Renda $(\geq 3)$ & 1.80 & 0.27 & 1.16 & 2.78 & 0.03 \\
& Núm. parceiros $(>1)$ & 0.39 & 0.56 & 0.16 & 0.98 & 0.09 \\
& Tratamento ARV (IP) & 1.79 & 0.30 & 1.10 & 2.90 & 0.05 \\
& Tratamento ARV (ITRNN) & 1.07 & 0.33 & 0.62 & 1.84 & 0.84 \\
& Idade (30-45) & 1.88 & 0.37 & 1.03 & 3.44 & 0.08 \\
& Idade ( $>45)$ & 1.85 & 0.32 & 1.09 & 3.13 & 0.06 \\
& Fumou & 0.82 & 0.27 & 0.52 & 1.28 & 0.46 \\
\hline \multirow{3}{*}{ Não-oncogênicos } & Idade (30-45) & 1.68 & 0.40 & 0.88 & 3.22 & 0.19 \\
& Idade ( $>45)$ & 0.78 & 0.32 & 0.46 & 1.30 & 0.42 \\
& Fumou & 0.53 & 0.30 & 0.32 & 0.87 & 0.04 \\
\hline & HPV oncogênicos & 0.40 & 0.38 & 0.21 & 0.74 & 0.02 \\
\hline & Fragilidade & & & & & 0.02 \\
\hline
\end{tabular}

Tabela 4.5: Coeficientes estimados exponencializados/Razões de taxas de clareamento, erros padrões, limites inferiores (LI) e superiores (LS) para intervalos de confiança com coeficiente de confiança $90 \%$ e valores$P$ para as variáveis explicativas relacionadas com o tempo até clareamento de HPV oncogênicos e nãooncogênicos.

para acreditar que os tempos até o clareamento de HPV oncogênicos e não-oncogênicos não são independentes quando observados em uma mesma mulher. O coeficiente de Kendall (3.3) para este modelo é $\tau=0.17$, sugerindo dependência leve ou moderada segundo Cai et al. (2007). Para este modelo, $R^{2}=0.21$ indicando poder de explicação moderado [Carvalho et al. (2011)].

A análise de diagnóstico de modelos de sobrevivência de fragilidade é um tópico ainda pouco explorado [Colosimo \& Giolo (2006)]. Contudo, um resultado esperado nesse caso seria que diferentes escolhas para a distribuição da fragilidade, além do método de maximização da log-verossimilhança gerassem valores próximos para as estimativas dos efeitos fixos e de seus erros padrões e que todos apontassem para as mesmas mulheres com risco diferenciado [Carvalho et al. (2011)]. Para confir- 


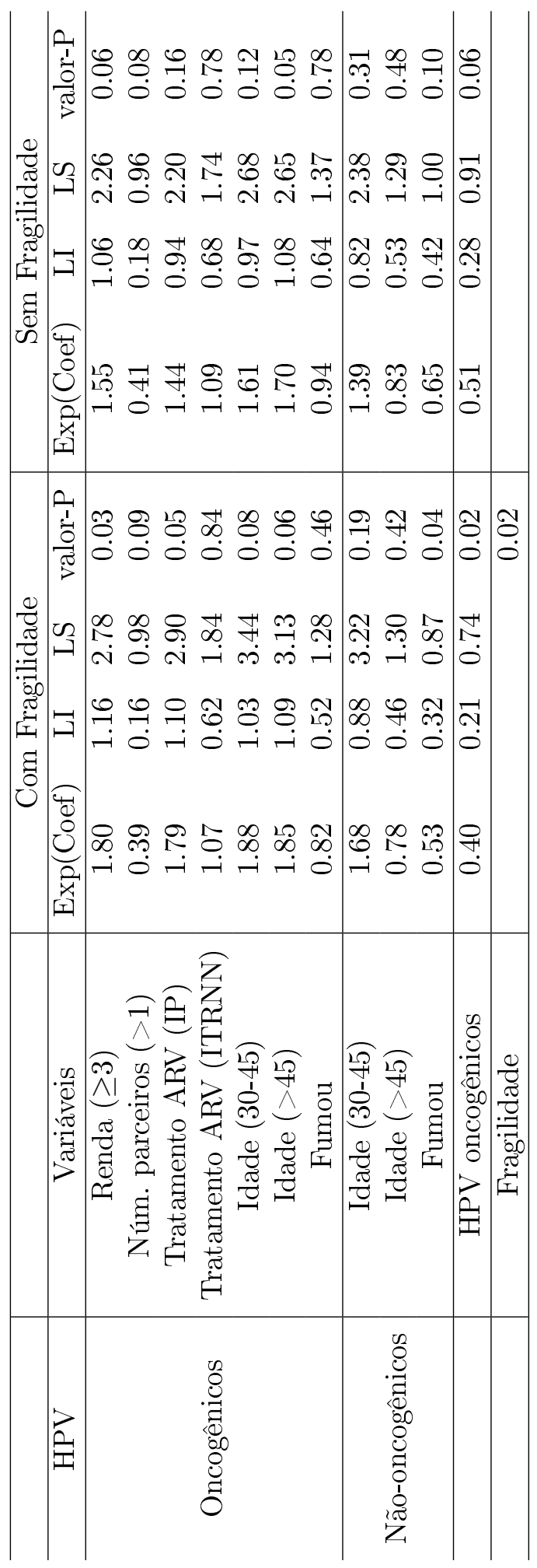

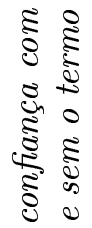

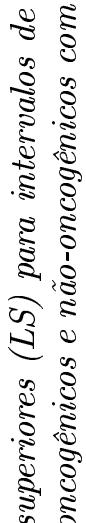

칼

\& :

है

के है

हี

$\therefore$

है छ

है $\frac{0}{0}$

ऽ ह

\&

త్

8

वै है

ब क व

के है

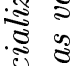

है है

हुำ

क :

है

के รe

क क

है

है

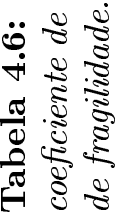


mar estas hipóteses ajustamos o modelo de fragilidade para o clareamento de HPV oncogênicos e não-oncogênicos utilizando 4 abordagens:

1. Método de máxima verossimilhança parcial penalizada que coincide com os resultados do método de máxima verossimilhança completa (FUML) utilizando o algoritmo EM assumindo fragilidades com distribuição Gama;

2. Método de máxima verossimilhança parcial penalizada que coincide com os resultados do método de máxima verossimilhança restrita (REML) assumindo fragilidades com distribuição Normal;

3. Método de minimização do AIC assumindo fragilidades com distribuição Gama (ver Duchateau \& Janssen (2008), para maiores detalhes);

4. Método de minimização do AIC assumindo fragilidades com distribuição Normal.

Os resultados dos ajustes dos modelos para a proposta de análise de diagnóstico de Carvalho et al. (2011) são mostrados na Tabela 4.7. As estimativas dos modelos de fragilidade utilizando o método de máxima verossimilhança parcial penalizada que concidem com os resultados do método FUML admitindo distribuição Gama para as fragilidades (abordagem 1) e com o método REML admitindo distribuição Normal para as fragilidade (abordagem 2) são muito próximas. Para as duas abordagens que utilizam o método de minimização do AIC (abordagens 3 e 4), verificamos estimativas $30 \%$ maiores para fatores que aumentam a taxa de clareamento e estimativas $58 \%$ menores para fatores que reduzem a taxa de clareamento, quando comparados com a abordagem 1. Contudo, os coeficientes significativos $(\alpha=0.10)$ para a abordagem 1 continuaram significativos sob as abordagens $3 \mathrm{e}$ 4. Utilizando métodos de verossimilhança parcial penalizada obtemos um efeito mais conservador (relativamente as abordagens baseadas no método de minimização do AIC) para cada covariável.

A Figura 4.5 apresenta as fragilidades das 10 mulheres com menores fragilidades estimadas e 10 mulheres com maiores fragilidades estimadas, e tem como objetivo comparar a ordem das fragilidades estimadas pelas 4 abordagens. Essa ordem não foi exatamente a mesma para as 4 abordagens; no entanto as ordens das fragilidades estimadas para as mulheres com maiores e menores fragilidades foram semelhantes, sendo que as 2 abordagens que utilizaram o método de minimização do AIC apresentaram fragilidades mais significativas.

Com base na Tabela 4.7 e na Figura 4.5 verificamos que, independentemente da escolha da distribuição e do método de estimação do parâmetro do termo de fragilidade, obtemos estimativas semelhantes.

Admitindo a validade dos pressupostos do modelo de fragilidade (1.6) para o clareamento e com base na Tabela 4.5, para mulheres com fragilidades iguais, observamos que a taxa de clareamento para mulheres com renda na faixa de 3 ou mais salários mínimos é 1.80 (IC 90\%, 1.16; 2.78) vezes aquela correspondente a mulheres com renda na faixa de até 2 salários mínimos. A taxa de clareamento de HPV oncogênicos para mulheres com mais de um parceiro sexual no último ano é 0.39 (IC $90 \%, 0.16 ; 0.98$ ) vezes aquela associada a mulheres que tiveram um parceiro ou menos. A taxa de clareamento para mulheres na faixa etária 35 a 40 anos é 1.88 (IC 90\%, 1.03; 3.44) vezes aquela associada a mulheres na faixa de idade "menor do que 35 anos". Para mulheres na faixa etária 40 ou mais anos essa taxa de clareamento fica multiplicada por 1.85 (IC 90\%, 1.09; 3.13). A taxa de clareamento de HPV oncogênicos para mulheres que usam o ARV inibidor de protease (IP) é 1.79 


\begin{tabular}{ccccccccc}
\hline & \multicolumn{3}{c}{ Fragilidade Gama (FUML) } & \multicolumn{4}{c}{ Fragilidade Normal (REML) } \\
\hline & Exp(Coef) & LI & LS & valor-P & Exp(Coef) & LI & LS & valor-P \\
Renda $(\geq 3)$ & 1.80 & 1.16 & 2.78 & 0.03 & 1.83 & 1.16 & 2.88 & 0.03 \\
Núm. parceiros $(>1)$ & 0.39 & 0.16 & 0.98 & 0.09 & 0.37 & 0.15 & 0.97 & 0.09 \\
Tratamento ARV (IP) & 1.79 & 1.10 & 2.90 & 0.05 & 1.82 & 1.10 & 2.99 & 0.05 \\
Tratamento ARV (ITRNN) & 1.07 & 0.62 & 1.84 & 0.84 & 1.06 & 0.60 & 1.85 & 0.87 \\
Idade (30-45) & 1.88 & 1.03 & 3.44 & 0.08 & 1.93 & 1.03 & 3.61 & 0.08 \\
Idade $(>45)$ & 1.85 & 1.09 & 3.13 & 0.06 & 1.90 & 1.10 & 3.30 & 0.05 \\
Fumou & 0.82 & 0.52 & 1.28 & 0.46 & 0.84 & 0.53 & 1.35 & 0.55 \\
Idade $(30-45)$ & 1.68 & 0.88 & 3.22 & 0.19 & 1.63 & 0.84 & 3.17 & 0.23 \\
Idade $(>45)$ & 0.78 & 0.46 & 1.30 & 0.42 & 0.76 & 0.44 & 1.29 & 0.39 \\
Fumou & 0.53 & 0.32 & 0.87 & 0.04 & 0.53 & 0.32 & 0.89 & 0.04 \\
Tipo HPV oncogênicos & 0.40 & 0.21 & 0.74 & 0.02 & 0.37 & 0.19 & 0.70 & 0.01 \\
\hline & Fragilidade Gama (AIC) & Fragilidade Normal (AIC) \\
\hline Renda $(\geq 3)$ & Exp(Coef) & LI & LS & valor-P & Exp(Coef) & LI & LS & valor-P \\
Núm. parceiros $(>1)$ & 2.31 & 1.32 & 4.06 & 0.01 & 2.45 & 1.26 & 4.74 & 0.03 \\
Tratamento ARV $($ IP) & 0.32 & 0.10 & 0.95 & 0.09 & 0.20 & 0.05 & 0.78 & 0.05 \\
Tratamento ARV (ITRNN) & 2.52 & 1.38 & 4.59 & 0.01 & 2.74 & 1.37 & 5.47 & 0.02 \\
Idade $(30-45)$ & 1.03 & 0.52 & 2.03 & 0.95 & 0.95 & 0.44 & 2.06 & 0.91 \\
Idade $(>45)$ & 2.82 & 1.16 & 6.84 & 0.06 & 2.97 & 0.91 & 9.65 & 0.13 \\
Fumou & 2.23 & 1.07 & 4.67 & 0.07 & 2.68 & 1.00 & 7.22 & 0.10 \\
Idade $(30-45)$ & 0.67 & 0.35 & 1.26 & 0.30 & 0.84 & 0.35 & 2.01 & 0.75 \\
Idade $(>45)$ & 2.21 & 0.84 & 5.85 & 0.18 & 1.77 & 0.53 & 5.91 & 0.43 \\
Fumou & 0.62 & 0.29 & 1.32 & 0.30 & 0.54 & 0.21 & 1.40 & 0.28 \\
Tipo HPV oncogênicos & 0.35 & 0.17 & 0.69 & 0.01 & 0.36 & 0.15 & 0.88 & 0.06 \\
\hline & 0.21 & 0.10 & 0.46 & $<0.01$ & 0.14 & 0.06 & 0.34 & $<0.01$ \\
\hline
\end{tabular}

Tabela 4.7: Comparação dos efeitos fixos dos modelos de fragilidade para o clareamento de HPV oncogênicos e não-oncogênicos (coeficientes estimados exponencializados/Razões de taxas de clareamento, limites inferiores (LI) e superiores (LS) dos intervalos de confiança com coeficiente de confiança 90\% e valores-P).

(IC 90\%, 1.1; 2.9) vezes aquela correspondente a mulheres que não usam nenhum medicamento. A taxa de clareamento de HPV não-oncogênicos para mulheres que fumam é 0.53 (IC 90\%, 0.32; 0.87) vezes aquela correspondente a mulheres que não fumam. Para cada mulher, os HPV oncogênicos apresentam uma taxa de clareamento 0.4 (IC $90 \%, 0.21 ; 0.74$ ) vezes aquela correspondente a HPV não-oncogênicos.

Com base no modelo final de clareamento cujos resultados são apresentados na Tabela 4.5, calculamos as razões de taxas de clareamento e os respectivos intervalos de confiança (90\%) para a comparação de determinadas pacientes segundo suas características demográficas, comportamentais e clínico laboratoriais supondo que as pacientes comparadas apresentam a mesma fragilidade. Os resultados estão apresentados na Tabela 4.8. Para o clareamento de HPV oncogênicos pacientes com as características "renda $<3$ salários", "mais de um parceiro sexual", "não usa tratamento ARV" e "idade < 30 anos" foram tomadas como referêcia e para o clareamento de HPV nãooncogênicos pacientes com a caracaterística "fumou alguma vez" foram tomadas como referência por serem as características que indicam a menor taxa de clareamento para cada tipo de HPV. A Tabela 4.8 apresenta também a razão de taxas de clareamento de HPV oncogênicos em relação aos não-oncogênicos.

Analisamos também possíveis diferenças nos modelos finais de incidência considerando apenas 
(a)

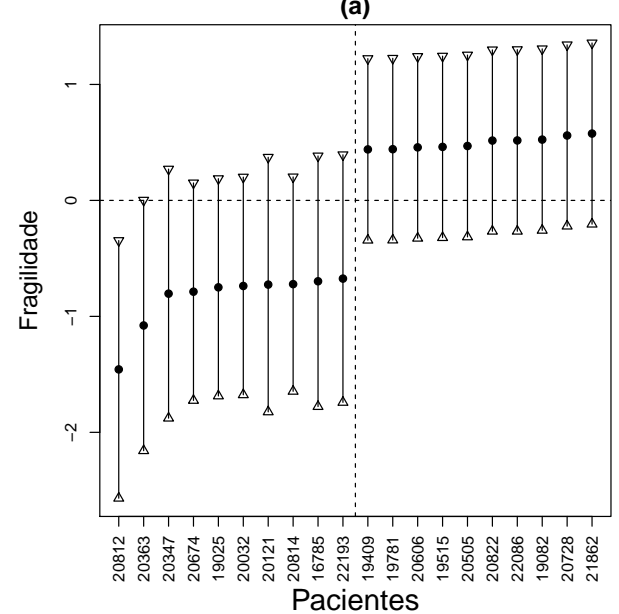

(c)

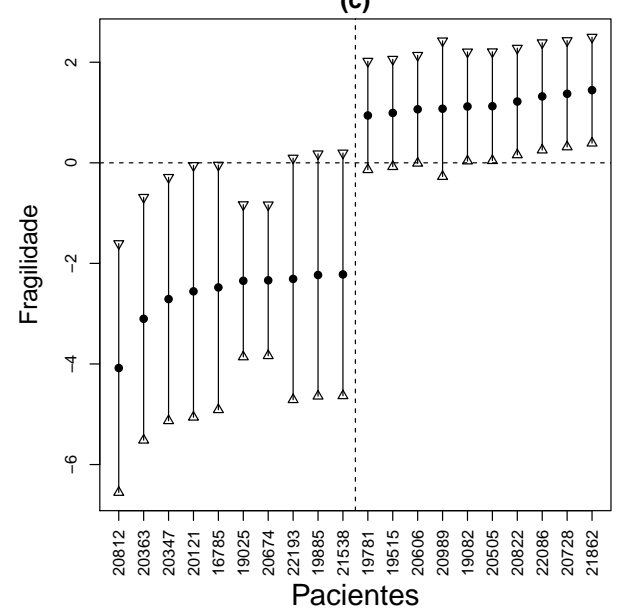

(b)

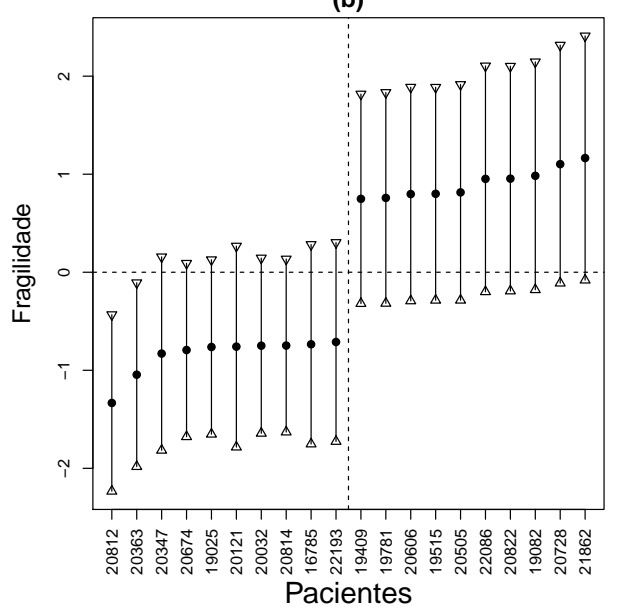

(d)

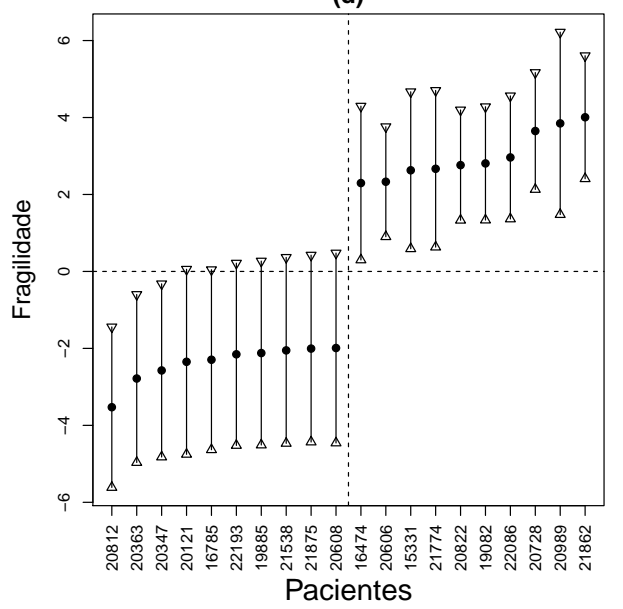

Figura 4.5: Estimativa pontual da fragilidade e seu intervalo de confiança de $90 \%$ para as 10 mulheres com menores fragilidades e as 10 com maiores fragilidades utilizando os modelos: (a)Gama-EM (b)Normal-REML (c)Gama-AIC (d)Normal-AIC.

as pacientes que iniciaram o acompanhamento sem infecção por cada tipo de HPV; repetimos essa abordagem para o modelo de clareamento, considerando apenas as que iniciaram o estudo infectadas por cada tipo de HPV. Os totais de pacientes por desfecho e pelo filtro "iniciar sem (ou com) cada tipo de HPV" são apresentados na Tabela 4.9.

O termo de fragilidade do modelo de fragilidade para a incidência, apenas para as mulheres que iniciaram sem infecção por HPV não significativo (valor- $\mathrm{P}=0.38$ ) sugerindo que o modelo de Cox de riscos proporcionais pode ser empregado nesse caso. Com base nos resultados apresentados na Tabela A.9 do Apêndice A, verificamos que apenas a variável renda tornou-se não significativa. As demais covariáveis continuaram significativas, com valores para a razão das taxas de incidência semelhantes aos obtidos sob o modelo final apresentados na Tabela 4.1, que inclui as pacientes que iniciaram o estudo infectadas por HPV mas que em algum momento clarearam o vírus.

Os resultados do ajuste do modelo de fragilidade para o clareamento levando em conta apenas as mulheres que iniciaram o estudo infectadas por HPV é apresentado na Tabela A.10 do Apêndice A. Todas as covariáveis continuaram significativas com valores para a razão das taxas de clareamento semelhantes aos do modelo final que inclui as pacientes que iniciaram o estudo sem infecção por HPV mas em algum momento foram infectadas (Tabela 4.5).

Os resultados para os modelos finais para a incidência e clareamento apresentados nas Tabelas 
4.1 e 4.5, respectivamente, foram corroborados pelos resultados dos modelos com o filtro "iniciar sem cada tipo de HPV", para a incidência, e "iniciar com cada tipo de HPV", para o clareamento (Tabelas A.9 e A.10 do Apêndice A respectivamente), com a única diferença na variável renda que não foi significativa quando avaliamos o modelo de incidência com este filtro de dados.

\subsection{Comparação com erro padrão bootstrap}

Utilizamos o método bootstrap [Efron (1979)], reamostrando as pacientes, para avaliar estimativas dos erros padrões de cada coeficiente, calculados por meio de

$$
\widehat{\mathbf{V}}=\widehat{\mathbf{F}}^{-1}
$$

no modelo de incidência, e por meio de (3.20) para o modelo de clareamento. Existe uma segunda alternativa (3.17) proposta por Gray (1992) para a escolha da matriz de covariâncias dos estimadores dos parâmetros dos modelos de fragilidade. Para o modelo de clareamento, podemos verificar qual é a proposta mais apropriada, comparando-as com as estimativas dos erros padrões bootstrap. Ainda para o modelo de clareamento, podemos avaliar dois tipos de erros padrões bootstrap: o primeiro com o $\theta$ de (3.7) fixado no valor estimado sob o modelo final e o outro, reestimando o parâmetro $\theta$ para cada amostra bootstrap. Ao todo foram geradas 1000 amostras bootstrap com reposição tanto para o modelo de incidência quanto para o modelo de clareamento. O script implementado em $\mathrm{R}$ pode ser encontrado em

\section{https://www.dropbox.com/sh/4a9k1ryvcx6jsvr/QQe6PxeWEz}

A Tabela 4.10 apresenta os erros padrões obtidos com o emprego de (4.2) e pelo método bootstrap para cada covariável do modelo de incidência, além dos respectivos intervalos de confiança $(90 \%)^{4}$ para os coeficientes exponencializados. Os erros padrões obtidos sob ambos os métodos são muito próximos, sendo que o erro padrão bootstrap apresentou valores $19 \%$ maiores, em média. As variáveis significativas no modelo final de incidência ("usou drogas" e "renda" para os tipos oncogênicos; "escolaridade" e "número de gestações" para os tipos não-oncogênicos, além do tipo do HPV), continuaram significativas $(\alpha=0.10)$.

A Tabela 4.11 apresenta os erros padrões para cada covariável do modelo de clareamento obtidos por meio das matrizes de covariâncias (3.20), (3.17)e pelo método bootstrap, fixando $\theta=\hat{\theta}=0.405$ (o valor estimado no modelo final para o clareamento) em cada amostra bootstrap, além dos respectivos intervalos de confiança (90\%). Os erros padrões baseados na matriz (3.20) são mais próximos dos erros padrões bootstrap e todas as variáveis significativas com base nos intervalos de confiança estimados por meio de (3.20) se mantiveram signficativas com base nos intervalos de confiança estimados pelo método bootstrap $(\alpha=0.10)$, o que confirma os resultados encontrados para o modelo final de clareamento de HPV oncogênicos e não-oncogênicos.

$\mathrm{Na}$ avaliação dos erros padrões estimados por bootstrap $\operatorname{com} \theta$ sendo reestimado a cada reamostragem não houve convergência do algoritmo em aproximadamente $30 \%$ a $40 \%$ dos casos. A primeira hipótese para isto é a presença de algumas variáveis associadas a categorias com pouca frequência ("número de parceiros", por exemplo); no entanto, o problema se manteve quando esta

\footnotetext{
${ }^{4}$ Os intervalos de confiança bootstrap são obtidos com base nos quantis $5 \%$ e $95 \%$ para os coeficientes exponencializados das 1000 amostras bootstrap.
} 
foi excluída da análise. A segunda hipótese é que poderia haver muitas censuras, mas este também não foi o caso, pois das 144 pacientes avaliadas, apenas 38 tiveram censura para ambos os tipos de HPV, 57 clarearam pelo menos um tipo e 49 clarearam ambos os tipos. A terceira hipótese é que a inserção de determinadas variáveis controle não significativas, ou, a inclusão de uma quantidade muito grande de variáveis no modelo poderia ser responsável pela não convergência. A Tabela 4.12 resume a porcentagem de amostras em que não houve convergência. Um estudo sobre este problema será objeto de futuras pesquisas. 


\begin{tabular}{|c|c|c|c|c|c|c|c|}
\hline $\mathrm{HPV}$ & Renda & $\begin{array}{c}\text { Número de } \\
\text { parceiros }\end{array}$ & Tratamento & Idade & Fumou & $\begin{array}{l}\text { Razão de taxas } \\
\text { de clareamento }\end{array}$ & $\mathrm{IC}(90 \%)$ \\
\hline Oncogênico & $\geq 3$ & $\leq 1$ & IP & $>45$ & - & 15.2 & $(4.1 ; 55.9)$ \\
\hline Oncogênico & $<3$ & $>1$ & Nenhum & $<30$ & - & & \\
\hline Oncogênico & $<3$ & $\leq 1$ & IP & $>45$ & - & 8.5 & $(2.7 ; 27.1)$ \\
\hline Oncogênico & $<3$ & $>1$ & Nenhum & $<30$ & - & & \\
\hline Oncogênico & $\geq 3$ & $>1$ & IP & $>45$ & - & 5.9 & $(2.4 ; 14.6)$ \\
\hline Oncogênico & $<3$ & $>1$ & Nenhum & $<30$ & - & & \\
\hline Oncogênico & $\geq 3$ & $\leq 1$ & Nenhum & $>45$ & - & 8.5 & $(2.5 ; 28.7)$ \\
\hline Oncogênico & $<3$ & $>1$ & Nenhum & $<30$ & - & & \\
\hline Oncogênico & $\geq 3$ & $\leq 1$ & IP & $<30$ & - & 8.2 & $(2.6 ; 25.6)$ \\
\hline Oncogênico & $<3$ & $>1$ & Nenhum & $<30$ & - & & \\
\hline Oncogênico & $<3$ & $\leq 1$ & IP & $30-45$ & - & 8.6 & $(2.7 ; 27.3)$ \\
\hline Oncogênico & $<3$ & $>1$ & Nenhum & $<30$ & - & & \\
\hline Oncogênico & $\geq 3$ & $>1$ & IP & $30-45$ & - & 6.0 & $(2.4 ; 15.1)$ \\
\hline Oncogênico & $<3$ & $>1$ & Nenhum & $<30$ & - & & \\
\hline Oncogênico & $\geq 3$ & $\leq 1$ & Nenhum & $30-45$ & - & 8.7 & $(2.7 ; 27.9)$ \\
\hline Oncogênico & $<3$ & $>1$ & Nenhum & $<30$ & - & & \\
\hline Oncogênico & $<3$ & $>1$ & IP & $>45$ & - & 3.3 & $(1.6 ; 6.6)$ \\
\hline Oncogênico & $<3$ & $>1$ & Nenhum & $<30$ & - & & \\
\hline Oncogênico & $<3$ & $\leq 1$ & Nenhum & $>45$ & - & 4.7 & $(1.6 ; 14.0)$ \\
\hline Oncogênico & $<3$ & $>1$ & Nenhum & $<30$ & - & & \\
\hline Oncogênico & $<3$ & $\leq 1$ & IP & $<30$ & - & 4.6 & $(1.7 ; 12.7)$ \\
\hline Oncogênico & $<3$ & $>1$ & Nenhum & $<30$ & - & & \\
\hline Oncogênico & $\geq 3$ & $>1$ & Nenhum & $>45$ & - & 3.3 & $(1.6 ; 7.0)$ \\
\hline Oncogênico & $<3$ & $>1$ & Nenhum & $<30$ & - & & \\
\hline Oncogênico & $\geq 3$ & $>1$ & IP & $<30$ & - & 3.2 & $(1.6 ; 6.4)$ \\
\hline Oncogênico & $<3$ & $>1$ & Nenhum & $<30$ & - & & \\
\hline Oncogênico & $\geq 3$ & $\leq 1$ & Nenhum & $<30$ & - & 4.6 & $(1.6 ; 12.9)$ \\
\hline Oncogênico & $<3$ & $>1$ & Nenhum & $<30$ & - & & \\
\hline Oncogênico & $<3$ & $>1$ & IP & $30-45$ & - & 3.4 & $(1.8 ; 6.2)$ \\
\hline Oncogênico & $<3$ & $>1$ & Nenhum & $<30$ & - & & \\
\hline Oncogênico & $<3$ & $\leq 1$ & Nenhum & $30-45$ & - & 4.8 & $(1.7 ; 14.1)$ \\
\hline Oncogênico & $<3$ & $>1$ & Nenhum & $<30$ & - & & \\
\hline Oncogênico & $\geq 3$ & $>1$ & Nenhum & $30-45$ & - & 3.4 & $(1.6 ; 7.2)$ \\
\hline Oncogênico & $<3$ & $>1$ & Nenhum & $<30$ & - & & \\
\hline Oncogênico & $\geq 3$ & $>1$ & Nenhum & $<30$ & - & 1.8 & $(1.2 ; 2.8)$ \\
\hline Oncogênico & $<3$ & $>1$ & Nenhum & $<30$ & - & & \\
\hline Oncogênico & $<3$ & $\leq 1$ & Nenhum & $<30$ & - & 2.6 & $(1.0 ; 6.4)$ \\
\hline Oncogênico & $<3$ & $>1$ & Nenhum & $<30$ & - & & \\
\hline Oncogênico & $<3$ & $>1$ & IP & $<30$ & - & 1.8 & $(1.1 ; 2.9)$ \\
\hline Oncogênico & $<3$ & $>1$ & Nenhum & $<30$ & - & & \\
\hline Oncogênico & $<3$ & $>1$ & Nenhum & $>45$ & - & 1.8 & $(1.0 ; 3.4)$ \\
\hline Oncogênico & $<3$ & $>1$ & Nenhum & $<30$ & - & & \\
\hline Oncogênico & $<3$ & $>1$ & Nenhum & $30-45$ & - & 1.9 & $(1.0 ; 3.4)$ \\
\hline Oncogênico & $<3$ & $>1$ & Nenhum & $<30$ & - & & \\
\hline Não-oncogênico & - & - & - & - & Não & 1.9 & $(1.1 ; 3.1)$ \\
\hline Não-oncogênico & - & - & - & - & Sim & & \\
\hline Não-oncogênico & - & - & - & - & - & 2.5 & $(1.3 ; 4.7)$ \\
\hline Oncogênico & - & - & - & - & - & & \\
\hline
\end{tabular}

Tabela 4.8: Comparações das taxas de clareamento para pacientes com determinadas características demográficas, comportamentais e clínico-laboratoriais (razões de taxas e intervalos de confiança de 90\%). 


\begin{tabular}{cc|ccc}
\hline \multicolumn{2}{c|}{ Desfechos } & Total & Total iniciou sem & Total iniciou com \\
\hline \multirow{2}{*}{ Incidência } & Oncogênicos & 134 & 69 & - \\
& Não-oncogênicos & 134 & 91 & - \\
\hline Clareamento & Oncogênicos & 153 & - & 127 \\
& Não-oncogênicos & 141 & - & 105 \\
\hline
\end{tabular}

Tabela 4.9: Totais por desfecho e por filtro de dados.

\begin{tabular}{c|c|cc|cc}
\hline Variáveis & Exp(Coef) & Erro Padrão & $\begin{array}{c}\text { Erro Padrão } \\
\text { bootstrap }\end{array}$ & $\mathrm{IC}(90 \%)$ & $\begin{array}{c}\mathrm{IC}(90 \%) \\
\text { bootstrap }\end{array}$ \\
\hline Usou Drogas & 1.88 & 0.38 & 0.50 & $(1.01 ; 3.50)$ & $(1.09 ; 5.18)$ \\
Núm. parceiros $(>1)$ & 1.83 & 0.45 & 0.57 & $(0.88 ; 3.83)$ & $(0.66 ; 4.33)$ \\
Renda $(\geq 3)$ & 0.62 & 0.29 & 0.30 & $(0.39 ; 1.00)$ & $(0.35 ; 0.94)$ \\
Idade $(30-45)$ & 1.07 & 0.37 & 0.43 & $(0.58 ; 1.97)$ & $(0.51 ; 2.05)$ \\
Idade $(>45)$ & 0.68 & 0.30 & 0.34 & $(0.42 ; 1.12)$ & $(0.37 ; 1.12)$ \\
Fumou & 0.76 & 0.29 & 0.30 & $(0.47 ; 1.22)$ & $(0.44 ; 1.20)$ \\
\hline Escolaridade $(5-8)$ & 0.97 & 0.35 & 0.43 & $(0.55 ; 1.71)$ & $(0.49 ; 2.01)$ \\
Escolaridade $(>9)$ & 2.08 & 0.33 & 0.39 & $(1.21 ; 3.60)$ & $(1.12 ; 4.07)$ \\
Gestações $(>1)$ & 1.76 & 0.30 & 0.35 & $(1.09 ; 2.86)$ & $(1.06 ; 3.19)$ \\
Idade $(30-45)$ & 0.90 & 0.36 & 0.45 & $(0.50 ; 1.64)$ & $(0.45 ; 1.84)$ \\
Idade $(>45)$ & 0.74 & 0.33 & 0.43 & $(0.43 ; 1.27)$ & $(0.35 ; 1.30)$ \\
Fumou & 0.75 & 0.29 & 0.36 & $(0.46 ; 1.20)$ & $(0.38 ; 1.27)$ \\
\hline HPV oncogênicos & 2.15 & 0.46 & 0.52 & $(1.01 ; 4.55)$ & $(1.06 ; 5.32)$ \\
\hline
\end{tabular}

Tabela 4.10: Comparação dos erros padrões estimados pela matriz $\widehat{\mathbf{V}}=\widehat{\mathbf{F}}^{-1}$ e por bootstrap e os respectivos intervalos de confiança de $90 \%$ para os coeficientes exponencializados do modelo de incidência de HPV oncogênicos e não-oncogênicos.

\begin{tabular}{c|c|ccc|ccc}
\hline & Erro & $\begin{array}{c}\text { Erro } \\
\text { Variáveis }\end{array}$ & $\begin{array}{c}\text { Erro Padrão } \\
\text { bootstrap }\end{array}$ & IC $(90 \%)_{1}$ & IC $(90 \%)_{2}$ & $\begin{array}{c}\text { IC }(90 \%) \\
\text { bootstrap }\end{array}$ \\
\hline Renda $(\geq 3)$ & 1.80 & 0.27 & 0.24 & 0.27 & $(1.16 ; 2.78)$ & $(1.21 ; 2.66)$ & $(1.25 ; 3.10)$ \\
Núm. parceiros $(>1)$ & 0.39 & 0.56 & 0.53 & 0.62 & $(0.16 ; 0.98)$ & $(0.16 ; 0.93)$ & $(0.11 ; 0.81)$ \\
Trat. ARV (IP) & 1.79 & 0.30 & 0.27 & 0.29 & $(1.10 ; 2.90)$ & $(1.15 ; 2.79)$ & $(1.24 ; 3.20)$ \\
Trat. ARV (ITRNN) & 1.07 & 0.33 & 0.30 & 0.35 & $(0.62 ; 1.84)$ & $(0.65 ; 1.75)$ & $(0.61 ; 1.86)$ \\
Idade (30-45) & 1.88 & 0.37 & 0.32 & 0.37 & $(1.03 ; 3.44)$ & $(1.12 ; 3.17)$ & $(1.16 ; 3.92)$ \\
Idade $(>45)$ & 1.85 & 0.32 & 0.28 & 0.33 & $(1.09 ; 3.12)$ & $(1.17 ; 2.93)$ & $(1.15 ; 3.45)$ \\
Fumou & 0.82 & 0.27 & 0.24 & 0.26 & $(0.52 ; 1.28)$ & $(0.56 ; 1.21)$ & $(0.50 ; 1.17)$ \\
\hline Idade $(30-45)$ & 1.68 & 0.40 & 0.34 & 0.45 & $(0.88 ; 3.22)$ & $(0.97 ; 2.93)$ & $(0.91 ; 3.85)$ \\
Idade $(>45)$ & 0.78 & 0.32 & 0.28 & 0.37 & $(0.46 ; 1.30)$ & $(0.49 ; 1.22)$ & $(0.41 ; 1.34)$ \\
Fumou & 0.53 & 0.30 & 0.27 & 0.32 & $(0.32 ; 0.87)$ & $(0.34 ; 0.82)$ & $(0.28 ; 0.78)$ \\
\hline HPV oncogênicos & 0.40 & 0.38 & 0.36 & 0.44 & $(0.21 ; 0.74)$ & $(0.22 ; 0.72)$ & $(0.16 ; 0.69)$ \\
\hline
\end{tabular}

Tabela 4.11: Comparação dos erros padrões estimados pela matriz $\widehat{\mathbf{V}}=\widehat{\mathbf{H}}^{-1}$, pela matriz $\widehat{\mathbf{V}}=\widehat{\mathbf{H}}^{-1} \widehat{\mathbf{F}} \widehat{\mathbf{H}}^{-1}$ e por bootstrap para $\theta$ fixado e os respectivos intervalos de confiança de $90 \%$ para os coeficientes exponencializados do modelo de clareamento de HPV oncogênicos e não-oncogênicos. 


\begin{tabular}{l|c}
\hline \multicolumn{1}{c|}{ Variáveis no modelo } & $\begin{array}{c}\text { Ajustes em que não } \\
\text { houve convergência(\%) }\end{array}$ \\
\hline tipo de HPV + renda & $0 \%$ \\
tipo de HPV + renda + fumou (não-onc.) & $0 \%$ \\
tipo de HPV + renda + fumou (não-onc.) + tratamento ARV & $1.6 \%$ \\
tipo de HPV + renda + fumou (não-onc.) + tratamento ARV + idade (onc.) & $3.4 \%$ \\
tipo de HPV + renda + fumou (não-onc.) + tratamento ARV + idade (onc.) + & $6.2 \%$ \\
número de parceiros & \\
tipo de HPV + renda + fumou (não-onc.) + tratamento ARV + idade (onc.) + & $30 \%$ \\
número de parceiros + fumou (onc.) & \\
tipo de HPV + renda + fumou (não-onc.) + tratamento ARV + idade (onc.) + & \\
número de parceiros + fumou (onc.) + idade (onc.) & \\
\hline
\end{tabular}

Tabela 4.12: Porcentagem de amostras bootstrap em que não houve convergência do modelo final de clareamento de HPV oncogênicos e não-oncogênicos para determinadas covariáveis no modelo. 


\section{Capítulo 5}

\section{Conclusões e Considerações Finais}

Os resultados apresentados no Capítulo 4 indicam fatores de risco distintos associados à incidência/clareamento de HPV oncogênicos e não-oncogênicos. O uso de drogas, o total de gestações e a escolaridade são fatores de risco para a incidência, e a renda é um fator de proteção. Os fatores que indicam um clareamento mais rápido são: renda, tratamento ARV para o esquema IP e idade; os fatores que indicam um clareamento mais lento são: número de parceiros e hábito tabagista.

\section{Incidência de HPV oncogênicos}

Para os HPV oncogênicos indentificou-se o uso de drogas como fator de risco, concordando com o resultado de Rezza et al. (1998) que relacionam este fator de risco à promiscuidade e prostituição, tornando mulheres com esse tipo de comportamento mais sucetíveis a serem infectadas por HPV. A renda também foi identificada como um fator de proteção para os HPV oncogênicos, resultado já encontrado anteriormente por Palefsky (2003). O efeito do número de parceiros no último ano embora não significativo, condiz com estudos anteriores [Rousseau et al. (2000), Kjver et al. (1997), Giuliano et al. (2002)].

\section{Incidência de HPV não-oncogênicos}

A escolaridade é um fator de risco para os HPV não-oncogênicos. Embora de díficil interpretação, este resultado condiz com os resultados de Rousseau et al. (2000). O número de gestações foi condiderado como fator de risco para a incidência de HPV não-oncogênicos, resultado que Hildesheim et al. (1993) já tinham encontrado para HPV de modo geral. Os trabalhos de Palefsky (2003) e Bauer et al. (1993) mostraram maior risco de HPV para mulheres que não engravidaram.

\section{Clareamento de HPV oncogênicos}

A investigação de fatores associados ao clareamento de HPV oncogênicos e não-oncogênicos ainda foi pouco explorada na literatura e não foram encontrados estudos que abordassem este tipo de relação. Dentre os fatores que indicam um clareamento mais rápido apresentados na Tabela 4.5, o que chama mais atenção é o efeito do tratamento ARV, pois isto indica que mulheres tratadas com o esquema baseado na droga IP obtiveram um clareamento mais rápido para HPV oncogênicos, e isto poderá ser levado em conta na escolha do tratamento específico para cada mulher. 


\section{Clareamento de HPV não-oncogênicos}

Um resultado relevante para o clareamento de HPV não-oncogênicos é a associação com o hábito tabagista, e isto atribui-se ao fato conhecido de que o cigarro suprime o sistema imune, especialmente em mulheres HIV-positivas [RA \& Winkelstein (1990)], fazendo com que seu organismo tenha maior dificuldade para clarear o HPV. A taxa de clareamento de HPV não-oncogênicos ser maior do que a taxa de HPV oncogênicos concorda com a hipótese de Giuliano et al. (2002) de que os HPV não-oncogênicos tendem a ser mais transientes que os HPV oncogênicos.

\subsection{Comentários finais}

O modelo adotado para a incidência de HPV oncogênicos e não-oncogênicos, mesmo tendo um baixo poder de explicação $\left(R^{2}=0.1\right)$ atendeu às hipóteses de riscos proporcionais e não apresentou valores aberrantes ou influentes que prejudicassem a qualidade do seu ajuste; além disso, foi eficaz para identificar alguns fatores de risco para mulheres HIV-positivas. Não houve necessidade de incluir o termo de fragilidade, ou seja, não rejeitamos a hipótese de independência entre os tempos até incidência de HPV oncogênicos e não-oncogênicos. Para a incidência de HPV oncogênicos, a taxa de incidência para as pacientes que usam drogas é 1.88 (IC 90\%, 1.01; 3.50) vezes maior do que para as que não usam. A renda é um fator de proteção, pois a taxa de incidência de pacientes com renda igual ou superior a 3 salários mínimos é 0.62 (IC 90\%, 0.38; 1.00) vezes a taxa referente àquelas com renda menor que 3 salários mínimos. A escolaridade e o número de gestações foram identificados como fatores de risco para a incidência de HPV não-oncogênicos. Para a primeira, a taxa de incidência para mulheres que tiveram mais do que 9 anos de escolaridade é 2.08 (IC $90 \%, 1.21 ; 3.6)$ vezes a taxa correspondente a mulheres com escolaridade menor que 5 anos, e para a última, a taxa de incidência para mulheres que tiveram mais do que uma gestação é 1.76 (IC $90 \%, 1.09 ; 2.86)$ vezes aquela correspondente a mulheres que tiveram uma ou nenhuma. Os HPV oncogênicos apresentam uma taxa de incidência 2.15 (IC 90\%, 1.01; 4.55) vezes aquela associada a HPV não-oncogênicos.

Podemos incluir as pacientes que iniciaram com determinado tipo de HPV e em algum momento clarearam nas análises de incidência, pois a inclusão destas, pouco interfere nas estimativas obtidas sob o modelo final de incidência.

Utilizando o método bootstrap para estimar os erros padrões e os intervalos de confiança para os estimadores dos coeficientes do modelo para incidência, confirmaram-se os resultados encontrados para os erros padrões estimados por meio da matriz de covariâncias (4.2) sob o modelo de Cox padrão.

Rejeitamos a hipótese de que não existe dependência entre os tempos até o clareamento de HPV oncogênicos e não-oncogênicos. O modelo proposto apresentou um poder de explicação moderado $\left(R^{2}=0.21\right)$ e as diferentes escolhas de distribuição e de métodos de estimação para o termo de fragilidade geraram estimativas similares. Com base nas fragilidades estimadas para cada mulher pudemos identificar quais pacientes tiveram maior ou menor dificuldade para clarear os HPV, um resultado que poderá ser utilizado para a proposta de tratamentos diferenciados.

Identificamos a renda, a idade e o tratamento ARV como fatores que indicam um clareamento mais rápido para HPV oncogênicos. Supondo mulheres com fragilidades iguais, a taxa de clarea- 
mento para mulheres com renda na faixa de 3 ou mais salários mínimos é 1.80 (IC 90\%, 1.16; 2.78) vezes aquela correspondente a mulheres com renda na faixa de até 2 salários mínimos. A taxa de clareamento de HPV oncogênicos para mulheres com mais de um parceiro sexual no último ano é 0.39 (IC $90 \%, 0.16 ; 0.98$ ) vezes a taxa de clareamento referente a mulheres que tiveram um parceiro ou menos. A taxa de clareamento para mulheres na faixa de idade 35 e 40 anos (40 ou mais) é 1.88 (IC 90\%, 1.03; 3.44) [1.85 (IC 90\%, 1.09; 3.13)] vezes aquela associada a mulheres na faixa de etária "menor do que 35 anos". A taxa de clareamento de HPV oncogênicos para mulheres que usam o ARV IP é 1.79 (IC 90\%, 1.1; 2.9) vezes aquela associada a mulheres que não usam nenhum medicamento. A taxa de clareamento de HPV não-oncogênicos para mulheres que fumam é 0.53 (IC $90 \%, 0.32 ; 0.87)$ vezes a taxa referente a mulheres que não fumam. Os HPV oncogênicos apresentam uma taxa de clareamento 0.4 (IC 90\%, 0.21; 0.74) vezes a taxa de HPV não-oncogênicos.

A identificação de fatores que indicam aumento da taxa de clareamento, como o tratamento ARV com base na droga IP poderá influir na escolha dos medicamentos a serem administrados às pacientes, protegendo-as de lesões e até de câncer no colo do útero provocado pela longa persistência da infecção por HPV.

De forma análoga ao modelo para incidência, nas análises de clareamento podemos incluir as pacientes que iniciaram o estudo sem determinado tipo de HPV e em algum momento contrairam o vírus, pois esta inclusão pouco interfere nas estimativas dos parâmetros do modelo final de clareamento.

Utilizando o método bootstrap para estimar os erros padrões e os intervalos de confianca dos estimadores do modelo para clareamento, para $\theta$ com valor fixado em $\hat{\theta}$ obtido do modelo final, verificou-se maior proximidade entre as estimativas dos erros padrões bootstrap e as obtidas por meio da matriz de covariâncias (3.20), o que nos leva a concluir que esta é uma alternativa melhor para o teste de Wald (3.15) para hipóteses sobre os efeitos fixos. Com base nos intervalos de confiança bootstrap confirmaram-se as significâncias de cada covariável quando comparadas com aquelas baseadas nos intervalos de confiança obtidos com (3.20).

\subsection{Trabalhos futuros}

Uma possível extensão deste trabalho consiste na avaliação do impacto das mesmas variáveis avaliadas neste estudo (ver Tabela 2.1, além do nível de CD4 e tratamento ARV) na incidência e clareamento de HPV para cada subtipo específico de HPV dentre os 35 comentados no Capítulo 1, levando em conta recorrências sucessivas de cada um dos tipos e não apenas a primeira ocorrência. Para isto, podemos considerar modelos de fragilidade multiníveis (ver Duchateau \& Janssen (2008), por exemplo) sendo as pacientes consideradas como o primeiro nível e tipo de HPV, como o segundo nível.

Outra possível linha de pesquisa envolve a utilização de modelos de fragilidade com censura intervalar [Hougaard (2008)], visto que não sabemos o momento exato de ocorrência de cada evento;

Finalmente, também há interesse na modelagem conjunta de dados longitudinais e de sobrevivência, pois existem variáveis como o tratamento ARV e o nível de CD4 que variam com o tempo. Segundo Tsiatis \& Davidian (2004) e Yu et al. (2004), a utilização destes modelos leva à correção do viés e ao potencial aumento da eficiência na estimação dos parâmetros. 


\section{Apêndice A}

\section{Tabelas e Gráficos}

\begin{tabular}{c|c|ccccc}
\hline \multicolumn{1}{c}{ Estratégia 1) } & Stepwise todas as variáveis & & & \\
\hline HPV & Variáveis & $\operatorname{Exp}$ (Coef) & Erro padrão & LI & LS & valor-P \\
\hline \multirow{3}{*}{ Oncogênicos } & Usou Drogas & 2.56 & 0.33 & 1.49 & 4.38 & $<0.01$ \\
& Idade (30-45) & 0.87 & 0.34 & 0.50 & 1.54 & 0.70 \\
& Idade (>45) & 0.69 & 0.28 & 0.44 & 1.09 & 0.18 \\
& Fumou & 0.68 & 0.28 & 0.43 & 1.08 & 0.17 \\
\hline \multirow{5}{*}{ Não-oncogênicos } & Escolaridade (5-8) & 1.03 & 0.33 & 0.60 & 1.78 & 0.92 \\
& Escolaridade (>9) & 1.83 & 0.30 & 1.11 & 3.00 & 0.05 \\
& Idade (30-45) & 1.07 & 0.35 & 0.61 & 1.89 & 0.84 \\
& Idade (>45) & 0.84 & 0.30 & 0.51 & 1.38 & 0.56 \\
& Fumou & 0.83 & 0.27 & 0.53 & 1.30 & 0.50 \\
\hline & HPV oncogênicos & 1.51 & 0.39 & 0.80 & 2.85 & 0.29 \\
\hline
\end{tabular}

Tabela A.1: Coeficientes estimados exponencializados/Razões de taxas de incidência, erros padrões, limites inferiores (LI) e superiores (LS) para intervalos de confiança com coeficiente de confiança 90\% e valores-P para o modelo de incidência de HPV oncogênicos e não-oncogênicos obtido por meio do método forward stepwise com todas as variáveis explicativas.

\begin{tabular}{c|c|ccccc}
\hline \multicolumn{8}{c}{ Estratégia 2) } & Stepwise variáveis dos artigos & & \\
\hline HPV & Variáveis & Exp(Coef) & Erro padrão & LI & LS & valor-P \\
\hline \multirow{3}{*}{ Oncogênicos } & Usou Drogas & 2.56 & 0.33 & 1.49 & 4.38 & $<0.01$ \\
& Idade $(30-45)$ & 0.87 & 0.34 & 0.50 & 1.54 & 0.70 \\
& Idade ( $>45)$ & 0.69 & 0.28 & 0.44 & 1.09 & 0.18 \\
& Fumou & 0.68 & 0.28 & 0.43 & 1.08 & 0.17 \\
\hline \multirow{5}{*}{ Não-oncogênicos } & Escolaridade (5-8) & 1.03 & 0.33 & 0.60 & 1.78 & 0.92 \\
& Escolaridade (>9) & 1.83 & 0.30 & 1.11 & 3.00 & 0.05 \\
& Idade (30-45) & 1.07 & 0.35 & 0.61 & 1.89 & 0.84 \\
& Idade (>45) & 0.84 & 0.30 & 0.51 & 1.38 & 0.56 \\
& Fumou & 0.83 & 0.27 & 0.53 & 1.30 & 0.50 \\
\hline & HPV oncogênicos & 1.51 & 0.39 & 0.80 & 2.85 & 0.29 \\
\hline
\end{tabular}

Tabela A.2: Coeficientes estimados exponencializados/Razões de taxas de incidência, erros padrões, limites inferiores (LI) e superiores (LS) para intervalos de confiança com coeficiente de confiança $90 \%$ e valores-P para o modelo de incidência de HPV oncogênicos e não-oncogênicos obtido por meio do método forward stepwise apenas com as variáveis explicativas dos artigos relacionados. 


\begin{tabular}{c|c|ccccc}
\hline \multicolumn{9}{c}{ Estratégia 3) Uma a uma para todas as variáveis } & & \\
\hline HPV & Variáveis & Exp(Coef) & Erro padrão & LI & LS & valor-P \\
\hline \multirow{3}{*}{ Oncogênicos } & Usou Drogas & 1.88 & 0.38 & 1.01 & 3.51 & 0.10 \\
& Renda $(\geq 3)$ & 0.62 & 0.29 & 0.38 & 0.99 & 0.09 \\
& Núm. parceiros $(>1)$ & 1.81 & 0.45 & 0.86 & 3.77 & 0.19 \\
& Idade $(30-45)$ & 1.05 & 0.37 & 0.58 & 1.93 & 0.88 \\
& Idade (>45) & 0.67 & 0.29 & 0.42 & 1.10 & 0.18 \\
& Fumou & 0.75 & 0.29 & 0.47 & 1.21 & 0.32 \\
\hline \multirow{5}{*}{ Não-oncogênicos } & Escolaridade (5-8) & 0.97 & 0.34 & 0.55 & 1.71 & 0.93 \\
& Escolaridade (>9) & 1.81 & 0.31 & 1.08 & 3.03 & 0.06 \\
& Idade (30-45) & 0.93 & 0.36 & 0.52 & 1.67 & 0.84 \\
& Idade (>45) & 0.81 & 0.31 & 0.49 & 1.36 & 0.50 \\
& Fumou & 0.80 & 0.29 & 0.50 & 1.28 & 0.43 \\
\hline & HPV oncogênicos & 1.54 & 0.41 & 0.78 & 3.01 & 0.29 \\
\hline
\end{tabular}

Tabela A.3: Coeficientes estimados exponencializados/Razões de taxas de incidência, erros padrões, limites inferiores (LI) e superiores (LS) para intervalos de confiança com coeficiente de confiança $90 \%$ e valores-P para o modelo de incidência de HPV oncogênicos e não-oncogênicos selecionando cada variável uma a uma, dentre todas as variáveis explicativas, comparando-as com o modelo nulo e colocando-as em um único modelo.

\begin{tabular}{c|c|ccccc}
\hline & \multicolumn{9}{c}{ Estratégia 4) Uma a uma para as variáveis dos artigos } & & \\
\hline HPV & Variáveis & Exp(Coef) & Erro padrão & LI & LS & valor-P \\
\hline \multirow{3}{*}{ Oncogênicos } & Usou Drogas & 1.88 & 0.38 & 1.01 & 3.51 & 0.10 \\
& Renda $(\geq 3)$ & 0.62 & 0.29 & 0.38 & 0.99 & 0.09 \\
& Núm. parceiros $(>1)$ & 1.81 & 0.45 & 0.86 & 3.77 & 0.19 \\
& Idade $(30-45)$ & 1.05 & 0.37 & 0.58 & 1.93 & 0.88 \\
& Idade $(>45)$ & 0.67 & 0.29 & 0.42 & 1.10 & 0.18 \\
& Fumou & 0.75 & 0.29 & 0.47 & 1.21 & 0.32 \\
\hline \multirow{5}{*}{ Não-oncogênicos } & Escolaridade (5-8) & 0.97 & 0.34 & 0.55 & 1.71 & 0.93 \\
& Escolaridade (>9) & 1.81 & 0.31 & 1.08 & 3.03 & 0.06 \\
& Idade (30-45) & 0.93 & 0.36 & 0.52 & 1.67 & 0.84 \\
& Idade (>45) & 0.81 & 0.31 & 0.49 & 1.36 & 0.50 \\
& Fumou & 0.80 & 0.29 & 0.50 & 1.28 & 0.43 \\
\hline & HPV oncogênicos & 1.54 & 0.41 & 0.78 & 3.01 & 0.29 \\
\hline
\end{tabular}

Tabela A.4: Coeficientes estimados exponencializados/Razões de taxas de incidência, erros padrões, limites inferiores (LI) e superiores (LS) para intervalos de confiança com coeficiente de confiança $90 \%$ e valores-P para o modelo de incidência de HPV oncogênicos e não-oncogênicos selecionando cada variável uma a uma, dentre todas as variáveis dos artigos relacionados, comparando-as com o modelo nulo e colocando-as em um único modelo. 


\begin{tabular}{c|c|ccccc}
\hline & \multicolumn{2}{c}{ Estratégia 1) Stepwise todas as variáveis } & & \\
\hline HPV & Variáveis & Exp(Coef) & Erro padrão & LI & LS & valor-P \\
\hline \multirow{5}{*}{ Oncogênicos } & Renda $(\geq 3)$ & 1.80 & 0.27 & 1.16 & 2.78 & 0.03 \\
& Núm. parceiros $(>1)$ & 0.39 & 0.56 & 0.16 & 0.98 & 0.09 \\
& Tratamento ARV (IP) & 1.79 & 0.30 & 1.10 & 2.90 & 0.05 \\
& Tratamento ARV (ITRNN) & 1.07 & 0.33 & 0.62 & 1.84 & 0.84 \\
& Idade (30-45) & 1.88 & 0.37 & 1.03 & 3.44 & 0.08 \\
& Idade (>45) & 1.85 & 0.32 & 1.09 & 3.13 & 0.06 \\
Não-oncogênicos & Fumou & 0.82 & 0.27 & 0.52 & 1.28 & 0.46 \\
\hline & Idade (30-45) & 1.68 & 0.40 & 0.88 & 3.22 & 0.19 \\
& Idade (>45) & 0.78 & 0.32 & 0.46 & 1.30 & 0.42 \\
& Fumou & 0.53 & 0.30 & 0.32 & 0.87 & 0.04 \\
\hline & HPV oncogênicos & 0.40 & 0.38 & 0.21 & 0.74 & 0.02 \\
\hline & Fragilidade & & & & 0.02 \\
\hline
\end{tabular}

Tabela A.5: Coeficientes estimados exponencializados/Razões de taxas de clareamento, erros padrões, limites inferiores (LI) e superiores (LS) para intervalos de confiança com coeficiente de confiança $90 \%$ e valores-P para o modelo de clareamento de HPV oncogênicos e não-oncogênicos obtido por meio do método forward stepwise com todas as variáveis explicativas.

\begin{tabular}{c|c|ccccc}
\hline \multicolumn{2}{c}{ Estratégia 3) Uma a uma para todas as variáveis } & & \\
\hline HPV & Variáveis & Exp(Coef) & Erro padrão & LI & LS & valor-P \\
\hline \multirow{3}{*}{ Oncogênicos } & Renda ( $\geq 3)$ & 1.77 & 0.26 & 1.14 & 2.73 & 0.03 \\
& Tratamento ARV (IP) & 1.97 & 0.30 & 1.21 & 3.20 & 0.02 \\
& Tratamento ARV (ITRNN) & 1.15 & 0.33 & 0.67 & 1.96 & 0.67 \\
& Idade (30-45) & 1.89 & 0.37 & 1.02 & 3.49 & 0.09 \\
& Idade (>45) & 1.71 & 0.32 & 1.01 & 2.89 & 0.09 \\
& Fumou & 0.86 & 0.27 & 0.55 & 1.34 & 0.58 \\
\hline \multirow{3}{*}{ Não-oncogênicos } & Idade (30-45) & 1.54 & 0.40 & 0.79 & 2.99 & 0.29 \\
& Idade (>45) & 0.76 & 0.32 & 0.45 & 1.28 & 0.38 \\
& Fumou & 0.58 & 0.30 & 0.35 & 0.95 & 0.07 \\
\hline & HPV oncogênicos & 0.35 & 0.39 & 0.19 & 0.67 & 0.01 \\
\hline & Fragilidade & & & & & 0.01 \\
\hline
\end{tabular}

Tabela A.6: Coeficientes estimados exponencializados/Razões de taxas de clareamento, erros padrões, limites inferiores (LI) e superiores (LS) para intervalos de confiança com coeficiente de confiança $90 \%$ e valores-P para o modelo de clareamento de HPV oncogênicos e não-oncogênicos selecionando cada variável uma a uma, dentre todas as variáveis explicativas, comparando-as com o modelo nulo e colocando-as em um único modelo. 


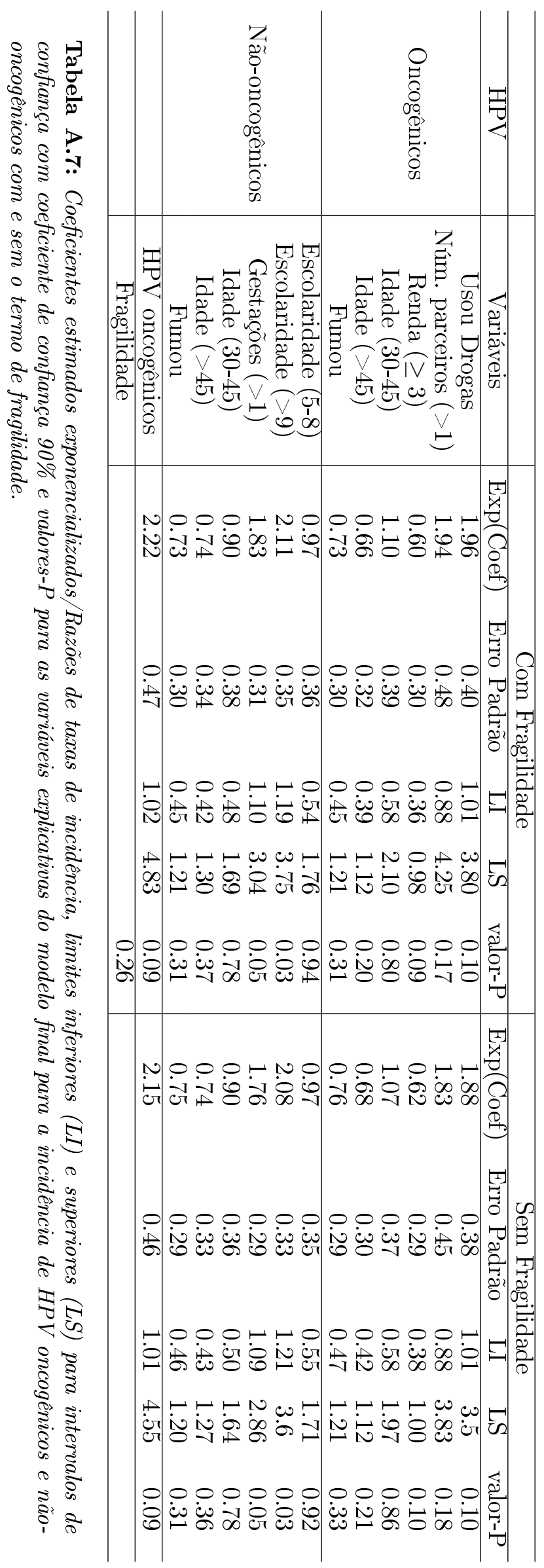




\begin{tabular}{c|c|cc|cc}
\hline & & \multicolumn{2}{|c|}{$\begin{array}{c}\text { Modelo final sem } \\
\text { pontos aberrantes }\end{array}$} \\
\hline \multirow{5}{*}{ HPV } & Moriáveis & Coef. & valor-P & Coef. & valor-P \\
\hline & Usou Drogas & 0.63 & 0.10 & 0.60 & 0.11 \\
& Núm. parceiros $(>1)$ & 0.60 & 0.18 & 0.62 & 0.16 \\
& Renda $(\geq 3)$ & -0.48 & 0.10 & -0.51 & 0.09 \\
& Idade $(30-45)$ & 0.07 & 0.86 & 0.17 & 0.66 \\
& Idade $(>45)$ & -0.38 & 0.21 & -0.33 & 0.28 \\
& Fumou & -0.28 & 0.33 & -0.27 & 0.35 \\
\hline \multirow{5}{*}{ Não-oncogênicos } & Escolaridade $(5-8)$ & -0.03 & 0.92 & -0.10 & 0.79 \\
& Escolaridade $(>9)$ & 0.73 & 0.03 & 0.59 & 0.09 \\
& Gestações $(>1)$ & 0.57 & 0.05 & 0.46 & 0.12 \\
& Idade $(30-45)$ & -0.10 & 0.78 & -0.14 & 0.72 \\
& Idade ( $>45)$ & -0.30 & 0.36 & -0.22 & 0.51 \\
& Fumou & -0.29 & 0.31 & -0.32 & 0.30 \\
\hline & HPV oncogênicos & 0.76 & 0.09 & 0.65 & 0.16 \\
\hline
\end{tabular}

Tabela A.8: Comparação dos efeitos fixos do modelo final para a incidência de HPV oncogênicos e não-oncogênicos com e sem pontos aberrantes. (coeficientes estimados e valores-P).

\begin{tabular}{c|c|ccccc}
\hline HPV & Variáveis & Exp(Coef) & Erro Padrão & LI & LS & valor-P \\
\hline \multirow{5}{*}{ Oncogênicos } & Usou Drogas & 2.52 & 0.48 & 1.14 & 5.59 & 0.06 \\
& Núm. parceiros $(>1)$ & 1.39 & 0.64 & 0.48 & 4.01 & 0.61 \\
& Renda $(\geq 3)$ & 0.67 & 0.48 & 0.31 & 1.49 & 0.41 \\
& Idade $(30-45)$ & 2.02 & 0.67 & 0.67 & 6.04 & 0.29 \\
& Idade $(>45)$ & 0.69 & 0.42 & 0.35 & 1.38 & 0.38 \\
& Fumou & 0.72 & 0.45 & 0.35 & 1.51 & 0.47 \\
\hline \multirow{5}{*}{ Não-oncogênicos } & Escolaridade (5-8) & 0.95 & 0.44 & 0.46 & 1.95 & 0.91 \\
& Escolaridade (>9) & 2.64 & 0.40 & 1.37 & 5.10 & 0.02 \\
& Gestações (>1) & 1.93 & 0.37 & 1.05 & 3.56 & 0.08 \\
& Idade (30-45) & 1.01 & 0.42 & 0.51 & 2.03 & 0.98 \\
& Idade (>45) & 0.73 & 0.40 & 0.38 & 1.41 & 0.43 \\
& Fumou & 0.85 & 0.36 & 0.47 & 1.54 & 0.65 \\
\hline & HPV oncogênicos & 2.61 & 0.56 & 1.04 & 6.53 & 0.09 \\
\hline
\end{tabular}

Tabela A.9: Coeficientes estimados exponencializados/Razões de taxas de incidência, erros padrões, limites inferiores (LI) e superiores (LS) para intervalos de confiança com coeficiente de confiança $90 \%$ e valores-P para as variáveis explicativas relacionadas com o tempo até incidência de HPV oncogênicos e não-oncogênicos apenas para as pacientes que iniciaram sem HPV oncogênicos ou HPV não-oncogênicos. 


\begin{tabular}{c|c|ccccc}
\hline HPV & Variáveis & Exp(Coef) & Erro Padrão & LI & LS & valor-P \\
\hline \multirow{5}{*}{ Oncogênicos } & Renda $(\geq 3)$ & 1.68 & 0.30 & 1.03 & 2.76 & 0.08 \\
& Núm. parceiros $(>1)$ & 0.34 & 0.66 & 0.11 & 1.00 & 0.10 \\
& Tratamento ARV (IP) & 1.79 & 0.34 & 1.03 & 3.13 & 0.08 \\
& Tratamento ARV (ITRNN) & 1.01 & 0.37 & 0.55 & 1.85 & 0.98 \\
& Idade (30-45) & 2.23 & 0.41 & 1.14 & 4.38 & 0.05 \\
& Idade ( $>45)$ & 2.11 & 0.38 & 1.13 & 3.94 & 0.05 \\
& Fumou & 0.85 & 0.30 & 0.51 & 1.40 & 0.59 \\
\hline \multirow{2}{*}{ Não-oncogênicos } & Idade (30-45) & 2.18 & 0.53 & 0.91 & 5.22 & 0.14 \\
& Idade (>45) & 0.61 & 0.36 & 0.33 & 1.10 & 0.17 \\
& Fumou & 0.51 & 0.36 & 0.28 & 0.92 & 0.06 \\
\hline & HPV oncogênicos & 0.33 & 0.45 & 0.16 & 0.70 & 0.02 \\
\hline & Fragilidade & & & & & 0.04 \\
\hline
\end{tabular}

Tabela A.10: Coeficientes estimados exponencializados/Razões de taxas de clareamento, erros padrões, limites inferiores (LI) e superiores (LS) para intervalos de confiança com coeficiente de confiança $90 \%$ e valores-P para as variáveis explicativas relacionadas com o tempo até clareamento de HPV oncogênicos e não-oncogênicos apenas para as pacientes que iniciaram com HPV oncogênicos ou HPV não-oncogênicos. 


\section{Referências Bibliográficas}

Aalen, O. O. (1988). Heterogeneity in survival analysis. Stat Med 7, 1121-1137. 17

Ahrens, W. \& Pigeot, I. (2004). Handbook of Epidemiology. Berlin: Springer. 3, 4

Athanasiou, T. \& Darzi, A. (2010). Key Topics in Surgical Research and Methodology. Berlin: Springer. 3

Base SAS® 9.3 Procedures Guide (2011). SAS Institute Inc., Cary. 17

Bauer, H. M., Hildesheim, A., Schiffman, M. H., Glass, A. G., Rush, B. B. \& Scott., D. R. (1993). Determinants of genital human papillomavirus infection in low-risk women in Portland, Oregon. Sex Transm Dis 20, 274-8. 41

Breslow, N. E. (1972). Discussion of the paper by D. R. Cox. J R Statist Soc 34, 216-217. 20

Brown, D. R., Shew, M. L., Qadadri, B., Neptune, N., Vargas, M., Tu, W., Juliar, B. E., Breen, T. E., \& Fortenberry, J. D. (2005). A longitudinal study of genital human papillomavirus infection in a cohort of closely followed adolescent women. J Infect Dis 191, 182-92. 5

Cai, J., Fan, J., Zhou, H. \& Zhou, Y. (2007). Hazard models with varying coefficients for multivariate failure time data. Ann Stat 35, 324-354. 30

Carvalho, M. S., Andreozzi, V. L., Codeço, C. T., Campos, D. P., Barbosa, M. T. S. \& Shimakura, S. E. (2011). Análise de Sobrevivência Teoria e aplicaçôes em saúde. Rio de Janeiro: Editora FIOCRUZ. 6, 30, 32

Clayton, D. G. (1978). A model for association in bivariate life tables and its aplication an epidemiological studies of familial tendency in chronic disease incidence. Biometrika 65, 141-51. 17

Clifford, G. M., Howell-Jones, R. \& Franceschi, S. (2011). Judging the carcinogenicity of human papillomavirus types by single/multiple infection ratio in cervical cancer. Int $J$ Cancer 129, 1792-1794. 1

Colosimo, E. A. \& Giolo, S. R. (2006). Análise de Sobrevivência Aplicada. São Paulo: Edgard Blucher. 5, 9, 18, 20, 22, 23, 30

De Sanjose, S., Quint, W. G., Alemany, L., Geraets, D. T., Klaustermeier, J. E., Lloveras, B., Tous, S., Felix, A., Bravo, L. E., Shin, H.-R., Vallejos, C. S., De Ruiz, P. A., Lima, M. A., Guimera, N., Clavero, O., Alejo, M., Llombart-Bosch, A., Cheng-Yang, C., Tatti, S. A., Kasamatsu, E., Iljazovic, E., Odida, M., Prado, R., Seoud, M., Grce, M., Usubutun, A., Jain, A., Suarez, G. A. H., Lombardi, L. E., Banjo, A., Menéndez, C., Domingo, E. J., Velasco, J., Nessa, A., Chichareon, S. C. B., Qiao, Y. L., Lerma, E., Garland, S. M., Sasagawa, T., Ferrera, A., Hammouda, D., Mariani, L., Pelayo, A., Steiner, I., Oliva, E., Meijer, C. J., Al-Jassar, W. F., Cruz, E., Wright, T. C., Puras, A., llave, C. L., Tzardi, M., Agorastos, T., Garcia-Barriola, V., Clavel, 
C., Ordi, J., Andújar, M., Castellsagué, X., Sánchez, G. I., Nowakowski, A. M., Bornstein, J., Muñoz, N., Bosch, F. X., Survey, R. I. \& Group, H. P. V. T. T. S. (2010). Human papillomavirus genotype attribution in invasive cervical cancer: a retrospective cross-sectional worldwide study. Lancet Oncol 11, 1048-1056. 1

Duchateau, L. \& Janssen, P. (2008). The Frailty Model. New York: Springer. 17, 18, 32, 43

Efron, B. (1979). Bootstrap methods: Another look at the jackknife. Ann. Statist. 7, 1-26. 22, 35

Elandt-Johnson, R. C. (1975). Definition of rates: some remarks on their use and misuse. Am $J$ Epidemiol 102, 267-271. 3

Franco, E., Villa, L., Rohan, T., Ferenczy, A., Petzl-Erler, M. \& Matlashewski, G. (1999). Design and methods of the Ludwig-McGill longitudinal study of the natural history of human papillomavirus infection and cervical neoplasia in Brazil. Ludwig-McGill study group. Rev Panam Salud Publ 6, 223-233. 1

Genest, C. \& MacKay, R. J. (1986). Copules archimédiennes et familles de lois bidimensionnelles dont les marges sont donnês. Can J Stat 14, 145-159. 18

Giuliano, A. R., Papenfuss, M., Abrahamsen, M. \& Inserra, P. (2002). Differences in factors associated with oncogenic and nononcogenic human papillomavirus infection at the United States-Mexico border. Cancer Epidem Biomar 11, 930-934. 24, 41, 42

Giuliano, A. R., Siegel, E. M., Roe, D. J., Ferreira, S., Baggio, M. L., Galan, L., Duarte-Franco, E., Villa, L. L., Rohan, T. E., Marshall, J. R., Franco, E. L. \& Study, L.-M. H. N. H. (2003). Dietary intake and risk of persistent human papillomavirus (HPV) infection: the Ludwig-McGill HPV natural history study. J Infect Dis 188, 1508-1516. 4

Gray, R. J. (1992). Flexible methods for analyzing survival data using splines, with applications to breast cancer prognoses. J Amer Stat Assoc 87, 942-951. 21, 22, 35

Grinsztejn, B., Veloso, V. G., Levi, J. E., Velasque, L., Luz, P. M., Friedman, R. K., Andrade, A. C., Moreira, R. I., Russomano, F., Pilotto, J. H., Bastos, F. I. \& PALEFSKY, J. (2009). Factors associated with increased prevalence of human papillomavirus infection in a cohort of HIV-infected Brazilian women. Int J Infect Dis 13, 72-80. 6, 24

Hastie, T. \& Tibshirani, R. (1990). Generalized Additive Models. New York: Chapman. 25

Hildesheim, A., Gravitt, P., Schiffman, M. H., Kurman, R. J., Barnes, W. \& Jones, S. (1993). Determinants of genital human papillomavirus infection in lowincome women in Washington, D.C. Sex Transm Dis 20, 279-85. 41

Ho, G. Y., Bierman, R., Beardsley, L., Chang, C. J. \& Burk, R. D. (1998). Natural history of cervicovaginal papillomavirus infection in young women. $N$ Engl $J$ Med 338, 423-428. 1, 24

HougaARD, P. (2008). Semiparametric regression models for interval-censored survival data, with and without frailty effects. Stat Ind Technol 4, 307-317. 43

INCA (2012). Estimativas 2012: incidência de câncer no Brazil. Brasil: Ministério da Saúde, Instituto Nacional do Câncer. 1

Kaplan, E. L. \& MeieR, P. (1958). Nonparametric estimation from incomplete observations. $J$ Am Stat Assoc 53, 457 - 81. 9

Kendall, M. G. (1938). A new measure of rank correlation. Biometrika 30, 81-93. 17 
Kuaer, S. K., van den Brule, A. J., Bock, J. E., Poll, P. A., Engholm, G., Sherman, M. E., Walboomers, J. M. \& Meijer, C. J. (1997). Determinants for genital human papillomavirus (HPV) infection in 1000 randomly chosen young Danish women with normal Pap smear: are there different risk profiles for oncogenic and nononcogenic HPV types? Cancer Epidem Biomar 6, 799-805. 4

Kuver, S. K., van den Brule, A. J. C., Bock, J. E., Poll, P. A., Engholm, G., Sherman, M. E., Walboomers, J. M. M. \& Meijer, C. J. L. M. (1997). Determinants for genital human papillomavirus (HPV) infection in 1000 randomly chosen young Danish women with normal Pap smear: are there different risk profiles for oncogenic and nononcogenic HPV types? Cancer Epidem Biomar 6, 799-805. 12, 24, 41

KLEin, J. P. (1992). Semiparametric estimation of random effects using Cox model based on the EM algorithm. Biometrics 48, 795-806. 6, 19

Klein, J. P. \& Moeschberger, M. (2003). Survival analysis: techniques for censured end truncated data. New York: Springer-Verlag. 19, 24

Kleinbaum, D. G. (2005). Survival Analysis: A Self-Learning Text. New York: Springer. 9

Last, J. M. (2001). A Dictionary of Epidemiology. Oxford: Oxford University Press, Inc. 1, 2

LeE, S. \& KLeIn, J. P. (1998). Bivariate models with a random environmental factor. Indian Journal of Productivity, Reliability and Quality Control 13, 1-18. 17

Levi, J. E., Fernandez, S., Tateno, A. F., Lima, L. P., Eluf-Neto, J. \& Pannuti, C. S. (2004). Presence of multiple human papillomavirus types in cervical samples from HIV-infected women. Gynecol Oncol 92, 225-31. 1

Levi, J. E., Kleter, B., Quint, W. G., Fink, M. C., Canto, C. L., Matsubara, R., Linhares, I., Segurado, A., Vanderborght, B., Neto, J. \& Doorn., L. V. (2002). High prevalence of human papillomavirus (HPV) infections and high frequency of multiple HPV genotypes in humanimmunodeficiency virus-infectedwomen in Brazil. J Clin Microbiol 40, 3341-5. 1

Lindsey, J. K. \& LAmbert, P. (1998). On the appropriateness of marginal models for repeated measurements in clinical trials. Stat Med 17, 447-469. 6

Macleod, A. J. (1984). A generalization of Newton-Raphson. Int. J. Math. Ed. Sci. Tech. 15, 117-120. 19

Massad, L. S., Riester, K. A., Anastos, K. M., Fruchter, R. G., Palefsky, J. M. \& LuRK, R. D. (1999). Prevalence and predictors of squamous cell abnormalities in Papanicolaou smears from women infected with HIV-1. J Acquir Immune Defic Syndr 21, 33-41. 1

McCullagh, P. \& Nelder, J. A. (1989). Generalized Linear Models. London: Chapman and Hall/CRC. 4

McGilchrist, A. C. \& Aisbett, C. W. (1991). Regression with frailty survival analysys. Biometrics 47, 461-466. 17

McKenzie, N. D., Kobetz, E. N., Hnatyszyn, J., Twiggs, L. B. \& Lucci, J. A. (2010). Women with HIV are more commonly infected with non-16 and -18 high-risk HPV types. Gynecol Oncol 116, 572-577. 1, 2

Orem, J., Otieno, M. W. \& Remick, S. C. (2004). AIDS-associated cancer in developing nations. Curr Opin Oncol 16, 468-76. 1 
PAlefsky, J. M. (2003). Cervical human papillomavirus infection and cervical intraepithelial neoplasia in women positive for human immunodeficiency virus in the era of highly active antiretroviral therapy. Curr Opin Oncol 15, 382 - 8. 1, 12, 24, 41

Perrons, C., Jelley, R., Kleter, B., Quint, W. \& Brink, N. (2005). Detection of persistent high risk human papillomavirus infections with hybrid capture ii and SPF10/LiPA. J Clin Virol 32, 278-285. 1

R Development Core Team (2009). R: A language and environment for statistical computing. R Foundation for Statistical Computing, Vienna. URL http://www.R-project.org. 17

RA, R. A. R. \& Winkelstein, W. J. (1990). HIV infection, cigarette smoking and CD4+ Tlymphocyte counts: preliminary results from the San Francisco mens health study. AIDS 4, 327-33. 42

Rezza, G., Giuliani, M., Serraino, D., Branca, M., Benedetto, A. \& Garbuglia, A. (1998). Risk factors for cervical presence of human papillomavirus DNA among women at risk for HIV infection. DIANAIDS collaborative study group. Epidemiol Infect 121, 173 - 7. 12, 41

Rousseau, M. C., Franco, E. L., Villa, L. L., Sobrinho, J. P., Termini, L., Prado, J. M. \& Rohan, T. E. (2000). A cumulative case-control study of risk factor profiles for oncogenic and nononcogenic cervical human papillomavirus infections. Cancer Epidem Biomar 9, 469-476. $1,4,12,24,41$

Rousseau, M. C., Pereira, J. S., Prado, J. C., Villa, L. L., Rohan, T. E. \& Franco, E. L. (2001). Cervical coinfection with human papillomavirus (HPV) types as a predictor of acquisition and persistence of HPV infection. J Infect Dis 184, 1508-1517. 1

Sahasrabuddhe, V. V., Mwanahamuntu, M. H., Vermund, S. H., Huh, W. K., Lyon, M. D., Stringer, J. S. A. \& Parham, G. P. (2007). Prevalence and distribution of HPV genotypes among HIV-infected women in Zambia. Br J Cancer 96, 1480-1483. 1, 4, 24

Schoenfeld, D. (1982). Partial residuals for the proportional hazards model. Biometrika 69, 51-55. 25

Stata 11 Base Reference Manual (2011). StataCorp., College Station. 17

Therneau, T. M. \& Grambsch, P. M. (2000). Modeling Survival Data: Extending the Cox Model. New York: Springer-Verlag. 19, 20, 25, 27

Therneau, T. M., Grambsch, P. M. \& Pankratz, V. S. (2003). Penalized survival models and frailty. J Comput Graph Stat 12, 156-75. 20, 21, 22

Trottier, H. \& Franco, E. L. (2006). The epidemiology of genital human papillomavirus infection. Vaccine 24 Suppl 1, S1-15. 1, 24

Tsiatis, A. A. \& Davidian, M. (2004). Joint modeling of longitudinal and time-toevent data: an overview. Statistica Sinica 14, 809-834. 43

Vaupel, J. W., Manton, K. G. \& Stallard, E. (1979). The impact of heterogeneity in individual frailty on the dynamics of mortality. Demography 16, 439-454. 5

Verweij, J. M. \& Houwelingen, H. C. V. (1994). Penalized likelihood in cox regression. Stat Med 13, 2427-2436. iii, v, 22

Walboomers, J. M. M., Jacobs, M. V., Manos, M. M., Bosch, F. X., Kummer, J. A. \& SнAн, K. V. (1999). Human papillomavirus is a necessary cause of invasive cervical cancer worldwide. J Patholx 189, 12-9. 1 
Wei, L. J., Lin, D. Y. \& Weissfeld, L. (1989). Regression analysis of multivariate incomplete failure time data by modeling marginal distribution. J Am Stat Assoc 84, 1065-73. 6

Wienke, A. (2012). Frailty Models in Survival Analysis. Boca Raton: Chapman \& Hall/CRC Biostatistics Series. 21

Winer, R. L., Lee, S.-K., Hughes, J. P., Adam, D. E., Kiviat, N. B. \& Koutsky, L. A. (2003). Genital human papillomavirus infection: Incidence and risk factors in a cohort of female university students. Am J Epidemiol 157, 218-226. 24

Woodman, C. B., Collins, S., Winter, H., Bailey, A., Ellis, J., Prior, P., Yates, M., Rollason, T. P. \& Young, L. S. (2001). Natural history of cervical human papillomavirus infection in young women: a longitudinal cohort study. Lancet 357, 1831-1836. 5

Xue, X., Gange, S. J., Zhong, Y., Burk, R. D., Minkoff, H., Massad, L. S., Watts, D. H., Kuniholm, M. H., Anastos, K., Levine, A. M., Fazzari, M., D’Souza, G., Plankey, M., PAlefsky, J. M. \& Strickler, H. D. (2010). Marginal and mixed-effects models in the analysis of human papillomavirus natural history data. Cancer Epidem Biomar 19(1), 159-69. 1, 5, 6

Yu, M., Law, N. J., Taylor, J. M. G. \& Sandler, H. M. (2004). Joint longitudinal survivalcure models and their application to prostate cancer. Statistica Sinica 14, 835-862. 43 